Florida International University

FIU Digital Commons

FIU Electronic Theses and Dissertations

University Graduate School

3-25-1996

\title{
The effect of different instructional groupings on student achievement and attitudes from a computer-based interactive videodisk biology unit
}

Jorge Luis Alonso

Florida International University

DOI: $10.25148 /$ etd.FI13101602

Follow this and additional works at: https://digitalcommons.fiu.edu/etd

Part of the Education Commons

\section{Recommended Citation}

Alonso, Jorge Luis, "The effect of different instructional groupings on student achievement and attitudes from a computer-based interactive videodisk biology unit" (1996). FIU Electronic Theses and Dissertations. 1205.

https://digitalcommons.fiu.edu/etd/1205 


\section{FLORIDA INTERNATIONAL UNIVERSITY}

Miami, Florida

\section{THE EFFECT OF DIFFERENT INSTRUCTIONAL GROUPINGS ON STUDENT ACHIEVEMENT AND ATTITUDES FROM A COMPUTER-BASED INTERACTIVE VIDEODISC BIOLOGY UNIT}

A dissertation submitted in partial satisfaction of the requirements for the degree of DOCTOR OF EDUCATION

I $\mathbf{N}$

CURRICULUM AND INSTRUCTION

b $\mathbf{y}$

Jorge Luis Alonso

1996 
To: Dean I. Ira Goldenberg

College of Education

This dissertation, written by Jorge L. Alonso, and entitled The Effect Of Different Instructional Groupings On Student Achievement And Attitudes From Computer-Based Interactive Videodisc Biology Unit, having been approved in respect to style and intellectual content, is referred to you for judgment.

We have read this dissertation and recommend that it be approved.

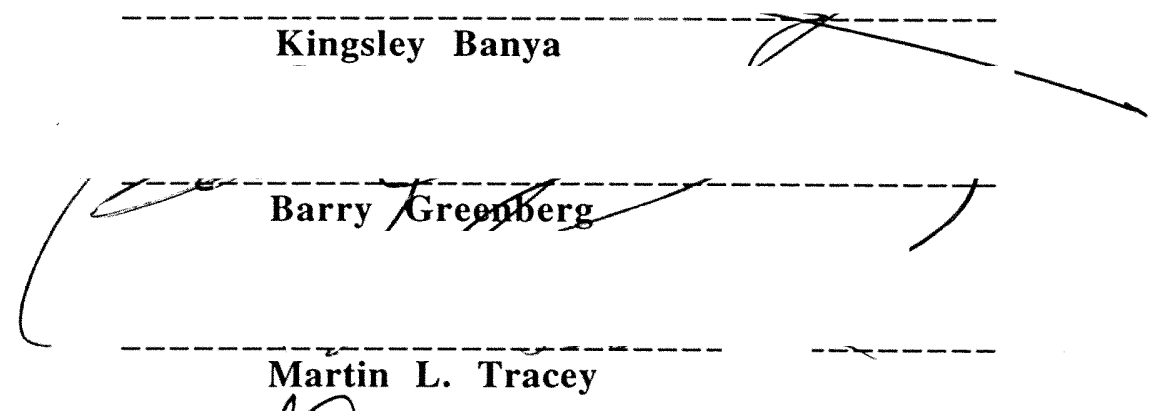

Date of Defense: $3 / 25 / 96$

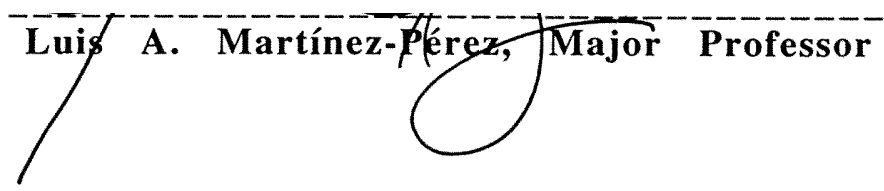

The dissertation of Jorge L. Alonso is approved.

Dean f. Ira Goldenberg
College of Educhtign

Dr. Richard L. Canpbell

Dean of Graduate Studies

Florida International University, 1996 
${ }^{\circledR}$ COPYRIGHT 1996 by Jorge Luis Alonso

All rights reserved 
I dedicate this dissertation to my parents, Pepín and Melba, for instilling the value of knowledge; and to my wife Sandy, for her love, patience and understanding. 


\section{ACKNOWLEDGMENTS}

I wish to thank the members of my committee for their helpful comments and suggestions, and particularly for their inspiration throughout the years. I also would like to thank Dr. L. R. Gay, for helping proof-read this document as it evolved, and for her support and encouraging words.

I would also like to thank several teachers and administrators at South Miami Senior High for making this research study a possibility. Thomas Shaw, principal, for allowing this study to take place and for his generous support for the science program. Verdell King, former assistant principal for curriculum, for her inspiring leadership and indispensable assistance in obtaining the technology necessary for this research study. Also to Miguel Germain and John Ware, both biology teachers during the summer term of 1995, for allowing me to use their students as subjects in this research study.

A special thanks to Carrie L. Dawson from DCPS Office of Educational Accountability for her continuing assistance, advise, and thorough validation of the achievement test; and to Felicia Mendez and Constance Thornton from DCPS Science Education Office for their advice and assistance in focusing the biology unit on emerging National Science Education Content Standards.

Finally, I would like to thank the 64 students who participated in this research study. I hope that it was a new and exciting way for them to learn biology. 


\section{ABSTRACT OF THE DISSERTATION}

\section{THE EFFECT OF DIFFERENT INSTRUCTIONAL GROUPINGS ON STUDENT ACHIEVEMENT AND ATTITUDES FROM A COMPUTER-BASED INTERACTIVE VIDEODISC BIOLOGY UNIT. b y}

Jorge Luis Alonso

Florida International University, 1996 Miami, Florida 33199

\section{Professor Luis A. Martínez-Pérez, Major Professor}

The purpose of this research study was to determine the effect of two different instructional groupings (cooperative and traditional whole-class) on student achievement and attitudes using a computer-based interactive videodisc biology unit.

The subjects were 64 high school biology students assigned to two heterogeneous experimental groups, randomly selected from two preassigned summer school biology classes, one honors, the other regular. A two-group, posttest-only, control group experimental research design was utilized. Achievement at three cognitive levels and attitudes towards science laserdisc instruction were measured at the conclusion of the study.

The cooperative group consistently outperformed the traditional group in achievement posttest scores. Factorial ANOVA on total (overall) achievement scores indicated that subjects in 
cooperative groups significantly outperformed those in the traditional group, and also that the instructional group, class level, and gender interacted in an ordinal fashion to make a significant difference in how female and male subjects were affected by the treatments depending on their class (aptitude) level. Regular level females and honors level males performed much better when in cooperative groups, whereas group membership did not appear to make a difference for either honors level females or regular level males. A t-test comparing honors level males revealed that cooperative groups were close to being significantly better in total achievement posttest scores than their traditional group counterparts. Factorial MANOVA comparing the instructional groups at three cognitive levels found no significant difference.

Analysis on the attitudes posttest data also revealed that subjects in cooperative groups demonstrated more positive attitudes towards science laserdisc instruction; however these differences were not found to be significant. Significant interactions in attitudes of females and males from different class levels had the opposite effect as achievement: honors level females and regular level males demonstrated more positive attitudes towards science laserdisc instruction when in cooperative groups, whereas group membership did not appear to make a difference for honors level males, and regular level females demonstrated the lowest attitudes ratings of any group when involved in cooperative groups. This contrast between achievement and attitudinal results suggests cross-gender interaction in traditionally defined gender roles. 


\section{TABLE OF CONTENTS}

\section{CHAPTER}

I. INTRODUCTION

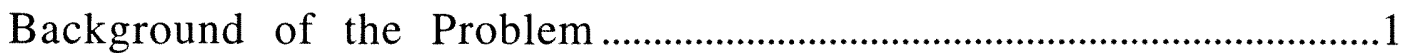

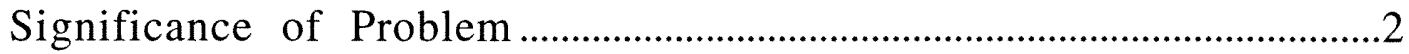

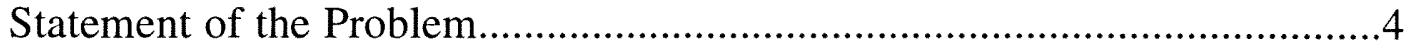

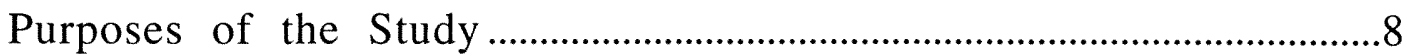

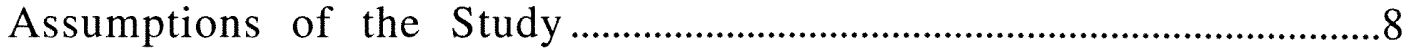

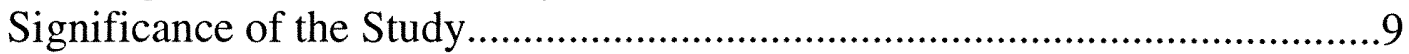

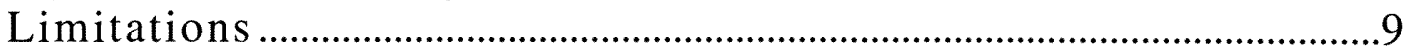

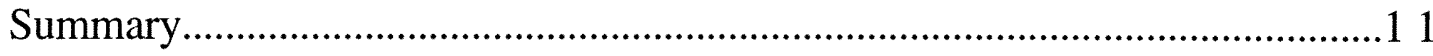

II. REVIEW OF THE RELATED LITERATURE ................................................13

A Historical Perspective of Science Instruction ......................................13

Instructional Groupings

Traditional, Cooperative and Individualized.............................5 1

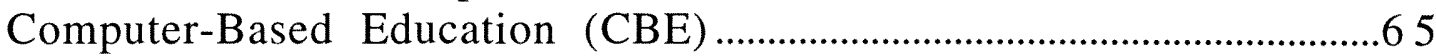

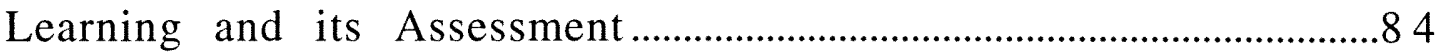

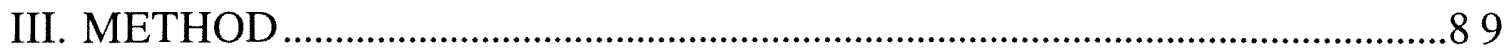

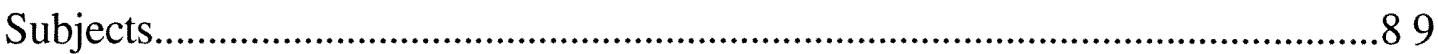

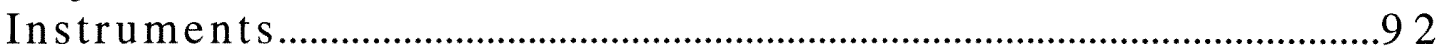

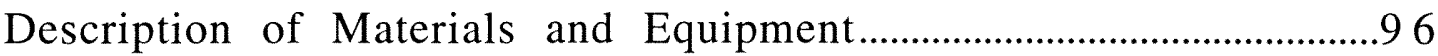

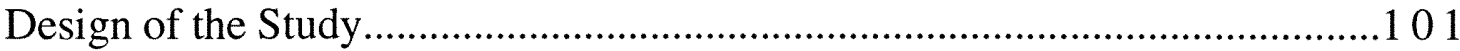

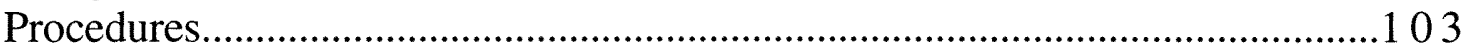

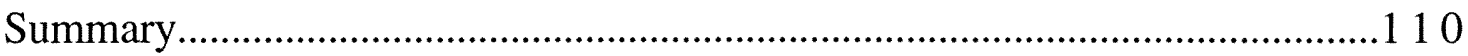

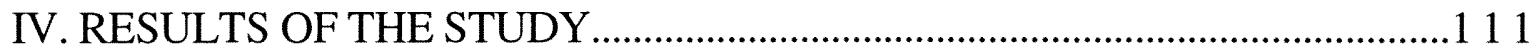

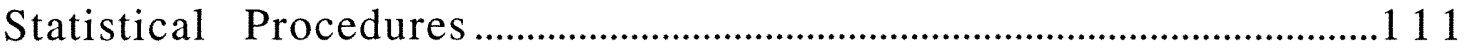

Results of Statistical Analysis on the Achievement

Posttest Data....................................................................................11 15

Results of Statistical Analysis on the Attitudes

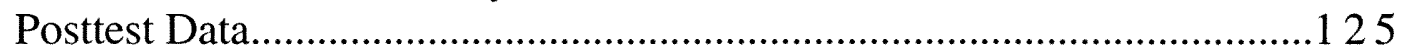

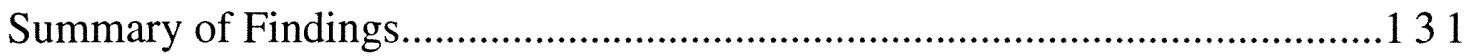

V. SUMMARY, DISCUSSION, AND IMPLICATIONS...................................1 133

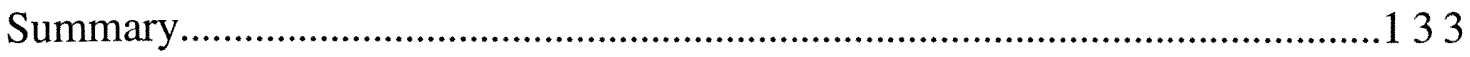

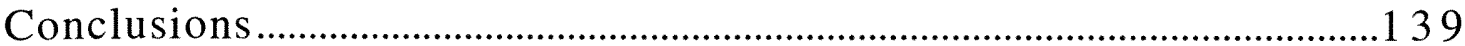

Implications for Future Investigation................................................143 


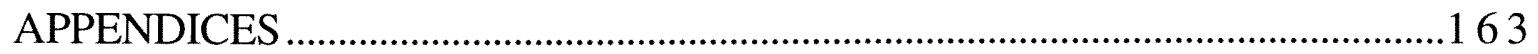

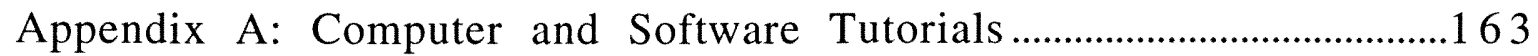

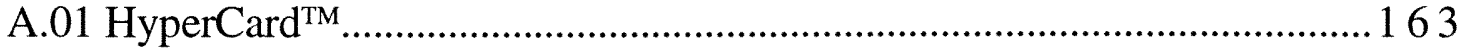

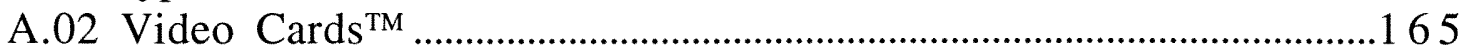

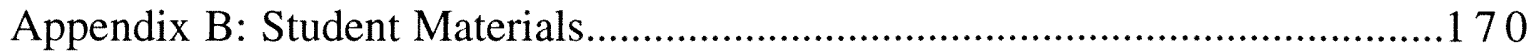

B.01 Animal Kingdom Taxonomic guide ..............................................170

B.02 Animal Kingdom Taxonomic Guide...........................................18

B.03 Questions for Animal Diversity .........................................................194

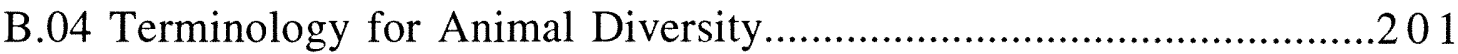

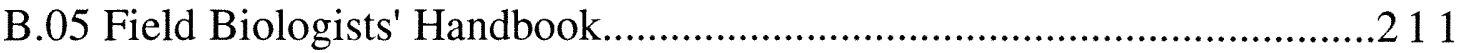

B.06 Student Instructions for Cooperative Groups ...............................215

B.07 Parent Permission Forms..............................................................2218

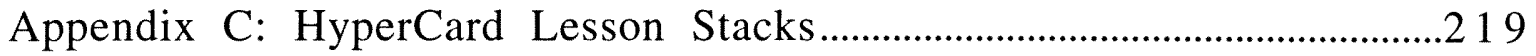

C.01 Five Kingdoms HyperCard Stack (Complete) ................................219

C.02 Animal Kingdom Presentation Stack..........................................23 30

C.03 Animal Kingdom Cooperative Group Stack................................23 34

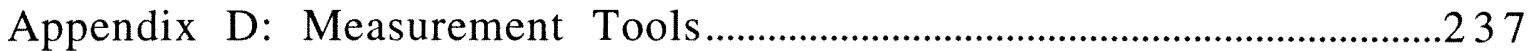

D.01 Researcher-designed achievement test...................................237

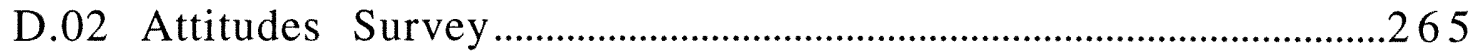

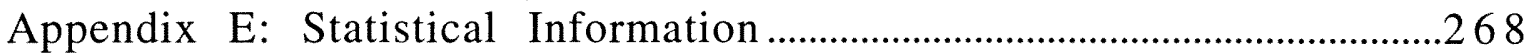

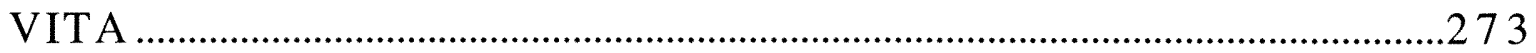




\section{CHAPTER I}

Introduction

Everyone knows that learning takes place through the senses. The more senses involved, the greater the opportunity for concept development, resulting in greater and longer lasting comprehension. Thus, the power a computer-controlled videodisc to quickly access from a large collection of visual images (pictures, graphs, diagrams, movies), many with audio component as well as textual data about these visuals, can help students in developing clear and powerful conceptual frameworks.

\section{Background of the Problem}

In the past decade, computer-based interactive videodiscs have made tremendous hardware and software advances with corresponding reduction in cost. The result has been the introduction of this new and potentially exciting technology into educational institutions throughout the nation.

Interactive videodiscs can be used at several different levels of sophistication, from remote control and barcode reader access (Level 1), to computerized interactive control (Level 3). At Level 3, the power of the computer as an instructional tool makes the technology more accessible for use in individualized and cooperative-group instruction, as well as for traditional whole-class presentation. This is specially true when the videodisc authoring programs are used in 
conjunction with hypermedia-based lessons which can direct the students' exploration of a particular subject through a series of researcher-designed educational computer screens.

Several research studies have attempted to ascertain the effectiveness of using this new technology in the classroom. These studies have explored different facets of computer based interactive videodisc (CBIV) instruction and their effect on the achievement and attitudes of students. Most of these studies compare CBIV to other instructional media such as traditional lecture, laboratory exercises, traditional computer based instruction, print based material, and noninteractive video. Other studies have explored the issue of the amount of instructional time required by different media, variations in levels of user control, degree of guidance and inquiry, as well as the use of CBIV under different instructional group arrangements.

In this research study two CBIV instructional groupings, cooperative and traditional whole-class, were compared in their effect on student achievement and attitudes. These two instructional groupings have been thoroughly researched during the last two decades, but very few studies have investigated their effect when the students are engaged in computer-based interactive videodiscs instruction.

Significance of Problem

In the present circumstances of reduced funding for education, science teachers are often asked to defend their continued 
commitment to the instructional use of computer-based technology. Teachers are often being asked to support with research findings their visions of the future of educational technology in the science classroom. The purpose of this study is to determine the effect on students' achievement and attitudes of two different instructional groupings, cooperative and whole-class, when taught a biology unit by the use of computer-based interactive videodiscs (CBIV).

Different instructional student groupings significantly affects the expense involved in bringing state of the art instructional technology into the science classroom. A presentational CBIV set-up for traditional whole-class instruction can cost from $\$ 4,000$ to $\$ 6,000$, depending on whether a 32" television set or an LCD panel for overhead projection is utilized to display the computer screen to the class. A set of eight CBIV cooperative group stations, which can accommodate a class of 32 students working in groups of four, will cost approximately $\$ 28,000$. Is the effect of cooperative instruction on student achievement and attitudes worth this additional 5 to 7 fold expense? Recent instructional research indicates that cooperative group instruction is superior to both individualized and traditional whole-class instruction in achievement and attitudinal effects; however, very few research studies have explored this issue when the students are engaged in learning by means of computerbased interactive video. This research study attempted to answer this question. 


\section{Statement of the Problem}

Is one of the two instructional grouping methods most commonly utilized--cooperative and traditional whole-class-superior to the other in the retention of learned information (at three different cognitive levels) and in its effect on attitudes when the students are engaged in a computer-based interactive videodisc biology lesson?

\section{Definitions}

Multimedia: "..a class of computer-driven interactive communication systems which create, store, transmit, and retrieve textual, graphic, and auditory networks of information" (Gayeski, 1993).

Hypermedia: computer software consisting of networks of related text files that can be accessed by icons or search strategies (hypertext) with added graphics, audio files, and/or video clips (Gayeski, 1993). Hypermedia provides the opportunity for multimedia to be raised to a higher level of interactivity.

Computer-Based Interactive Videodisc (CBIV) Biology Unit: consists of an electronic multimedia biology presentation developed by either the subjects (in a cooperative group) or the teacher (for traditional whole-class instruction). The electronic unit was used by interacting with a videodisc authoring computer program which controls a 
videodisc containing still images, graphs, diagrams, movies, and data about these visuals. The audio-visual events utilized were organized in a sequence consistent with a biology unit dealing with the taxonomic relationships (anatomical, embryological, behavioral, and evolutionary) involved in classifying the diversity of animal life.

Traditional Whole-Class Instruction (Presentation, Lecture/Discussion): a group of 32 students, receiving instruction in a traditional teacher-led presentation, in which the computer is utilized by the teacher to control a videodisc in order to present a multimedia biology unit. The teacher leads the students in the presentation of a pre-arranged CBIV multimedia unit on the diversity of animal life, and the students take four individualized achievement quizzes and a comprehensive achievement test in order to earn grades based on individual achievement only.

Cooperative Group Instruction: 32 students work in heterogeneous groups of four, each taking an individual role within the group (taxonomist, field biologist, computer specialist, and research manager), and sharing two common goals: (1) the development of computer-based interactive videodisc (CBIV) multimedia presentation on the diversity of animal life, and (2) to take four individualized achievement quizzes and a comprehensive achievement test to earn grades based on the average team scores as well as individual scores. The teacher provides consulting assistance to the group. 
Retention of Learned Information (achievement): measured by an 80-item researcher-designed comprehensive achievement test (see Appendix D.02) from the biology unit dealing with the taxonomic relationships (anatomical, embryological, behavioral, and evolutionary) involved in classifying the diversity of animal life; items for this comprehensive achievement test were written to measure three different cognitive levels (knowledge, comprehension, and application). In addition to this comprehensive achievement test, four achievement quizzes (20 items each) obtained from several established sources, were also administered after instructional intervals of approximately 2-3 hours; their use was for instructional purposes only, and the scores were not utilized for determining student achievement for this research study.

Attitudes: "the affect for or against a psychological object" (Mueller, 1986), was measured at the end of the research study by the Attitude toward Science in School Assessment (ATSSA), an instrument developed as a measure of a single dimension of a general attitudes toward science, specifically, how students feel toward science as a subject in school (Germann, 1988) (see Appendix D.01). A researcher-modified version of this instrument was also administered in which the statement 'using computer-based laserdiscs' or 'by means of computer-based laserdiscs' was added to each item in order to measure the strength of the individual's attitudes toward science laserdisc instruction (see Appendix D.01). 
Statement of the Hypothesis

Based on the general support for cooperative-group instruction in the literature reviewed herein, the following hypotheses were considered:

$\mathrm{H}_{1}(1)$ : Students receiving cooperative-group instruction will have significantly better total (overall) achievement scores than those receiving traditional whole-class instruction in a CBIV biology unit.

$\mathrm{H}_{1}(2)$ : Students receiving cooperative-group instruction will have significantly better knowledge-level achievement scores than those receiving traditional whole-class instruction in a CBIV biology unit.

$\mathrm{H}_{1}(3)$ : Students receiving cooperative-group instruction will have significantly better comprehension-level achievement scores than those receiving whole-class instruction in a CBIV biology unit.

$\mathrm{H}_{1}(4)$ : Students receiving cooperative-group instruction will have significantly better application-level achievement scores than those receiving traditional whole-class instruction in a CBIV biology unit. 
$\mathrm{H}_{1}(5)$ : Students receiving cooperative-group instruction will have significantly better attitudes towards science laserdisc instruction than those receiving traditional whole-class instruction in a CBIV biology unit.

\section{Purposes of the Study}

This study encompasses three main purposes. They are to measure the effect of the two instructional groupings on:

1. student achievement at three cognitive levels on a researcher-designed biology tests from a unit dealing with the taxonomic relationships involved in classifying the diversity of animal life.

2. student attitudes towards science laserdisc instruction as a subject in school.

3. the comparative cost-effectiveness.

\section{Assumptions of the Study}

This research study assumed that subjects (students) selected from summer school regular and honors-level classes are no different from the student population that enrolls in similar biology classes during the regular school year.

The study also assumed that the computer program and the way in which it was utilized were simple, yet interactive enough to maintain the students' interest for the duration of the research 
study. It also assumed that the effect of CBIV is proportionally greater when utilized over a longer period of time.

\section{Significance of the Study}

The results of this research study are significant to educators who realize the interactive potentials of computers and are engaged in bringing state of the art technology into the classroom in order to convey a more dynamic concept of the world of science to their students.

Which level of user control? What degree of guidance and inquiry? Which instructional group arrangement maximizes student learning and improves attitudes toward science? Which of these instructional strategies works best for different genders, ethnic groups, or students from different aptitude levels? These are questions which must be answered by educators if we are to take advantage of and prepare students for the technological revolution that is taking place as a result of the merging of information and communication technologies with the computer as its central coordinating component. It is the responsibility of educators to place students at the leading edge of this information revolution.

\section{$\underline{\text { Limitations }}$}

The results of this study will only be generalizable to subjects and conditions similar to those of the study itself. The use of two 
and one half hours block for each day of instruction as opposed to the more typical fifty minute to one hour block, was necessary because of the summer school schedule. Also the period of time during which the students received biology instruction by means of CBIV was limited to only 15 hours by the curriculum, which specifies that at least 5 other biology units be taught in these courses during the 6 weeks of summer school.

This research study also assumed that subjects (students) selected from summer school regular and honors-level classes are no different from the student population that enrolls in similar biology classes during the regular school year. This may or may be not be true, since the summer school regular level biology student has already failed to achieve a passing grade in a similar class during the regular school year, and the honors student is devoting extra (vacation) time in order to advance academically; these characteristics may not be typical of the average student enrolled in similar classes during the regular school year.

The most significant limitation was the lack of commercially available, high quality, audio-visual material in laserdiscs, or any similar media, that can be utilized as inquiry-based instruction. This is particularly true for the dynamic units of biological evolution and the molecular basis of heredity, which can be easily designed to involve students in the higher cognitive levels of problem-solving and critical thinking. 


\section{$\underline{\text { Summary }}$}

Most science educators are convinced that computer-based interactive multimedia can help students in developing clear and powerful conceptual frameworks. The question is how to best design and deliver the potential of this new technology in an instructional setting. Studies have explored the issue of the amount of instructional time required by different media, variations in levels of user control, degree of guidance and inquiry, as well as instructional group arrangements. In this research study the use of CBIV under different instructional group arrangements was explored: two CBIV instructional groupings, cooperative and traditional whole-class, were compared in their effect on student achievement and attitudes.

These two instructional groupings have been thoroughly researched during the last two decades, but very few studies have investigated their effect when the students are engaged in computer-based interactive videodiscs instruction.

Based on the general support for cooperative-group instruction found in the literature reviewed, five research hypotheses favoring cooperative groups in achievement and attitudes were considered in this research study. Their purpose was to determine if the advantages reported in the literature for cooperative group instruction are generalizable to students involved in using computerbased interactive videodisc.

Limitations of this study include the length of time per day $(2.5$ hours) and for the entire study (15 hours) during which the subjects 
were engaged in CBIV instruction. Another very important

limitation identified is the lack of commercially available laserdiscs which utilize visuals adequate for instruction at the higher cognitive levels. 


\section{CHAPTER II \\ Review of the Related Literature}

This chapter reviews the categories of literature pertinent to this study, namely the historical trends and current focus of science education, research on methods of instruction, research on the effect of the new computerized multimedia technology on instruction, and research on learning styles and assessment.

\section{A Historical Perspective of Science Instruction}

Before undertaking a detailed analysis of the present state of computer-based multimedia technology in science instruction, it is always wise to reflect upon our past in order to learn from history, so that it can help us direct and focus our vision of future educational developments.

The Early Development of Formal Science Education

The American colonists were all practicing scientists in certain ways; this was not because they earned degrees in science, but because they all used it in their everyday life. They made candles; refined salt for preserving food; isolated potash from field or fireplace ashes for making soap; and prepared dyes from roots, bark, and seeds. Chemistry and physics found its way into industry early 
in the life of the young colony when Massachusetts governor John Winthrop, Jr., who came to Boston in 1631, established several chemical-related industries in New England, including iron smelting and salt refining.

The early settlers in the colonies tried to imitate, if not duplicate, their homeland's schools whose curriculum was inherited from the Middle Ages. In their Latin grammar schools the studies were described as formal discipline of the mind, and the curriculum at the primary levels consisted of reading, writing, and arithmetic, while at the upper levels it was dominated by humanistic rather than naturalistic studies and classical rather than scientific studies. Their educational programs served the purpose of providing personnel to assume leadership roles as members of the clergy or civil servants for the state. We find no science courses in the offering of the Latin grammar schools of the seventeenth and eighteenth centuries (DeBoer, 1991).

Formal science education in America began with physicians who came from England to instruct the country's prospective young doctors, at first in private tutoring. Later, physicians started medical schools, and science education gained its first foothold in American colleges. Biology and chemistry were identified most closely with medicine and pharmacy and were taught extensively in American medical colleges even before the Revolutionary War.

The Latin grammar schools apparently could not cope with changing social conditions and during the late seventeenth century gave way to the evolution of the American academy. It was secular 
interest advocated by Thomas Huxley and Herbert Spencer which began to crowd religion out, and the anti-colonial political ferment which stimulated this evolutionary progression. Benjamin Franklin proposed the establishment of the first academy in Philadelphia, but Massachusetts proved a more hospitable location and they first developed there during the Revolution. Their curriculum included not only the old Greek and Latin grammar but also practical geometry, logic, and geography; eventually a few academies included chemistry and natural philosophy as Franklin had originally suggested (DeBoer, 1991).

Before 1820 only a few academies had been established in America. Of these, only 7 gave instruction in the physical sciences. By 1825 there were 12 offering rather bookish courses; by 1850 the number increased to about 35. Utilitarian aims dominated the early academies, and the sciences fit right into their curricula. Several academies primarily trained boys in the sciences applied to agriculture and industrial arts. The most successful scientific school founded in this period was the Rensselaer Polytechnic Institute, which opened at Troy, New York, in 1824. Academies grew slowly in numbers at first but in the period from 1825-1850 they reached the height of their popularity (Steiner, 1977).

At the college level it was also Benjamin Franklin as a trustee of the College of Philadelphia (later the University of Pennsylvania) who was instrumental in establishing the first course of natural history devoted to chemistry at the undergraduate level in 1757. The course, Chemistry, Fossils, and Agriculture, was taught by 
William Smith, an Anglican clergyman and the college's first provost. At other colonial colleges such as Harvard, Yale, William and Mary, Princeton, and King's College (later Columbia University), chemistry was only part of a general course in natural philosophy or natural history taught to seniors after they had acquired proper training in the classics (Latin, Greek, rhetoric, philosophy, logic, and mathematics) (Fisher, 1986).

Many people consider Benjamin Rush--educator, patriot, and signer of the Declaration of Independence--the father of science education in America. While studying medicine at Edinburgh University, in Scotland, Rush attended the chemistry lectures given by Joseph Black. Black was noted for his pioneering contributions to the new chemistry developed by Antoine Lavoisier, the founder of modern chemistry. Upon his return to America in 1769, Rush was appointed to a professorship of chemistry. In 1770 Rush published what may be the earliest American textbook of chemistry, A Syllabus of a Course of Lectures on Chemistry. His textbook laid the foundation for chemical education in this country, and for many years it was the only American chemistry textbook. Rush saw chemistry as a practical subject that could be of immense value in his virtually undeveloped country. He devoted his first lecture to the indispensability of chemistry to medicine and described the effects on the body of toxic substances, diet and medicinals. Subsequent lectures introduced students to the history of chemistry, chemical attraction, and laboratory apparatus. Rush's course was divided into 
seven units: salts, earths, inflammables, metals, waters, vegetables, and animal substances (Ashman, 1985).

Science was, however, a white man's subject, and chemical education for women and free blacks was meager during the early years of our country. When women did learn chemistry in school, it was as part of home economics study. In 1787 Benjamin Rush delivered a series of lectures at the Young Ladies' Academy of Philadelphia, making it the first course in chemistry for American girls. His lectures were collected in A Syllabus of Lectures Concerning the Application of Natural Philosophy and Chemistry to Domestic and Culinary Purposes, which became the first textbook on home economics in the United States and perhaps in the world. The Young Ladies' Academy continued to offer Rush's course of chemistry applied to home economics, and by the middle of the 19th century chemistry was considered, along with botany and astronomy, a science fitting for the education of young women (Lippincott \& Bodner, 1984). Most female academies and girls' high schools offered courses in astronomy, geography, and natural philosophy with as much chemistry as would be useful in domestic economy. The more technical aspects of the sciences, however, remained a subject primarily for white men.

The first blacks to become educated in the sciences were trained as physicians, mostly in the tradition of the time, self-taught or apprentice-trained. In the 1800's the first few professionally trained black physicians received medical degrees abroad. It was not until 1847 that the first black student, David J. Peck, was 
graduated from a medical school, Rush Medical College in Chicago. By 1860 , at least nine northern medical schools had admitted black students into their lectures (Morais, 1970).

The Evolution of Science Instruction in the 19th Century

Early science education did not much resemble our modern courses. The content was meager and the teaching methods were superficial and rudimentary. Few teachers knew enough about their subject, and the few textbooks did not help much. Most scientific apparatus, chemicals, and textbooks had to be imported from England or Scotland. In the early academies and colleges, chemistry was taught entirely by textbook and lectures, with the gradual introduction of demonstration experiments. The scarcity of suitable apparatus dictated that demonstrations be performed only by the teacher; students had no opportunity to do individual work in a laboratory (DeBoer, 1991).

These instructional practices were supported by the Yale Report of 1828 , which promoted faculty psychology. When applied to curriculum and instruction, faculty psychology likened the mind to muscles to be trained, and it designated certain instructional techniques (drill and recitation) and subjects (liberal arts) as justified curriculum inclusions because they trained the faculties of reason, imagination, will, and other such human characteristics. This school of psychology continued to influence science instruction throughout most of the 19th and 20th centuries; it was first challenged by the 
research of pragmatists William James and E. L. Thorndike who demonstrated that no particular subject had a monopoly on the development of the mind (Klein, 1991).

The influence of laboratory instruction, as we know it, came from Germany during the mid-19th century. In 1826 the German organic chemist Justus Von Liebig began to teach his students at the University of Gissen by assigning laboratory space and individual experiments. Those American college graduates who crossed the Atlantic to study graduate chemistry under Liebig during the 1830's and 1840's returned to this country eager to institute the laboratory method of science instruction in American schools. The laboratory method spread rapidly throughout the larger city school systems, and by the last quarter of the 19th century American high school chemistry had gained the reputation of being a subject where students had to get their hands dirty (Blosser, 1981).

It was in 1858 that Edward A. Sheldon made his trip to Toronto and returned with an enlarged vision which caused him to offer new courses at Oswego, New York. In these new courses he dealt with form, color, size, weight, animals, plants, the human body, and moral instruction. In his 1863 book Lessons on Objects, the Object Study Method successfully challenged the listening, note taking, reading, and rote reciting so prevalent at common school levels. It was a small step from object study to nature study, field work, laboratory work, demonstration methods, and an approach to teaching and learning which removed the textbook and the teacher from the preeminent position as the source of all truth (Steiner, 1977). 
In 1882 the Department of Interior, Bureau of Education, issued a bulletin with the following statement: "Instruction in natural science should be a training in thinking. Pupils should be led to form general ideas and laws from the objects of study and the phenomena presented to them, to draw conclusions upon the causes of such phenomena and predict the future action of the causes they have learned to know. In this way not only a knowledge but also an understanding of nature is reached. The natural science school book should be used only as a book of reference in reviewing, as a means of saving writing, for recalling to memory the things observed in the course of study, as a help in looking up modes of expression, and particularly as a general model" (Ashman, 1985).

\section{The American High School}

The American academy was a transitional stage between the old world Latin grammar school and the yet to come American high school, which in fact first appeared at a time when the academy was showing its period of greatest growth. The American high school was not developed to replace the academy, but as an alternative to those who would not go on to college and would enter all phases of commercial life. Two important provisions were envisioned in their design: (a) education at public expense, and (b) a continuation of common school education (Johnson, P. G., 1977).

The English Classical School in Boston was the first high school in the year 1821; its title was soon changed to the English High 
School. Because of its success, the Massachusetts legislature provided funds to develop additional high schools throughout the state, as they became the pattern of post-elementary education. The high school provided education for all children at public expense with a curriculum attuned to the needs and interests of the masses. As high schools spread around the young nation, the famous Kalamazoo Case in Kalamazoo, Michigan, tested the legality of assessing taxes for the support of education beyond the common school (elementary level). After 1874 the high school movement grew by leaps and bounds. In only 20 years (1870-1890) the number of high schools increased five times in number. In 1890 slightly more than 2,500 high schools existed with around a quarter of a million students (Lippincott \& Bodner,1984). This growth reflected the country's growth in population and the steady increase in the standard of living of Americans.

The beginnings of high school science offerings are noticed when the content of natural philosophy and natural history are examined. Natural philosophy contained materials from astronomy, the earth sciences, chemistry, and physics. Natural history on the other hand included about equal portions of botany and zoology with no attempt at integration. Emphasis in natural history was on learning facts and on the physiology and morphology of plants and animals (Williamson, 1977).

\section{Attempts to Control Curricula (1870's-1900)}


As more and more youths extended their education into the public high schools, the offerings and instructional practices changed to meet the needs and interest of this broadening spectrum of students. Diversity became a greater problem when the public high schools were called upon to serve a larger number of students who were college bound. The problem became intolerable to many college admission officers and the teaching staff, and in their judgment, something had to be done.

Harvard University led the way and by so doing helped to standardize high school science courses. In 1872 Harvard began accepting science courses from a student's high school as entrance credits. By so doing, Harvard could dictate what were acceptable not only as high school science courses but also the content. One standardizing document of interest was the Harvard Descriptive List (1887) which reported the 46 acceptable experiments in high school physics which could be used for college entrance (Johnson, P. G.,1977).

New York established a Board of Regents and state examinations for graduation. The examinations were based on syllabi which were issued for the guidance of teachers and school leaders. The Regents Plan was established in 1877 and the first syllabus was made available in 1880 (Fisher, 1986). Many other states have issued syllabi under general title of courses of study but very few developed an examination system and only New York has maintained such a system. 
During this period from 1870 to 1900 high school science courses became miniature college science courses. College professors prepared the courses of study used in high school sciences and they wrote the textbooks. The science courses had little or no practical value but instead served to prepare the student for more of the same in college. Accrediting agencies were formed in various regions, all of them attempting to standardize the offerings and their quality, with their dictation from above. These were the forerunners of the College Entrance Examination Board, the most widely accepted college entrance examining body in the nation.

Another avenue of control was through committees established by organizations of national repute. Of particular influence was the Committee of Ten on Secondary School Studies, appointed in 1892 by the National Education Association (NEA) to deal with the problem of uniform college entrance requirements. The president of Harvard who was in the forefront of the humanist interest group and also a mental disciplinarian, Charles W. Eliot, was appointed its chairman. Of the ten persons serving on each of its nine subcommittees, $75 \%$ were either college staff members or headmasters of preparatory schools (Kliebard, 1987). They gave their attention to the courses that colleges recognized for admission. By these actions and by a system of accreditations of high schools by visiting teams the high schools were influenced to limit their curricular innovations.

As a result of these centralizing influences, most post-1900 high schools offered the following four-year sequence: first year, physical geography; second year, biology; third year, physics; fourth 
year, chemistry; these influences also encouraged quantitative laboratory work and field trips (Williamson, 1977). Standardization, however, placed an inordinate emphasis on the assimilation of subject matter of science as an end result of instruction with little emphasis on how it was acquired: knowledge of the products of science at the expense of the understanding of the processes of science.

The Nature Study Movement (1890's-1920's)

At the turn of the century agriculture was in its prime but at the same time there was a beginning trend toward urbanization. As a response to this trend, the nature study movement began to exert its influence on science teaching in the public schools. The movement gained its leadership from the colleges of agriculture by emphasizing gardening and subjective feelings for plants and animals. This emphasis had not only a profound effect on elementary school science but also on field and laboratory approaches to science at higher levels.

In 1890 the American Society of Naturalists considered the subject of science in the schools and submitted a report in which they proposed the following: (a) Instruction in natural sciences should commence in the lowest grades of the primary schools and should continue throughout the curriculum, and (b) in the lower grades the instruction should be chiefly by means of object lessons; and the aim should be to awaken and guide the curiosity of the child 
in regard to natural phenomena, rather than to present systematized bodies of facts and doctrines (Steiner, 1977).

In the decades that followed several ideas about a nature study program emerged. Two of these ideas have persisted. One was the nature garden idea, whose main objective was to maintain people in touch with nature for both aesthetic as well as for practical purposes; it maintained that in an urbanized environment, a garden could bring people closer to nature, something they viewed as beneficial for psychological well being as well as a practical solution to our nutritional maintenance. The other idea was not to study nature as a science, but to understand it without reference to the systematic order or relationship of the objects; the result is not directly the acquiring of science but the establishing of a living sympathy with everything that is.

In 1927 when Gerald S. Craig attempted to develop a course of study for elementary school, he found that the outstanding characteristic of the nature study and science programs in the schools seemed to lack organization. He began to study the programs in existence, the interest of children, and the literature available, in order to formulate a set of objectives for such program of study. He designed a nature study science program organized around 'key meanings'; materials with real phenomena were used in the development of the meanings; natural objects became supportive. His nature study program satisfied the social efficiency curriculum makers of the time, and even though its essence was that of the 
'nature study', this title fell into disuse in favor of that of 'elementary school science program'.

The General Science Movement (1900's-1930's)

The urgency to develop academically respectable science courses in high school had grown out of the college domination in the curriculum at the turn of the century. However, not too many students were academically prepared to succeed in such courses, and many did not remain in high school to be exposed to a balanced science curriculum. In response to this problem, some schools in Massachusetts began to offer a course "mildly physics and chemistry" in the Fall of 1904. The following year some astronomy was added and little by little the other sciences found a place, until the course became in fact, as well as in name, a course in General Science. The subject began to spread so rapidly that, by the second decade of the century, it had spread through the grades 7 to 12 and had become the most popular course in the science curriculum throughout the nation. General science was designed to serve a dual purpose both as a terminal subject for non-college students and as an exploratory course for those students who would later elect more specialized subjects, i.e., biology, chemistry, physics.

The influence of the social efficiency movement, vocationalism, and the home-project curriculum designers was reflected in the practical utilitarian science offerings of this period. These developments were related to the emergence of strong emphasis at 
the national level on agriculture, industry, and commerce. In relation to the still surviving school of faculty psychology, science was considered particularly useful to discipline the mind: it was believed to develop systematic habits, power of reasoning, and both precision and neatness. A new emphasis was also placed on demonstrations, laboratory methods, field work, and the utilization of reference books.

By the early 1920's what had become a six-year program at the high schools became divided into a three-year junior division and a three-year senior division. Physical and psychological reasons were found to justify the separation into these two levels, but it was the phenomenal increase in the number of students at the junior level which caused the construction of new buildings that eventually resulted in physical separation of the junior and senior high schools.

General science continued to be the leader in student enrollments among the high school sciences through 1934, was second only to biology in 1947 (Baez, 1982). In a period of 25 years it developed a very secure place among the major science courses of the 4- and the 6-year high schools. General science courses have also changed over the years, and become adapted to meet the changing needs of the students of our ever-changing society.

The influence of the general science curriculum spread to the other sciences, resulting in much curricular work involving attempts to identify major generalizations, principles, and theories. The biological sciences consisted of separate courses in botany, physiology, and zoology. A unified biological science course based on 
fundamental biological principles was proposed to be given in the second year of the four-year high school, after general science. The influence of proponents of a generalized curriculum eventually brought about the formulation of still another course, physical sciences, which began to appear here and there in the late 1930's.

\section{The Human Needs Emphasis (1930's-1940's)}

During the decade of the Great Depression from about 1930 to 1940 there was a great influx of high school age youth into the schools. There were limited opportunities for work and the schools were accepted as a constructive haven for all youth. By 1940 twenty eight states reported that ninety percent of the 14- and 15-year-old youths were in school (Holmes, 1982). This condition made it necessary to find appropriate curricular adjustments.

The revolutionary change in education from a major attention to specific information, to a concern for fundamental principles and significant generalizations, was in itself a recognition of human needs. Teachers had noted again that students forgot very rapidly what they had learned, especially the specific information peculiar to their course.

Many investigations contributed to changes in direction that helped the schools to respond to individual and societal needs. Ralph Tyler reported in 1930 that students retention of specific information was much less than their retention and ability to explain everyday phenomena and to apply facts and principles; other 
investigations added findings of the same nature (Fisher, 1986). Teachers also had learned that everyday phenomena and applications seemed to be of substantial interest to youth, especially those who did not plan to go to college. Surely greater stress on applications of principles and explanations of phenomena was a way to recognize individual, societal, and teacher needs. Thus the revision of science courses during this period was in the direction toward making them more general, more applied, and more suitable to the wide spectrum of interests and abilities found among the students. The demand to recognize individual and societal needs was especially acute in the biology area because of the many youths in school at the 10th grade level that elected to take biology as their science, since biology also met the requirement of a laboratory science for graduation.

The establishment in 1938 of the Committee on the Function of Science in General Education, was an outgrowth of the Progressive Education Association (PEA). In their report the committee revealed that their curriculum planning and experimentation would be needs oriented rather than science oriented. Needs were classified in such areas as personal living, personal-social relationships, social-civic relationships, and economic relationships. An illustration of the types of science courses they had in mind was functional chemistry which gave considerable attention to drugs, medicines, internal secretions, bacteria and disease, clothing, cosmetics, and hobbies. Another example was to fuse physical science with attention to household machines and appliances, public utilities, industries, 
matter and energy. Other illustrations were public health and genetics.

Most science teachers accepted the philosophy that individual and societal needs must come first in the organization of science courses and in planning instructional practices. For them the decrease or total dropping of time for laboratory work produced no trauma. Even the increasing use of instructional films showing the use of science in everyday affairs and in scientific pursuits during laboratory and classroom periods seemed to be a good thing because the students displayed considerable interest in the films and in the socially more relevant topics.

There was, however, another group of science teachers and science educators who deplored the "watering down" of science courses. They lamented the decreases in time for laboratory work and felt strongly that something must be done to strengthen the science part of science instruction. They also felt a need for an organization where they could exchange ideas about what was happening. Thus, The National Association of Biology Teachers (NABT) was organized in 1938 and The Biology Teacher became their journal. The leaders who were concerned about the academic respectability of their area formed the American Association of Physics Teachers (AAPT) in 1930 and the American Science Teachers Association (forerunner of NSTA) in 1934 (Steiner, 1977).

The various scientific societies and associations became the allies of these science-minded individuals. In addition to revising existing science courses and developing new types of courses, there 
were also many adjustments in instructional practices such as ability grouping, individualized and small group instruction. The academic respectability of many science courses was still compromised in many cases due to the greater power and influence of the social meliorists. The issue, however, never came to a full confrontation because World War II began and science teachers, scientists, and school leaders joined together to win the war and secure the peace. Science instruction was directed at preparing youth for effective performance during the emergency. This meant the development and offering of new science-based courses that would help youths make rapid and effective progress during basic training and then to perform well in the offensive, defensive, and productive units of the nation. Not only were many needs-oriented science courses abandoned and others greatly de-emphasized, but also projects that were designed to promote the needs types of courses were greatly slowed down or terminated because critically important personnel became involved in the war effort. Some new needs in addition to those directly related to military effectiveness came into the schools such as physical fitness, health, war gardening, and fuel economy.

The needs emphasis was redirected and related to the military emergency; it did not disappear from the educational scene. The designing of science courses with individual and societal needs in mind came into the schools during a depression emergency and it was greatly modified during a military emergency. Much of the needs emphasis was applicable during these difficult decades, but 
after the war was over a new era brought new needs and further modifications were required. Schools as social institutions have and will undoubtedly continue to be sensitive to contemporary needs.

The Nurture of Future Scientist after W.W.II (1940's-1950's)

The scientific and technological nature of World War II caused a severe relocation of many high school and college science teachers. Many graduate students in the sciences and mathematics also entered military service or became involved in research and development related to the war effort. A very large number of science-talented youth postponed their entry into collegiate studies in order to serve their nation during the emergency.

The immediate educational needs of the war resulted in many crash curriculum changes in science, health, physical education, the languages, and in the social sciences. Science educators responded by making major adjustments in course offerings and in developing numerous specialized courses such as preflight aeronautics, fundamentals of radio and/or electricity, and other courses directly related to the war effort. Crash science programs, usually lacking in thoughtful planning and development, and designed to solve special programs, are usually of short duration; this was especially true of science courses designed during the period of 10 years after World War II. Most specialized courses were dropped from the science program as tensions in society eased. 
The war experience, the cold war which followed it, and the proliferation of nuclear weapons, taught society to accept technology with its requisite demands as a basis for survival in a peacetime world. The emphasis on consumer and general education in the depression years was in conflict with the needs of a technologicallyoriented society and career needs in highly specialized fields. Whether science should be functional in meeting the needs of young people or should be taught with emphasis on the scientific enterprise and the preparation of scientist and engineers was the subject of numerous debates in the post-war years. The reports of special committees and/or commissions recognized the importance of science K-12 in maintaining a democratic society and recommended that science programs be designed to provide scientific literacy for all. They also recommended that individuals be prepared to assume active roles in a scientific and technological society.

The Golden Age (Mid 1950's- Mid 1970's)

Even before the end of World War II, American scientist and science educators were troubled about the superiority of other countries educational accomplishments, particularly the Soviet Union. It was not until the Russians proclaimed scientific and technological superiority to the world by the launching of Sputnik in 1957, however, that the problem became one of popular national concern. Americans reacted with the development of new science curricula in an attempt to meet the challenge presented by the Russians and 
spent over $\$ 100$ million during a twenty year period. During this 'Golden Age' of Science Education, public and private funds poured into new science programs, college campuses teemed with teachers taking science and mathematics refresher courses, and students enjoyed dramatic gains in science achievement and improved attitudes toward science (Sealey, 1985).

The NSF-funded curriculum projects involved an emphasis on student investigation and inquiry (or enquiry), and deplored the teaching of science as dogma. The entire science curriculum, from textbooks to laboratories were converted to reflect this new emphasis: the students were expected to explore and discover rather than to memorize; the laboratory became the context for giving students insights into the role played by experiment in uncovering new knowledge rather than being made up of cookbook exercises (DeBoer, 1991).

Researchers defined the new science curricula as programs that "were developed after 1955: emphasized the nature, structure, and processes of science; integrated laboratory activities into course discussions; and emphasized higher cognitive skills and an appreciation and understanding of the nature of science" (Sealey, 1985). Traditional curricula were those that were developed before 1955 (or patterned after these programs): "emphasized knowledge of scientific facts, laws, theories, and applications; used laboratory activities as verification exercises or secondary applications of concepts previously covered in class" (Sealey, 1985). The new curricular projects received the enthusiastic support of prominent 
educators such as Jerome S. Bruner and Joseph Schwab. Bruner stressed teaching the structure of the disciplines: using unifying themes, modes of inquiry and scientific attitudes. Schwab stressed the process by which scientists generated knowledge: teaching science as inquiry (DeBoer, 1991).

Numerous curricula were developed during this period, but they all had some common characteristics (Sealey, 1985):

1. Scientists, educators, psychologists, and teachers joined forces to write texts and develop the curricula.

2. Students were taught the 'structure of disciplines' in the way that scientist understood their subject: organized under broad unifying themes, including the modes of inquiry and the attitudes of scientific enterprise; there was less emphasis on having students memorize facts.

3. Laboratory activities were an integral part of the class discussions, emphasizing scientific inquiry, the 'discovery approach' and the development of higher cognitive skills.

4. The new curricula emphasized the nature and processes of science, its historical development as a dynamic human enterprise. By the mid-1970's, America appeared to have regained its lead over the Soviets in space exploration and the American public was no longer concerned with science education; new political, economic, and social pressures claimed the public's attention. By 1976, National Science Foundation funds for teacher education had been terminated and the 'Golden Age' ended abruptly. No major curriculum projects 
were funded by the National Science Foundation in the decade that followed.

After 1976, the National Science Foundation sponsored three large-scale status studies to determine the impact of the new curricula: a national survey of teaching practices, an intensive case study analysis of 11 school sites, and a review of the research literature from 1955 through 1975. Also in the 1970's, the National Assessment of Educational Progress published the results of a largescale investigation into American students' scientific knowledge and attitudes toward science (Sealey, 1985).

Analysis of the research evaluating the new curricula showed that the students exposed to it demonstrated an increase in scientific knowledge and skills across grade levels and in all science disciplines. Gains were evident regardless of individual student, teacher, or school characteristics. Furthermore, these students developed better attitudes toward science than students who had traditional courses. Their achievement scores increased by 14 percentile points; this increase was consistent among elementary, middle, and high school students. Female students, urban students, and low and high SES students showed the greatest achievement score gains (Sealey, 1985).

Most of the new curricula were never adopted by school systems, and no single new curriculum was adopted on a large scale. In fact, none was adopted by more than $25 \%$ of the school districts in the nation. These low adoption rates, coupled with the data on enhanced achievement of students who were in the new science 
curricula, take the responsibility for declining student scores on standardized achievement test away from this new science curricula (Shymansky, 1982). However, critics of this new curricula insisted that it had over emphasized the structure of the disciplines and that it tailored science courses to an educational elite planning careers in science, ignoring the interest of the majority of students; they claimed this was evident in its failure to increase student enrollment in the sciences inspite of the tremendous effort to improve science education nationwide.

Before the new science curricula, the textbook defined the school science program, as it does today. The textbook determines the content, the order, and the application of the content of science instruction. These books had not kept pace with the new conception of science, primarily because of the transfer of control in textbook writing from scientist to professional educators which had taken place ever since the 1920's. The new curricula changed all that; scientists with the help of educators and psychologists regained control, making up-to-date textbooks which reflected the new conception of science. No one today would recommend completely re-adopting the 1960's curricula. The issues and goals of science education are different in the 1990's. The world crises we face now outshadow the embarrassment we faced as a nation in the 1950's. Acid rain, nuclear waste disposal, economic competitiveness, "star wars" weapons, international terrorism - threats to the quality of life if not to our existence - are the issues we will have to consider as we strive to improve the scientific literacy of our students. Most experts 
in science education warn that, unless science is taught in relation to the individual and to society, we will continue to fall behind in scientific advancements and in meeting the challenges of modern society.

Many suggestions for improving science education have emerged from a study of the science curriculum development projects of the 1960's. "Project Synthesis" was the research effort of 23 science educators to synthesize and interpret more than 2,000 pages of information from the three National Science Foundation status studies and the National Assessment of Educational Progress report mentioned earlier. What Research Says to the Science Teacher reports the group's findings and urges teachers, administrators, and other concerned citizens to work for changes in science education. The report makes recommendations such as these (Lawson, 1990):

1. Set new goals for science education that take into account the complexities of modern society. School science should be much more than a preparation of a few students for further study in science.

2. Design science curriculum to meet these new goals. Focus on student experiences, technology, and the concerns of individuals and the society.

3. Give attention to teacher preparation and inservice programs. Teachers must have support and assistance so that the new goals and new curriculum can be internalized.

4. Incorporate research findings in curriculum design, in textbooks, and in instructional methods. 
5. Evaluate the effectiveness of new programs.

6. Seek out and study exemplary teaching and science programs locally, so that we can all benefit from studies of techniques and materials that work.

Obviously, these recommendations require the cooperation of the larger community of educators and researchers over a period of years. Some of them have been followed more than others as a the needs of a new era brought different priorities and perspective.

\section{Scientific Literacy and The New Progressivism (1970's-1980's)}

After the traumatic experience in an unpopular and highly technological war in S. E. Asia, and the realization of the ecological impact that our way of life has on our planet, Americans of the seventies developed a distrust for science and technology. As a result different types of science education programs emerged in the decades which followed, as always reflecting the needs of the times. This time, however, the shift was towards increased attention to student interest and the renewed focus on the social relevance of the curriculum, reminiscent of several fundamental principles of progressive education of the which spanned from the second to the fifth decades of this century. Reformers now looked at designing courses that were relevant to the lives of a broad range of students and instructional methods demonstrating a concern for the students individual differences in abilities and interest. This new emphasis sparked interest in individualized instructional programs and in the 
expansion of student choice in course selection. It also caused a shift towards scientific literacy, which has been described as an understanding of science and its applications to our social experience (Hurd, 1958). The theme of scientific literacy gained additional prominence when The National Science Teachers Association (NSTA) identified as the most important goal of science education for the 70's (NSTA, 1971).

Since no major science curricula reform project was initiated for over a decade, the major players in science curricular design were the textbook publishers and the socio-political and economic factors to which they responded. Two curricular attempts to incorporate the trends of this new emphasis are briefly described here.

\section{Science-Technology-Society (STS).}

According to advocates who emphasize the interrelations between science, technology and society, science education in the 70 's and 80 's was to be humanistic, value-oriented, and relevant to a wide range of personal, societal, and environmental concerns. The humanistic orientation was to emphasize man as a emotional and feeling creature as well as a reasoning one; the value orientation was to give students opportunities to discuss controversial scientific issues and their social and moral consequences; the ecological perspective was to develop the decision-making skills for an informed citizen needing to protect and preserve their life space (DeBoer, 1991). 
The STS approach was widely accepted and became implemented into many of the science programs designed during this period. However, a heated controversy arose in 1982 when Hofstein and Yager forcefully argued that the organization and logic of science curricula should revolve be around social issues rather than around the concepts of the disciplines. As president of the NSTA, Yager continued to advocate the interdisciplinary aspects of science and has gone as far as suggesting that science education be defined as "the discipline concerned with the study of the interaction of science and society" (Yager, 1982). Critics of this organizational logic argue that the societal issues approach does not teach the basics, and that it fractionalizes the discipline, not conveying any real understanding of the structural integrity of science; they argued that the current issue orientation does not prepare students with the scientific background necessary to understand the nature of new and rapidly changing problems that they will face in the near future (Kromhout and Good, 1983).

\section{Chemistry in the Community (ChemCom).}

Chemistry in the Community (ChemCom) is an innovative chemistry course which reflects an STS approach, and whose major objective is to enhance science literacy through a high school curriculum that emphasizes the impact of chemistry on society. Developed by the American Chemical Society's (ACS) Educational Division with financial support from the National Science Foundation and several ACS funding sources, ChemCom has been written by teams of high school, college, and university teachers, assisted by 
chemists from industry and government (American Chemical Society, 1991).

ChemCom is not intended to supplant traditional chemistry courses. Instead, it's an attempt by ACS to provide an alternative for the many students who shy away from other current chemical offerings. It's a "user friendly" course specially designed for the college-bound student not planning a career in chemistry or for the bright student not planning to go to college. It's designed to enhance public understanding of chemistry. A year-long course, it takes a nontraditional approach: it's issue-rather than content-oriented and it uses group discussions, team work, and labs in place of traditional lectures. Its purposes are to help students (American Chemical Society, 1991):

1. Realize the important role that chemistry will play in their personal and professional lives.

2. Use principles of chemistry to think more intelligently about current issues they will encounter that involve science and technology.

3. Develop a lifelong awareness of the potential and limitations of science and technology.

Each of ChemCom's eight units centers on a chemistry-related technological issue now confronting society and the world; the topic serves as a basis for introducing the chemistry needed to understand and analyze it. The setting for each unit is a community; this may be the school community, the town or region in which the students live, or the world community - Spaceship Earth. The eight units include 
the major concepts, basic vocabulary, and intellectual and laboratory skills expected in any introductory chemistry course. The program contains a greater number and variety of student-oriented activities than is customary: from numerous laboratory exercises to three levels of decision-making activities, and several types of problemsolving exercises.

ChemCom is not so mathematically rigorous as existing high school courses, although mathematics is used in appropriate context. The course contains less physical chemistry and a good deal more organic chemistry, nuclear chemistry, and biochemistry than existing courses. In each unit, chemistry and decision-making activities go hand-in-hand, and each unit closes with a comprehensive activity in which students are challenged to put their knowledge of chemistry to test in resolving a hypothetical, chemically related community issue.

Planning for ChemCom began in 1981 by a 15-member steering committee. The course was written over a three-year period by teams comprising mainly high school teachers. It was extensively reviewed by prominent chemists. Field testing began in 1985 at seven centers with close to 3000 students. It is increasingly being adopted by school districts across the nation (Ware, 1988).

\section{Projects for The Twenty-First Century}

The continuing decline in student achievement in science and mathematics throughout the last two decades, coupled with the scarcity of the number of students who pursue careers in science, 
pose extreme obstacles for meeting the national need for a pool of competent scientists and a scientifically literate society. After decades of neglect in science curricular design, the prospect of our deteriorating economic and technological advantage has led to the creation of the following two major science curricular reform efforts.

\section{Scope, Sequence, and Coordination}

The authors of Scope, Sequence, \& Coordination (SS\&C) curriculum project claim that in their many years of experience in the effectiveness-assessment of the established science education curriculum, they and many other researchers have found that science curriculum is built on a philosophy which is counter to the natural learning cycle of the student (Renner, 1988). The traditional curriculum, they claim, is based on an approach which emphasizes the memorization of abstract data and concepts and thus is not designed to stimulate or guide the development of those cognitive skills necessary to make the student a self learner; furthermore the disciplines are taught in a stratified or "layer cake" manner, thus segregating the scientific knowledge of each field into separate years which discourage integration of knowledge and understanding of science. It is not surprising that students who do not understand the principles and concepts of science and mathematics are not motivated to study these disciplines. This results in an increase in the number of students who drop out of the science and mathematics educational pipeline and reduces the science and mathematics literacy level of the general population (Gomez, 1989). 
This SS\&C project has created a Science and Mathematics Curriculum for the 7th through 12th grade which they claim helps increase the number of students who pursue careers in science and increase the science mathematics literary level of the general population. The project has been implemented by schools which obtain grants and work in close coordination and cooperation with the NSTA Scope, Sequence and Coordination (NSTA-SS\&C) project staff. As a design strategy the curriculum is concept driven, since mastering the conceptual framework of science and mathematics disciplines is essential to understanding, and it is well known that nobody likes something that he can not understand (Aldridge, 1989; Scope Sequence \& Coordination Project Staff, 1991).

The authors of SS\&C propose that the disciplines of physics, chemistry, biology, earth sciences and mathematics are to be taught following a parallel approach where all disciplines are taught every year of the six years of the secondary school curriculum. This will permit the use of a spiral approach where concepts and ideas of science are taught in a spiral of increased cognitive sophistication, from the concrete to the abstract, that is more in tune with the natural learning cycle of the student. The parallel approach will also permit the integration of knowledge across scientific and mathematics domains. The content should be presented in the context of the student's everyday experience, including societal and technological aspects. Integration of knowledge across disciplines through context, is known to increase motivation and understanding, which are two essential elements needed to make science fun, 
relevant and worth learning. Adding these elements to the curriculum, they believe, will help reduce the overall dropout rate from secondary science and mathematics courses and increase the science and mathematics literacy of all future citizens. This method of teaching is followed in many countries which now surpass the U.S. in levels of performance in science education (Gomez, 1989).

The spiral approach to teaching science that goes inductively from the phenomenological, qualitative and concrete to the theoretical abstract and quantitative permeates the SS\&C curriculum design. The success achieved by many independent researchers using this approach leads the authors to believe that the integration of all the above elements into a major overhaul of the U.S. science and mathematics curriculum is called for (Kumagai, 1990).

\section{Project 2061}

Named for the year Comet Halley will return to Earth, Project 2061 is being directed by F. James Rutherford of the American Association for the Advancement of Science (AAAS). It is an ambitious long-term project whose goal is the complete transformation of science, math, and social studies teaching, from kindergarten through 12 th grade; it describes a "common core of learning" emphasizing connections among scientific disciplines rather than boundaries. It is developing its vision in three stages: first, decide what students need to know; second, illustrate how they can learn it; third, spread the revolution around. Its $\$ 8.5$ million second phase was completed in 1993 and its third phase is now underway, 
being sponsored by the National Science Foundation (NSF), IBM, U.S. DOE, private foundations, and state and local governments (American Association for the Advancement of Science, 1993).

In Phase I, teams of prominent scientists focused on the substance of scientific literacy, spelling out the knowledge, skills, and attitudes all students should acquire as a consequence of their total school experience from $\mathrm{K}-12$; these prescriptions were reported in a 100-page exposition first published in 1989 titled "Science for All Americans. The book emphasizes concepts over data and considerably lightens the burden of facts students must know (Rutherford, 1990).

Phase II of Project 2061 was completed in 1993 and its results were published in book entitled Benchmarks for Science Literacy. It was executed at six sites around the country, were teams of educators and scientists transformed the reports from Phase I into blueprints for action. The main purpose of the second phase of the project was to produce a variety of alternative curriculum models that school districts and states can use as they undertake to reform the teaching of science, mathematics, and technology. Phase II also specifies the characteristics of reforms needed in other areas to make it possible for the new curricula to work: teacher education, testing policies and practices, new materials and modern technologies, the organization of schooling, state and local policies, and research.

In Phase III, the project will collaborate with scientific societies, educational associations and institutions, and other groups involved in the reform of science, mathematics, and technology 
education, in a nationwide effort to turn the Phase II blueprints into educational practice. Since the completion of Phase II in 1993 a few vanguard districts have started putting the 2061 philosophy into practice, with the aim of producing a report titled Designs for Science Literacy, which will advise on alternatives for local curriculum, and Blueprints for Reform, which will consider the broader educational system in which curriculum functions. Later, all these publications plus a resource data base will be incorporated and interrelated in the computerized Curriculum-Design \& Resource System (American Association for the Advancement of Science, 1993).

For Phase I, the national council recommendations were drawn from reports of five independent scientific panels as well as the advice of a large and diverse array of consultants and reviewers. The process took more than three years and culminated in the unanimous approval of Science for All Americans by the board of directors of the AAAS. A fundamental premise of Project 2061 is that the schools do not need to be asked to teach more and more content, but rather to focus on what is essential to scientific literacy and to teach it more effectively. The council's recommendations cover a broad array of topics, many are already common in school curricula, however, their treatment of such topics tends to differ in two ways (Rutherford, 1990):

1. The connections between subject-matter categories are emphasized and the amount of detail that students are expected to retain is considerably less than in traditional science, mathematics, and technology courses. 
2. Ideas and thinking skills are emphasized in order to provide a lasting foundation for learning more; details are treated as a means of enhancing, not guaranteeing, understanding of a general idea .

The Science for All Americans report describes four areas that students should be aware of in order to understand what scientific endeavor is and how it relates to their culture and their lives. The four areas are: Scientific Endeavor, Scientific Views of the World, Perspectives on Science, and Scientific Habits of Mind. Descriptions of each area constitute proposed learning goals that are appropriate for all Americans regardless of backgrounds and career aspirations. The council proposes that given clear goals, the right resources and good teaching throughout 13 years of schooling, all students will be able to reach all recommended goals by the time they graduate from high school. To support these changes in the content of instruction, changes are recommended in the way science and math are taught to make leaning in science consistent with the nature of scientific inquiry. Teachers should start with questions about nature, engage students actively, allow them to work in teams, and de-emphasize the memorization of technical vocabulary. The report warns that concentration on vocabulary detracts from the processes of science, puts learning for understanding in jeopardy, and produces misleading information about what students have learned. All students should leave school with an awareness of what Scientific Endeavor is and how it relates to their culture and their lives (Rutherford, 1990). 
The Benchmark for Science Literacy report describes in more detail what all students should know or be able to do in science, mathematics, and technology by the end of grades $2,5,8$, and 12 . It reports for each category identified in Science for All Americans specifically what the student should learn at each of the grade levels identified. These Benchmarks are useful for teachers to explore the concept of science literacy in relation to instruction at their grade levels, and for suggestions in making immediate and long-term curriculum and course improvements. Test writers can use it to develop grade-level materials and techniques for assessing student progress toward science literacy (American Association for the Advancement of Science, 1993).

\section{The Past and Future of Science Education}

To be able to understand the present state of our educational enterprise and to cope with our present socio-economic crisis as well as the many other problems which will certainly arise in our future, we must look at the many lessons learned from the efforts made and the experience gained in science education over the course of our history.

The international economic competitiveness of the United States and its hegemony in high technology rests to a great extent on the production of high quality scientific human resources. A series of national studies have indicated that the U.S. will have problems meeting this need (Baringa, 1990; Culotta, 1990; Textley, 1991). The 
low levels of performance in science evidenced in the general student population, coupled with the scarcity of the number of students who pursue careers in science, pose extreme obstacles for meeting the national need for a pool of competent scientists and a scientifically literate society. Within this perspective, the situation of minorities is of particular concern. Although by the year 2000, one third of the 18-year old population of the United States will be Black or Hispanic, these groups are dramatically under-represented in the fields of science and mathematics (Olivas, 1986).

Conditions of similar urgency have come about in the short history of our young nation. We must look to the past in order to learn from our great strides as well as from our mistakes, to guide our vision into the next century so that our schools better serve the needs of its citizens in meeting the challenges of the future.

Instructional Groupings: Traditional, Cooperative and Individualized

There are many different ways to structure classroom instruction. In this study cooperative group instruction was compared to the traditional whole-class instruction. This was done while both instructional groupings utilized computer-based interactive videodiscs (CBIV).

Traditional Whole-class Instruction 
Large-group instruction is the mainstay of traditional education. Conventionally, it ranges from large lecture hall to whole class presentations, which may include speeches, recitation sessions, dramatic or inspirational presentations, demonstrations, and other types of teacher-centered performances. The intent is to convey or deliver efficiently a fairly large quantity of information, ideas, or affective input in a relatively short period of time. The success of large group instruction depends upon the quality of performance of the teacher and willingness to pay attention on behalf of learners. Some of the most successful forms of large-group instruction in real life are not derived from lecture hall or single-person presentations, but from films, television, concerts, plays and other staged performances, and sporting events. While the instructional character of some of these is great and of others minimal, those who instruct large groups in schools might learn from some of the techniques employed. Disadvantages of traditional large group instruction include lack of personalization, ineffective performances, lack of teachers who are able to interest large groups, and the unlikelyhood that all learners in a large group would want or need to know the same things. Some argue that the advent of the printed page, or recently, electronic forms of communication, preempt the need for traditional, large-group lectures (Schubert, 1986). 
According to proponents of cooperative learning "cooperation is working together to accomplish shared goals. Within cooperative activities, individuals seek outcomes that are beneficial to themselves and to all other group members. Cooperative learning is the instructional use of small groups so that students work together to maximize their own and each other's learning. The idea is simple. Class members are split into groups of two to four members after receiving instruction from the teacher. The groups then work through the assignment until all group members have successfully understood and completed it. Day after day, they must resolve their personal differences and work together. Students realize they have a stake in each other's success. They become mutually responsible for each other's learning." (Johnson \& Johnson, 1991). The groups (teams) should consist of students who are heterogeneous in performance level, sex, and ethnicity. The reward structure should emphasize individual accountability, in that the group's success depends on the learning of each group member, as demonstrated on quizzes taken without teammate help, however, the individual students should also receive grades based on a cooperative incentive structure, in which the grades they earn are based on the average score achieved by all members of the team (Slavin, 1977, 1992). Proponents of cooperative group instruction claim it is the most important method of structuring learning situations, yet it is currently the least used. 
There are many wrong ways of organizing groups which do not lead to effective cooperation or learning. In such cases less able members sometimes create a "free rider" effect which destroys teamwork; more able group member may expend less effort to avoid the "sucker effect" of doing all the work; high-ability members may take over the important leadership roles in ways that benefit them at the expense of the others (the "rich-get-richer effect"). The group experience can be characterized by helplessness, diffusion of responsibility and social loafing, uneven division of labor, destructive conflict, and other patterns of behavior that debilitate the group performance (Johnson \& Johnson, 1989).

In order to avoid these barriers to cooperative learning the group experience must be properly structured. According to Johnson and Johnson $(1989,1991)$ "the first requirement for an effectively structured cooperative lesson is positive interdependence, which exists when a group member perceives that he or she is linked with others in a way such that he or she cannot succeed unless they do (and vice versa) and/or that he or she must coordinate his or her efforts with the efforts of others to complete a task." The second element for an effective cooperative lesson is face-to-face promotive interaction among group members; this means that teachers need to maximize the opportunity for students to promote each other's success by helping, supporting, encouraging, and praising each other's efforts to learn. The third element is individual accountability, which exists when the performance of each individual student is assessed and the results are given back to the group and 
the individual. The fourth element is the appropriate use of interpersonal and small-group skills; such collaborative skills include leadership, decision-making, trust-building, communication, and conflict-management skills. The fifth element is group processing, which exists when group members discuss how well they are achieving their goals and maintaining effective working relationships.

Working together in cooperative groups can have an effect on numerous variables of a students psycho-social make-up, and they can be classified within three broad and interrelated outcomes: (a) effort exerted to achieve, (b) quality of relationships among participants, and (c) participants' psychological adjustment and social competence (Johnson and Johnson, 1989).

Cooperative group instruction may be organized into three types of arrangements which vary according to the length of period the students work together. Informal learning groups are given a short discussion task and stay together for only a few minutes; formal learning groups are given an assignment to complete and typically stay together for several weeks; base groups are long-term groups whose purpose is primarily to provide peer support and accountability and stay together from at least one semester or year to optimally several years (Johnson \& Johnson, 1991).

Informal cooperative learning groups are temporary, ad hoc groups that last from only a few minutes to one entire class period. Their purposes are to focus student attention on the material to be learned, set a mood conductive to learning, ensure that students 
cognitively process the material being taught, and provide closure to and instructional session. These groups are often organized so that students engage in focused discussions before and after a lecture and by interspersing "turn-to-your-partner" discussions throughout the lecture (Johnson \& Johnson, 1991).

Formal cooperative learning groups may last from one class period to several weeks to complete a specific task or assignment. The teacher is expected to structure the learning group, teach what the students are to master and apply, monitor their functioning and intervene to provide academic and collaborative skills (Johnson \& Johnson, 1991). Science laboratory experiences lend themselves to such cooperative arrangements and they are generally structured to groups of two to four students, depending on the complexity of the task being performed. Students in such groups are expected to interact with each other, share ideas and materials, support and encourage each other's academic achievement, orally explain and elaborate the concepts and strategies being learned, and hold each other accountable for completing the assignment (Johnson \& Johnson, 1991).

Base groups are long-term, heterogeneous cooperative learning groups with stable membership. The purposes of such groups are to give the support, help, encouragement, and assistance that members need in order to make academic progress and develop cognitively and socially in healthy ways. Members of the group are assigned to as many of the same classes as possible and regularly work together to complete cooperative learning tasks. The use of base groups tends 
to improve attendance, personalize both the required work and the school experience, and improve the quality and quantity of learning (Johnson \& Johnson, 1991).

Approaches to implementing cooperative learning in classrooms and schools may be placed on a continuum, with conceptual applications at one end and direct applications at the other (Johnson, Johnson, and Holubec, 1990). The conceptual approach emphasizes teachers' understanding the essential components of cooperative learning and using that understanding to modify any lesson in any subject area using any curriculum so that the lesson is cooperative. The direct approach emphasizes teachers' knowing how to take a packaged lesson, strategy, or curriculum and implement it in a locked-step, technically correct manner. While expertise in using cooperative learning depends on a conceptual understanding of cooperation, the direct approach can facilitate teachers' implementation efforts (Johnson \& Johnson, 1991).

Although there is a growing consensus among researchers about the positive effects of cooperative learning on student achievement, there is still a great deal of confusion and disagreement about why cooperative learning methods affect achievement and under what conditions cooperative learning has these effects. There are researchers who emphasize the changes in incentive structure brought about by certain forms of cooperative learning, whereas others hold that changes in task structure are all that is required to enhance learning (Slavin, 1992). 
Most traditional classrooms use a competitive incentive structure, in which students compete for a limited number of good grades, the teacher's praise and attention, or other rewards. Other traditional classrooms use an individualistic incentive structure, in which students earn a particular grade if they achieve at a given, preestablished performance level. Alternatively, in a cooperative incentive structure that emphasizes individual accountability, the group's success depends on the learning of each group member, as demonstrated on a quiz taken without teammate help, were the grade each individual member earns is based on the average score achieved by all members of the heterogeneous team (Slavin, 1992).

Task structure refers to the ways in which the teacher (or students themselves) set up activities designed to result in student learning. Most traditional classrooms use independent task structures, in which students are expected to work by themselves, listen to the teacher, or respond to the teacher. Alternatively in a cooperative task structure students are encouraged to work together to help one another learn (Bossert, 1977).

Despite the many studies conducted to determine the effects of cooperation on performance, these effects are still rather poorly understood. Four reviews completely disagreed on the direction of the effects. D. W. Johnson and R. T. Johnson (1974) summarized the research by stating that cooperation is better than competition or individualization for all but the most concrete, repetitive tasks. In a later meta-analysis, Johnson, Maruyama, Johnson, Nelson, and Skon (1981) suggested that the evidence supporting cooperative incentive 
structures over competitive and individualistic ones in increasing productivity is so strong that further research on this comparison is unnecessary. However, Michaels (1977) reviewed much of the same literature and concluded that competition is usually better than cooperation for most tasks. Slavin (1977) held that over the brief duration of a laboratory study (usually less than two weeks), cooperation is more effective in increasing performance when coordination of efforts is vital to effective functioning, whereas competition is at least as effective as cooperation when coordination of efforts is not so important. Because most tasks of practical importance (including learning) do not require coordination of efforts between two or more individuals, this conclusion was closer to that of Michaels (1977) than to those of Johnson and Johnson (1974) or Johnson, Maruyana, Johnson, Nelson, and Skon (1981). However, Slavin (1977) held that over longer periods, growth of social pressures favoring performance in cooperative groups makes cooperation more effective. A similar conclusion was reached by Miller and Hamblin (1963), who postulated that cooperative reward structures were most effective for interdependent (cooperative) task structures but least effective for independent tasks.

The most obvious effect of a cooperative incentive structure should be to get individuals to help one another. Although it is clear that under certain conditions cooperative incentives lead to increased helping behavior, the degree to which help is valuable for performance depends on the task and outcome measure. Most of the tasks used in the laboratory research on cooperation, competition, 
and individualization on which cooperation produces the highest performance are problem-solving tasks in which the students were able to pool their abilities--a measure of group productivity instead of individual learning (Slavin, 1992).

Learning is a completely different from "group" productivity. Learning is a completely individual outcome that may or may not be improved by cooperation. It may well be that working in a group under certain circumstances does increase the learning of the individuals in that group more than working under other arrangements, but only an individual learning measure that cannot be influenced by group member help can indicate which incentive or task structure is best. In fact, what often happens in cooperative groups that produce a group product is that the most able group members simply do the work or give the answers to their teammates, which may be the most efficient strategy for group productivity but is a poor strategy for individual learning.

When positive effects of cooperative incentive and task structures on performance are found in brief experiments, the task involved have tended to be ones where helping is likely to improve performance and group members can easily monitor and thereby reinforce each others' performance. Where competitive or individualistic incentives have produced greater performance, the task have tended to be ones on which helping is unlikely to make much difference (Slavin, 1992).

From a motivational perspective, cooperative incentive structures create a situation in which the only way group members 
can attain their own personal goals is if the group is successful. Rewarding groups based on group performance creates an interpersonal reward structure in which group members will give or withhold social reinforcers (e.g., praise, encouragement) in response to teammates' task-relative efforts (Slavin, 1990, 1991, 1992). Evidence from practical applications of cooperative learning in elementary and secondary schools supports the motivational position that group rewards are essential to the effectiveness of cooperative learning, with one critical qualification. Use of group goals or group rewards enhances the achievement outcomes of cooperative learning if and only if the group rewards are based on the individual learning of all group members. Most often, this means that team scores are computed based on average scores on quizzes that all teammates take individually, without teammate help. In contrast, if group rewards are given based on a single group product, there is little incentive for group members to explain concepts to one another, and one or two group members do all the work (Slavin, 1992).

In addition to establishing the efficacy of cooperative instruction, researchers must identify factors which influence the effectiveness of learning in small groups. One of these factors is group composition with regard to student ability. Cooperative learning usually involve heterogeneous grouping. That is, groups are formed by combining students of disparate ability, gender, and ethnic background. However, there is considerable disagreement regarding the effects of heterogeneous grouping on performance and attitudes of students representing different abilities. 
Advocates of heterogeneous grouping claim that there might be some important advantages to having students from different abilities work together on cooperative tasks. They argue that while high ability students benefit from providing explanations to partners, low ability students benefit from the increased opportunities for support and encouragement. The results of some experimental studies showed that students of all abilities benefited from participating in a heterogeneous cooperative group compared to students of similar ability who worked alone (Dalton, Hannafin, \& Hooper, 1989; Hooper \& Hannafin, 1988; Johnson, Skon, \& Johnson, 1980). Simsek (1992) attempted to extend these findings by determining whether interactive videodisc instruction can be completed as effectively in a mixed small group as in a uniform ability group. Results of the study showed that heterogeneous ability grouping was not detrimental for achievement, regardless of students' ability levels. There was no significant difference in the performance of high-ability students in either groups; however, homogeneous ability grouping was detrimental for the achievement of low-ability students. One possible explanation for this result would be that homogeneously grouped low ability students may not be capable of supporting each other's learning needs. They may also perceive their partners as not being able to find and explain better solution proposals to the difficulties of the group. Similar results have been reported for computer-based cooperative learning (Dalton, Hannafin, \& Hooper, 1989; Johnson, Skon, \& Johnson, 1980). Moreover, comprehensive research reviews show that the benefits of 
cooperative learning are not limited to achievement effects; there is strong research evidence demonstrating the affective benefits of working in cooperative groups (Johnson \& Johnson, 1989; Slavin, 1991; Webb, 1988).

Critics claim that heterogeneous grouping promotes personal gains at the expense of others. Hill (1982) indicated that the performance of high ability students on complex tasks may be detrimentally affected by medium and low ability students. Beane and Lemke, however, found that high ability students benefited more from heterogeneous grouping (Simsek, 1992). Slavin (1991) suggested that heterogeneous grouping may offer few benefits to low ability students because they are simply given the correct answers and do not learn skills necessary to achieve when working alone. Goldman (1965), on the other hand, reported that students working with partners of higher abilities performed better than those working with partners of similar or lower abilities. Swing and Peterson (1982) found that peer interaction in mixed groups enhanced the achievement of high and low ability learners, but did not have any effect on the performance of medium ability students. Webb (1988) reached a similar conclusion that average students in homogeneous groups showed higher achievement and received more explanations than average students in heterogeneous groups.

In short, the results of cooperative learning studies which examined the effects of ability on student performance and attitudes are still inconclusive, and further research needs to be done to clarify contradictions. 
Individualized Instruction

Educators have systematically attempted new instructional methodologies for implementing new technology in the classroom. Originally much of the efforts resulted in individualized instruction which adjusts the instructional sequence to the cognitive and affective needs of each learner. However, the potential of individualized instruction may be limited by the difficulties associated with identifying individual differences and translating them into instructional prescriptions (Simsek \& Hooper, 1992). The following shortcomings have also been identified with individualized instruction: (a) isolation, causing boredom, frustration, and anxiety, and leading students to think that learning is impersonal; (b) the inability of the methodology to allow students to interact with and learn from each other, thus limiting students to the resources provided by the learning environment; (c) dramatic increase in instructional cost, particularly when a work station is required for each learner utilizing emerging interactive technologies such as computers and videodiscs (Hooper \& Hannafin, 1991; Johnson \& Johnson, 1986).

Recent efforts at providing effective instruction for all learners seem to indicate that cooperative learning has the potential to overcome the limitations of individualized instruction. Carlson and Falk (1989), for example, concluded that cooperative groups can successfully use interactive videodiscs and perform better than those 
working alone. Noell and Camine (1989) indicated that cooperative videodisc learning may be more efficient than individualistic use of this technology. Atkins and Blissett (1989) reported that students in small groups spent much of their time interacting with partners.

\section{Computer-Based Education (CBE)}

Studies investigating the effects of computer-based education on the achievement and attitudes of students have been reviewed since the early 1970's. They can be divided into at least nine categories depending on how the technological medium and instructional technique are designed to interact: (a) computerassisted instruction (CAI), generally referring to drill or practice

tutorials; (b) computer-managed instruction (CMI), generally referring to computer evaluation of student test performance, guiding students to appropriate instructional resources, and record keeping; (c) computer-simulated experimentation (CSE); (d) microcomputer-based laboratories (MBL), referring to an interface between a computer and a data collecting device; and more recently researched areas such as, (e) computer-based interactive videodiscs (CBIV) projects, in which students utilize computers to learn from the visual as well as the data-base capabilities inherent in such a system; (f) hypermedia, which are computer programs which allow for the organizing and designing of computerized lessons from various media sources, such as audiovisual, text and graphic information, videodisc, 
data bases, analysis devices, etc.; ( $\mathrm{g}$ ) telecommunications, which allow learners to collect and analyze data on local phenomena, access experts and data bases, and share their findings with students around the world; (h) microworlds, which are simulations of realworld scientifically relevant problems and phenomena in a school computer laboratory, allowing students to assume the role of novice scientists; and (i) intelligent tutoring systems (ITS) (Berger, Lu, Belzer, \& Voss, 1994).

Studies of computer-assisted instruction (CAI) generally report positive findings with respect to achievement gains and attitudes toward the learning process (Bunderson, Olsen, \& Baillio, 1981; Charp, 1981; Dalton, 1986). These findings also show that this form of instruction typically reduces the amount of time required for learning (Bunderson et al., 1981). In studies comparing different grade levels, middle grade and secondary students appear to benefit more from computer-based education than their younger counterparts (Bangert-Drowns, Kulik \& Kulik, 1985). Handicapped workers and disadvantaged high school students benefit especially from this type of instruction, more so than do those who are academically talented (Malouf, MacArthur, \& Radin, 1986). Such effects are reported across subjects, but mathematics and reading/language arts were the dominant areas of instruction studied.

Some studies from the many diverse forms of CBE can be related directly to computer based interactive videodisc (CBIV) as a associated medium of instruction. This is particularly useful because 
there is a lack of studies using CBIV in certain areas of concern to instructional designers, and existing CBE findings can help define some of the boundaries of design for multimedia programs and should be closely examined (Litchfield, 1993). Thus, in the following section on CBIV, some of the studies mentioned are from issues that CBIV shares with other related forms of CBE.

\section{Computer-Based Interactive Video}

The power of the computer as an instructional tool lies in its ability to manipulate multiple variables and to retrieve easily and quickly stores of data. Combine that with the capability of the new generation of video technology to provide conveniently and inexpensively vast amounts of varied visual and auditory material; the result is a new technological chimera of computer-based interactive video instruction.

These systems permit visual images stored on laser videodiscs or videotape to be incorporated interactively into computer-based instruction. Intelligent video systems convert television from a passive medium into an interactive one and provide the microcomputer with an exciting visual peripheral to complement its other capabilities (Wollman, 1981).

At its simplest, an interactive video system provides computer instruction and output coordinated with some videodisc or videotape output. Using one or more screens, computer and video materials alternately are presented under the control of the student and the 
author. More complex systems permit written material, such as a question, to be overlaid directly on the video display (Daynes, 1982).

There are two closely related video technologies available, the magnetic videotape and the laser videodisc. In a videodisc, each side offers the possibility of storing over 50,000 frames of visual material (pictures, diagrams, graphs, etc.) or up to 30 minutes of video action (at 30 frames/sec). Thirty minutes of audio can also be included on each of two tracks, allowing audio options of stereo sound, or two languages (e.g., Spanish and English), or two intellectual levels (e.g., beginners and advanced scripts) (Bejar, 1992; Branch, Ledford, Roberson \& Roberson, 1987; Bunderson, Balillio, Olsen, 1984). Unlike the linear videotape process, individual frames or segments can be accessed very quickly and in any order. Because of its capability for quickly retrieving visual material, as well as for a number of other features which current videotape technology does not provide, many of the interactive video systems currently under development employ laser disc technology (Daynes, 1982). Unlike videotape, however, videodiscs are quite expensive to produce, and thus not as accessible for teachers to create their own intelligent video systems. Furthermore, once materials have been produced on discs, they may not be revised or edited, as with videotape.

Most industrial videodisc players can not only be controlled with a personal computer, but also with an infrared remote-control device or with a bar-code reader. These devices are made useful by the purposeful organization of most of the visual material within the videodiscs, as well as supplemental directories and lesson plans 
designed to help teachers incorporate videodisc into the classroom without the need of a computer.

The remote control device has several functions that allow the user to quickly access any of the visuals found in the videodisc. The still/step function is for moving forward or backward through the visuals, as with a carousel slide projector, by simply pressing a button. The search function allows random access of whichever frame the user desires by entering the frame number of the visual; a similar procedure is used to search by topics or chapters. The play function is used to play selected movies after their frame numbers have been entered (Ting \& Walker, 1993). This level of usage is categorized as Level 1, and it is not much different than the control available in home video players with remote control (Smith, 1987). It is very fast and convenient if the user follows the organizational sequence selected by the developers of the laserdisc, however it can be quite limiting and cumbersome if the users prefers his/her own sequence of visual events, since it requires that a frame number, which can have up to five digits, be imputed for each visual. Most limiting of all is the fact that, unlike its computer-controlled usage, data about the visuals cannot be accessed as it is being viewed, although it may be obtained from directories and/or lesson plans provided by the developers of the videodiscs.

Another option available to users of industrial videodisc players is the accessing of visuals by means of a barcode reader. This method is facilitated by directories and/or lesson plans containing barcode strips that allow for quick random access of any 
visual the user selects by simply scanning one or a series barcode strip in the desired sequence. Some of the more advanced programs have additional capabilities which allow for user generation of customized barcode printouts. The barcode reader method overcomes the limitations to random access posed by remote control method, but not the data access limitations. This level of usage can also be categorized as Level 1 since it is simply an extension of the remote control method, with some having the additional capability to use computer software in order to generate customized barcode printouts.

Level 2 has all of the capabilities of the Level 1 system in addition to a microprocessor and limited memory in the videodisc player. The videodisc contains a computer program that is loaded into the memory, and the interaction is controlled by the program. This level is not very popular because it requires specific hardware and does not allow upgrading for improved performance without remastering the video source (Smith, 1987).

The highest level of usage is categorized as Level 3, which consists of a player interfaced with an external computer (Smith, 1987). At this level interactive video can combine the advantages of traditional computer-assisted instruction and video instruction. Realistic video instruction as well as data banks of related information can be accessed quickly. This merging of two related technologies can empower students to control their learning by enabling them to select their sequence of learning or even design their own lessons (Ting \& Walker, 1993). 
Computer programs which allow for user management at Level 3 are known as authoring programs. Some of these programs only allow for authoring multimedia presentations. The more sophisticated programs are hypermedia-based, allowing the user to combine multimedia presentations with text and graphic capabilities, as well as data collection and analysis devices (Berger, et al., 1994).

One of the most flexible videodiscs authoring programs available to educators is VideoCards ${ }^{\mathrm{TM}}$ v.3.0, from Optical Data Corporation. It is a flexible and easy-to-use tool designed to help teachers and students make the most of the thousands of visuals and abundant data available in the videodiscs of The Living Textbook ${ }^{\circledR}$ Multimedia Libraries $^{\mathrm{TM}}$. This authoring program allows you to retrieve from a large collection of visuals (still images or movies) provided in the videodiscs, and in a matter of seconds display them in a TV monitor and simultaneously obtain information about each of those visuals in the computer screen. It also allows you to assemble a list of visuals and instruct the computer to display them automatically in a selected order and pace; you can even alter the presentation by displaying selected textual information over any of the visuals. Students can work independently, in cooperative groups, or as a whole-class and explore various topics in-depth and prepare multimedia presentations that can be shared with their own classmates and saved for future classes (Ting \& Walker, 1993).

In the early 1980's, videodisc instruction was used primarily by some governmental agencies and Fortune 500 corporations in various training and education programs. In 1984, the development 
and implementation of an intelligent videodisc in biology by Bunderson, et. al. of WICAT Systems, Inc., represents one of the first applications of this technology as an instructional aid for college science learning. In their pioneering studies student learning with videodisc instruction was compared to traditional lecture learning in introductory biology courses at three different colleges; videodisc students consistently displayed greater learning and retention gains, reduced study times, and higher productivity ratios. The subjects in this study generally liked the individual pace and the illustrations provided by the videodisc; they wanted more motion sequences and practice opportunities, and disliked technical problems and constraints.

The results from studies of computer-based education should not all be generalized to computer-based interactive video; as a related but different medium of instruction, it presents its own agenda of research issues (Bangert-Drowns et al., 1985; Clark, 1983). In a review reported by James Bosco in 1986, at the end of the first decade (1975-1985) of research on interactive video, the general conclusion was that interactive video was effective, and that benefits were most prevalent on user attitudes and training time variables and less prevalent on the achievement variable. These studies, however, were of limited utility in the formative aspects of their evaluation, primarily because in many cases it was the first, or one of the first projects of this type ever attempted (Slee, 1989).

A follow-up review performed to cover the period from 1985 to 1989 by Elisa Slee (1989) concludes that much of the research is 
misoriented, that its main purpose should be to improve rather than prove media; that the focus on the evaluation of interactive video and their uses should enable us to optimize the medium for particular situations, types of content, and types of learners.

In another review of the literature on media, Clark and Sugrue (1988) analyzed trends and identified areas for future research. They claimed that in many of the studies reporting the superiority of interactive video over some other instructional medium, that the active ingredient was usually some uncontrolled aspect of the instructional medium; they suggested that when examining the effects of different media, everything except the media compared must be the same, including instructional methods employed and content. Reeves (1992) agrees and also claims a novelty effect for the instructional technology.

In the educational arena interactive video is a relatively new instructional system that holds great promise for improved instruction. Teachers are enthusiastic about its potentials and have found it easy to use; it has also been well received by students because it allows them to work at their own pace and they find it more stimulating and motivating than traditional instruction (Evans, 1986). Research has shown that students studying by interactive video reported significantly less study time with equal or better learning gains than students who heard classroom lectures (Bunderson, et. al., 1984). However, Schaffer and Hannafin (1986) found that, while interactive video instruction produced greater 
learning than two alternative video instructional treatments, it also took more instructional time.

In a study comparing student reactions to biology instruction by interactive videodisc or conventional laboratory, Leonard (1989, 1992) found that students in a university introductory biology class who performed two laboratory simulations using interactive videodisc gave significantly more positive responses to post-lab questionnaire items on time efficiency, level of attention, understanding of experimental results, confidence in following instruction, and general satisfaction with what was learned than students who performed the actual laboratory investigation.

Strauss and Kinzie (1994) examined the effectiveness of the Interactive Frog Dissection, an interactive videodisc-based simulation of frog dissection as an alternative to actual laboratory frog dissection. Emphasis was placed on identification of organs within the frog and with dissection procedures. No significant difference in achievement or attitudes was shown on immediate posttest scores, however, there was significant interaction between treatment and time: those who used the simulation became less positive over time about the value of animal dissection, while those who dissected a frog became more positive.

Perhaps the most visible and variable features in multimedia programs are branching structures. Movement through a program is referred to as navigation; it is accomplished by interface designs using a series of choices appearing in the form of menu selections, icons, buttons, or screen hot spots. The degree of navigational choice 
is set by designers and incorporated as varying amounts of program and/or learner control. In multimedia programs, learner control is the amount of latitude a learner has over direction and depth of investigation. This degree of control can be preset by the program to afford the learner limited or total control. Hannafin and Colamaio (1987) investigated the comparative effects of linear control, learner control, and designer control in a set of materials assigned to teach basic principles of cardiopulmonary resuscitation (CPR). The linear control was a traditional linear video presentation; the other two treatments were interactive video under the control of the designer or the student. In the instructor control treatment, all branching to video segments was predetermined by the designer and was done in response to student answer. In contrast, the learner control treatment allowed the student to determine all choices at the same points that the designers had made their decisions in the alternate treatment. Both the learner and designer control groups performed better than the linear control group. No significant differences were found between the two interactive video treatments, however. The study also found that factual, procedural, and problem-solving questions embedded in the three sets of treatments had a significant effect on learning factual and problem-solving material.

While some learner control can be motivating to students, too much can be confusing; apparently the learner is not always the best judge of the instruction needed for effective learning (Litchfield, 1993). Low ability students are especially confused with high levels of learner control. Kinzie (1989) suggests three reasons for 
inconsistent benefits from learner control: a behaviorist rather than cognitive orientation, individual student differences, and discomfort and inexperience in exercising option control.

Based on a review of the literature pertaining to learner control in multimedia programs from 1989 to 1992, Litchfield (1993) offers the following suggestions for instructional designers: (a) programs using adaptive advisement have been shown to be effective and should be included in CBI and multimedia programs; (b) informing students of options based on performance can increase achievement and motivation; (c) because learners differ in their approaches to information retrieval, several search options should be included in programs; this will account for various learning styles and prior knowledge.

The instructional strategy of a program should be determined by the intended learning outcome, whether it is increasing students' knowledge, comprehension, application, problem solving, critical thinking, or decision making skills. In a study that compared the effects of two different interactive video instructional strategies and a conventional linear videotape unit on ninth graders' learning of economic principles, Dalton and Hannafin (1987) reported mixed results. On a recall subtest there were no significant differences among the three treatments. On an application subtest, however, students who received the context strategy, an interactive video unit that used application examples rather than mere factual information, did significantly better than students in the other two groups. 
Hazan (1994) developed a CBIV to reinforce learning of the biological concept of protein synthesis using the laserdiscs produced Optical Data Corp. entitled "The Living Textbook: Life Science", and found positive attitudes and multiple choice scores on achievement test, but not as well on essay questions. The researcher also found that students who took more time with the program achieved higher posttest scores.

Interactivity of computer-based systems often refers to the capabilities of hardware and software systems rather than the behavior of the learner; the term interactive does not clearly imply the nature of the instructional contingencies and the student behavior required. In a research study, Kritch, Bostrow \& Dedrick (1995) examined the level of interactivity of videodisc instruction on student recall of information presented by three different experimental versions: (a) constructed response, (b) click-tocontinue, and (c) the passive-observation condition. The study confirmed the significantly greater effectiveness of constructedresponse format that required the construction of missing key words, with the consequence of having to repeat if incorrect. Supplying missing words in frames required students to read more slowly, carefully, and to reread frames. The researchers claim that this confirms that active construction promotes recall and that evidence indicates that programmed instruction is appropriate for all student ability levels.

The computer-based interactive project ScienceVision developed at Florida State University used an inquiry-based strategy 
which enabled students to participate in the investigation, experimentation, and resolution of scientific problems. This instructional strategy tends to produce positive results for students using multimedia programs--especially when the students work cooperatively (Dawson, G., 1991; Tobin \& Dawson, 1992). According to Litchfield (1993), the amount of interactivity determines the degree of participation of in the program, so there should be data creation or manipulation, variable determination, investigation, action, or inquiry made, in order for the use of CBIV as the platform to be justified as being interactive.

The literature on CBIV is vast and conclusions are generally positive, though based on inconsistent and contradictory findings (Litchfield, 1993). In a meta-analysis (63 studies) of a 10 year review of achievement effects McNeil \& Nelson (1991), found that CBIV as instructional method can be effective, specially when students are arranged in cooperative groups and when guided and structured rather than being entirely under the control of the learner. Another meta-analysis (24 studies) of CBIV instruction by Fletcher (1990) applied in defense training, industry settings, and higher education found that it improved achievement for knowledge and performance outcomes.

\section{Hypermedia}

Hypermedia can be described as a computer-based environment for thinking and communication. It consists of 
audiovisual, as well as text and graphic capabilities and access to videodisc, data collection, and analysis devices (Berger, et. al., 1994). HyperCard ${ }^{\mathrm{TM}}$ is an implementation of hypermedia produced by Apple ${ }^{\circledR}$ Computer, Inc. and native to the Macintosh ${ }^{\mathrm{TM}}$ computer operating system; many other programs with similar capabilities have also been produced for both Apple and the $\mathrm{DOS}^{\mathrm{TM}}-\mathrm{W}$ indows ${ }^{\mathrm{TM}}$ operating systems; they include Linkway ${ }^{\mathrm{TM}}$, SuperCard ${ }^{\mathrm{TM}}$ and Hypermedia" ${ }^{\mathrm{TM}}$. "HyperCard is a piece of (computer) software that provides the user with access to decks of cards (representing screens) containing text and graphic elements which can be easily rearranged into a variety of combinations producing exciting new programs" (Gray, 1989). It allows the user to work at different levels of complexity from a read-only level to an authoring level at which the user can create, modify, or invent new applications from existing stacks. HyperCard uses a stack of cards metaphor in which information is stored on several related cards can be grouped into stacks. Programmable buttons can be used to link cards to one another or to access visuals and auditory overlays, still images, or animations. A point-click-zoom interface allows the user to make selections of content to cover, applications to use, and paths to explore through the stacks during instruction. The system keeps track of the user's path, allowing easy return from exploratory side paths. By giving students a tool that allows them immediately to gratify their intellectual curiosity through exploration, hypermedia turns students into active learners rather than passive receivers of knowledge. Students must take the initiative in selecting the paths 
they will explore and in clicking into the stacks--the software demands that the student make choices--"or everything just stops" (McCarthy, 1989). Icons representing intuitive functions can be used to guide navigation-when students click on a movie camera, animations begin; when they click on a forward arrow they move to the next stack; when they click on a help icon they may see a map overlay showing them where they have been and in what direction they are headed or providing more explicit instructions to address a problem related to the part of the hyperdocument in which they are engaged.

Although extensive research on hypermedia is not yet available, the utility of this medium for teaching science is undeniable--the combination of flexibility and a sizable storage capacity allows users to access and organize information in entirely new ways. The integration of HyperCard capabilities with graphics, videodisc, real-time data collection devices, and data base resources makes the program a useful educational tool. Special attributes of the program can address the need to teach science students to construct their own flexible knowledge base, to analyze continuous changes in scientific theory, and to evaluate evidence with a skeptical intelligence. Fostering flexibility in the acquisition and structuring of knowledge is a desirable way to educate people capable of looking beyond the existing paradigms to new and yet undiscovered ideas (Berger, et. al., 1994).

Hypermedia requires students to organize and relate ideas to one another and to what they already know. When students are 
required to make their own connections among information in the stacks, they are participating in the construction of meaning and building their own knowledge base. The flexibility and openendedness of hypermedia is noteworthy--the connections between pieces of information are dynamic and can be modified. Uninhibited exploration should enhance flexible thought, as well as originality; especially when students can so easily follow alternative paths and consider other possible explanations, combinations of ideas, or even new paradigms. Hypermedia environments present texts and other applications nonlinearly, requiring users to decide what information to read and in what order to read it. "Appropriate" path choice can enhance flexible and original thought, leading students to structure the information differently and even make unusual connections (Bowers and Tsai, 1990).

Little research has investigated what strategies students adopt in navigating through the informational network, what factors influence choices of the sequence of their instruction, and what impact the choice of paths through the network has on student learning. Charney (1989) has proposed that presenting hypertext information in a poor order can impair student learning. Most of the navigational issues discussed on the previous section on CBIV, equally apply to hypermedia.

Problems have been reported indicating limits to the utility of hypermedia. "The temptation is to make the system so free and interactive that users have complete control at every moment. Users can often feel bewildered and overwhelmed by choices and 
uncertainty" (Friedlander, 1989). "What you don't want is just a lot of random learning about a given subject. You want a presentation that has some built in direction; something that leads the students from one important piece of information to another" (McCarthy, 1989). Because of the complexity and variability of the medium, students may have a tendency to lose their sense of direction and can experience a cognitive burden when information is too abundant and many decisions must be made. Disorientation and cognitive overload-may reduce student learning, limiting the utility of hypermedia. When students become overwhelmed in a hypermedia environment, they fail to benefit from the flexible features of the system that can allow them to make unusual connections. To alleviate the problem. Concept maps can be accessed intermittently to give the learner a sense of direction during instruction (Marchionini, 1989; Berger, et. al., 1994).

The application of hypermedia is widespread. It is being used to teach everything from literature to foreign languages. It is also being used to teach science, particularly at the college level. For example, Dersheimer and Rasmussen (1990) have designed a SuperCard program (similar to HyperCard) called 'Seeing Through Chemistry'. This program uses several different media to reinforce the same concepts and principles so that students begin to integrate concepts into a robust conceptual framework that represents more than a collection of fragmented ideas. The program operates at several levels asking them inquiry-focused questions at three progressive levels of guidance: (a) inquiry-directed instruction 
permits students to jump interactively back and forth between their written explanation for a question and the stacks, without intervention; (b) assisted inquiry instruction (with hints) suggests areas in the stacks that will provide essential information; (c) guided instruction more directly guiding the student through the sequence of stacks.

Cordts, Beloin, and Gibson developed a HyperCard-based program entitled 'A Tutorial in Recombinant DNA Technology'. It has noteworthy animation and still image features for use in studentdirected learning. Navigational concerns are addressed through features like an easily accessible help section, a navigational map, and index features, all these features aiding the students in moving about the hyperdocument (Berger, et. al., 1994).

Hallada (1990), developed a 'ChemTutor' exam question and answer data base for introductory chemistry college students. The HyperCard program allows students to focus on areas in which they are having difficulty. Multiple-choice problems are randomly generated for students. When the student selects an answer, the program indicates whether or not the answer was correct. Wrong answers represent common misunderstandings and mistakes make by students; thus, further explanation is given when the answer is incorrect. In addition, Hallada has developed a system for keeping records on each student, including information on academic and class standing, the amount of time each student spends using the problemsolving program, which answers they choose, and how many times they choose to enter a problem domain. 
It is clear from the research in hyper systems that the majority of students need guidance to benefit from these learning experiences. As students become more sophisticated and competent in their use of hyper systems, problems with navigation, cognitive overload, and frustration will decrease. Patterns of links and methods of information access will be established parts of students' educational repertoire. Until this time, teachers, researchers and designers of multimedia programs are faced with many challenges.

\section{Learning and its Assessment}

Human learning evolved by using the full range of the senses with their associated brain power. Yet classrooms have become barren, left-brain deserts, filled with words and symbols that are divorced from the images and events they represent. Students seem to crave and respond strongly to visual images, and the videodisc seems to balance the skewed verbal diet of academia with a rich supply of visual images.

Human emotions seem to play an important role in what we pay attention to and what we remember. The social milieu is another factor that affects emotional response, and we seem to pay more attention to an event if those around us view it as important, and our perceptions of what others expect strongly influences our behavior. The videodisc may appeal to and stimulate a wider range of emotions than traditional classroom presentations for at least four 
reasons: (a) it is novelty; (b) its perceived importance as an instructional medium; (c) the power of the visual imagery, especially of events that are normally not visible (e.g., microscopy) or that are inaccessible (e.g., mating rituals); and (d) the rich interplay of styles of presentation (Bunderson, et al., 1984).

Because of the relative ease with which the videodisc can provide visual presentations, it offers several potential advantages over lecture teaching. The videodisc provides more and richer illustrations of new concepts, and more visual interpretations of the words, phrases, and examples used to develop the new concept. Multiple forms of representation of a new concept may help students to develop richer conceptual networks and avoid misunderstandings and misconceptions. A judicious combination in videodisc instruction may able to trigger a grater range of preexisting concept networks in students' minds than could a presentation limited to spoken and written words and simple diagrams (Bunderson, et al., 1984).

Current understanding of how human memory functions explains that we do not record and recall experiences as if our minds were tape recorders. Rather, we encode some features of an experience and combine them with some notions about how the world works in general and how that aspect of the world works in particular. This means that when students engage in different activities during learning, they build up quite different repertoires of understanding corresponding to their experiences. Thus, good videodisc instruction should produce learning that is qualitatively different from that of good classroom instruction because of its 
inherently different patterns of student activities (Bunderson, et al., 1984).

Too often "knowledge" of a subject is demonstrated by pure verbal learning, verbal responses to test questions and problems (the lexical loop). It is recognized that words are essential to help us organize materials, gain mental access to our memories, and make associations across time and space. Test results suggest that the visual imagery and the rich set of concrete and abstract examples provided by the videodisc enhance both the learning of terminology and promote the development of a relatively rich semantic network (Bunderson, et al., 1984). However, in order to perform at higher cognitive levels, students must not only master the relationships between words and concepts, but also make connections with actual, multidimensional, real-word situations. With the interactive videodisc, test of knowledge can involve observing, manipulating, referring to, and discriminating among features of images and events.

Learning styles are the various methods individuals have for perceiving and processing information while reacting to their environment. Very little research has been done on interactions between learning styles and instructional design or presentation. Research specifically addressing multimedia programs and learning styles is almost nonexistent (Litchfield, 1993).

In an investigation conducted using interactive video (Hannafin \& Colamaio, 1987), practice was found to be important for the learning of declarative knowledge and problem solving skills, but of 
little effect for procedural knowledge. A later study conducted by Hannafin, Phillips, and Tripp (1986) investigated the effects of practice and processing time on learning; practice resulted in favorable results only for factual knowledge where test scores more than doubled the scores for non-practiced items ( $90 \%$ correct to $44 \%$ ). However, test items at the application level were unaffected by practice. Results from this same study conducted by Hannafin, et al., suggests that the availability of orienting activity effects both the type and amount of learning. Students given an orienting activity performed best under reduced time while students who were not provided with orienting activities performed best with extended time. There were interactions between orienting activities and processing time, suggesting that neither element alone affects learning. This is an example of a study that uses interactive video as a research tool. One can imagine a similar study conducted without an interactive videodisc and replications of these results could be generalized to a variety of learning situations. An interactive videodisc study by Carlson (1991) found that the way individuals perceive and process information (learning styles) was affected by how the program was designed; thus indicating that matching learning style with the design of instruction was important for both achievement and positive attitudes.

The paucity of studies in this area indicates that much work is needed before we can know which design factors incorporating learning styles aspects increase achievement, attitudes, and motivation in multimedia programs. Designers should include a 
variety of methods in programs to account for different learning styles. Perhaps alternate pathways through a lesson could be selected depending on learner preference. This would allow students who may get confused by excessive branching to travel a more predetermined path thus decreasing frustration. Material could be presented in text, visuals, and sound to accommodate students with differing modalities. Visuals on screen could be accompanied by text in a manual. Audio could paraphrase or read text verbatim. Students could choose one or all of these features depending upon how they learn best. Knowledge of learning styles can afford designers with a wide range of instructional approaches that can increase students' achievement and motivation (Litchfield, 1993). 


\section{CHAPTER III}

Method

In conducting this research study, the following subjects, instruments, materials, experimental design and procedures were utilized in collecting data.

\section{Subjects}

The 64 subjects needed for this study were selected from the total population of 68 students enrolled in the 1995 summer school biology program at South Miami Senior High School (SMSH). The four students not selected were placed in an alternate individualized laboratory program in which they received instruction on the same unit as those selected for the research study. Subjects selected were primarily 9 th and 10th grade students attending summer school classes for either one of the following reasons: (a) failed to achieve a passing grade in biology class during the regular school year (due to either lack of motivation, excessive absences, insufficient background and/or language skills, etc.) and were re-taking a regular-level biology course, or (b) wanted to advance in their academic program by taking an honors-level biology class during summer school in order to enroll in higher level courses during the regular school year. Stratified random sampling procedures from the two different class levels (regular and honors) were followed in order to assure 
heterogeneity in the two experimental groups. Furthermore, randomized seating arrangements were executed in both experimental groups, and stratified placement from the two levels of biology classes into each cooperative group in order to also assure heterogeneity at the cooperative group level (two students from each class level into each cooperative group).

South Miami Senior High School is a multicultural middle-class public school in suburban Miami, a large city in Dade County, Florida. SMSH's student ethnic composition is $77.5 \%$ Hispanic (primarily Cuban-American and Nicaraguan, but also from a variety of Latin American backgrounds), $11.8 \%$ Afro-American, 9.7\% Caucasian, and 1.0\% Asian. Most students speak a language other than English at home. It is comprised of ninth trough twelfth grades and the great majority of its students $(94.5 \%)$ are drawn from a geographical region bordering the school; the rest are selected from throughout the county for participation in a Magnet School Program in the Media Arts including Commercial Art, Computer Graphics, Television, and Photography (Dade County School Board, 1994).

Socioeconomically, the population has historically been lowermiddle class, and is affected by the necessity of households to help new immigrant family members. The percent of parents at each educational level is distributed between $23 \%$ having elementary educations, 36\% having high school educations, and $40 \%$ having college educations or advanced degrees. Many parents cited the inability to pay for an education in their homelands as the reason that their formal education ceased. The stability of households is 
quite high: 69\% live with two parents (step-parents are not differentiated from natural parents), $25 \%$ live with one parent, $4 \%$ live with another relative, and $1 \%$ live in some other arrangement. The occupations of the parents reflect only a slight change from the last ten year study. Of the fathers, $25 \%(22 \%)$ are skilled workers, $20 \%(26 \%)$ are professionals, and $17 \%$ (N/A) work in service occupations. Of the mothers, 29\% (N/A) are homemakers, $14 \%(17 \%)$ are professionals, and 13\% (N/A) are service workers (Dade County School Board, 1994).

The seniors of South Miami Senior reflect the stability of the community by spending their entire high school years at the school. Forty-five percent have been here 4 years and forty-five percent have been here 3 years. Some students enter form a 6-8 middle school and some from a 6-9 middle school. Apparently there is an even age-grade distribution of students within the school, although nearly $20 \%$ of the senior class were nineteen-years-old by graduation. This reflects the immigrant nature of the community. Many students lose a year in the transition to a new country because they do not have access to previous school records. The failure rate also has increased over the past ten years. The attendance rate shows a decrease over the last three years. The 1988-89 attendance rate was $92.1 \%$ contrasted with a 90.3 rate in 1990-91. A new policy has been instituted to increased attendance (Dade County School Board, 1994).

Standardized test scores have declined over the past 10 years as have the scores of most of Dade County and Florida. One possible 
cause is the influx of foreign-born students. On the average, South Miami students score in the top $30 \%$ of the students in Dade County. The school emphasizes academic competition. State subject area tests and minimal competency tests, national examinations (such as CEEB, Advanced Placement examinations), and college entrance examinations (such as the ACT and SAT) gauge students' performance in addition to teacher evaluation of student progress. Furthermore, scholarships and awards garnered in talent and academic competitions are additional gauges of student performance. To further aid college-bound students, South Miami has become an ACT test center. Compulsory education is mandated to age sixteen. The largest rate of withdrawal (37\%) occurs in grade ten. However the withdrawal rate reaches a low of $12 \%$ in grade twelve. It should be noted that withdrawal rate is not synonymous with dropout rate. The largest percentage of withdrawals is for school transfer and is followed closely by the 'other' category (Dade County School Board, 1994).

\section{Instruments}

This study measured the subjects' achievement in a unit of biology lasting 15 hours of instruction (over three weeks during a regular school year). Because most of the published achievement tests in biology are comprehensive and cover a years' worth of instruction, they were not useful for the purpose of this research study. This necessitated that a researcher-designed achievement 
test be created for the unit of biology covered during this research study.

For instructional purposes four achievement quizzes (20 items each) and the 80-item researcher-designed comprehensive achievement test were administered from the biology unit on Animal Diversity. The items in the four quizzes were different from those in the comprehensive achievement test, and only the scores obtained in the achievement test were utilized for measuring achievement in the research study. The four quizzes were made up of only multiple choice items selected from several established test sources, and they were utilized for two main purposes: (a) to compare to and thus determine the concurrent validity of the researcher-designed comprehensive achievement test during a pilot study, and (b) to be used as an instructional motivating tool administered between instructional intervals of approximately two to four hours. The quiz items were selected to match 80 objectives written for the unit, and obtained from three sources: the test bank published by the author of the textbook used for the course, HBJ Biology (Harcourt Brace Jovanovich, 1992), the test bank for a reference textbook utilized in developing the unit (Campbell, 1993), and the biology item test bank developed by Dade County Public Schools (1989).

To establish the content validity of the researcher-designed comprehensive achievement test, three multiple choice test items were written to measure each one of the 80 objectives for the unit on Animal Diversity (for a total of 240 items), each at a different cognitive level--knowledge, comprehension, and application. To 
establish their reliability the items were field tested throughout the school year (September to June) of 1995 on an A.P. Biology class which was taught the same biology unit by means of CBIV traditional whole-class instruction. Based on the point biserial and discrimination index (r) ratings obtained from this field test, one test item was selected for each objective for the final test version; objectives for which all the items received low reliability ratings had the items rewritten and reevaluated in subsequent field tests until at least one item per objective was selected which achieved a point biserial value of at least +.500 and a discrimination index (r) of at least .600 . The result of this process was an 80 item multiple choice comprehensive achievement test, with items at three different cognitive levels, and comprising the 80 objectives intended by the researcher. In order to verify its content (face) validity, the final version of this test was sent to Assessment Department in Dade County Schools' Office of Educational Accountability where it was reviewed by experts in the fields of testing and biological sciences (Dawson, C. L., personal communications, 1995).

To determine the concurrent validity of the 80 researcherdesigned test items, at the end of a pilot study the test items were administered simultaneously with the 80 quiz items obtained from several established test sources. Student scores obtained in the test and quiz were compared and a concurrent correlation coefficient of +.89 was calculated from this comparison, indicating an acceptable level of relationship between the instruments. The test measured achievement in a particular unit of biology, so construct validity was 
not considered since no inferences about hypothetical construct were intended. Predictive validity was not considered either because it was not the intent of this research to predict future achievement in biological knowledge.

To establish the internal consistency of the achievement test, a rationale equivalence reliability procedure was followed that estimated the internal consistency by determining how all items on a test relate to all other items and to the total test; this calculation was performed by a computerized testing program LXR•TEST Version 4.1.9 which utilizes Cronbach's alpha formula (Bredehoft, J., Dewart, S., and Tindall, R., 1991). A Cronback's alpha reliability value of .97 was obtained for the researcher-designed achievement test, a value considered acceptable for any test (Gay, L. R.,1996).

At the end of the pilot study all subjects were also be given the Attitude Toward Science in School Assessment (ATSSA), an instrument developed by Germann (1988) as a measure of a single dimension of general attitudes toward science, specifically, how students feel toward science as a subject in school (see Appendix D.01). A modified version of this instrument was administered during both the pilot study and the research study in which the statement 'using computer-based laserdiscs' or 'by means of computer-based laserdiscs' were inserted into each item in order to measure the strength of the individual's attitudes toward science laserdisc instruction (see Appendix D.01).

The ATSSA is composed of 14 items in which responses are designed to measure the strength of the individual's attitudes by 
means of a Likert scale format. After development, this instrument was field tested on four studies having a total of 698 subjects. In the four studies, Cronbach's alpha estimates of reliability were all greater than 95. All 14 items loaded on only one factor with consistent factor loadings in all four studies. Percent of variation accounted for by this factor was $64.9,69.8,67.4$, and 59.2. Discrimination was demonstrated by item-total correlations, ranging between .61 and .89. The mean item-total correlations for the three field testing situations and this study were $.77, .81, .79$, and .73 , respectively (Germann, 1988).

The modified version of the attitudes inventory was created as an attempt to develop an instrument that measures attitudes toward science laser disc instruction more specifically. Since the modified version had not been previously validated, this was done during the pilot study when the subjects' scores obtained in the two attitudes inventories were compared and a concurrent correlation coefficient of +.98 was calculated from this comparison, demonstrating the validity of the modified version as compared to the established instrument. Thus, based on these results, only the more specific laserdisc-modified version was utilized for measuring the subjects attitudes at the conclusion of the research study.

\section{Description of Materials and Equipment}

The experiment was conducted in a computer multimedia laboratory whose use was modified depending on whether it was 
being used for cooperative or traditional whole-class instruction. For cooperative instruction the laboratory was supplied with eight Apple ${ }^{\circledR}$ Macintosh $^{\mathrm{TM}}$ LC 575 computers with 4 MB RAM, each connected to a Pioneer ${ }^{\circledR}$ LD-V2200 videodisc player, a 13" color TV monitor, and with a set of four videodiscs entitled "The Living Textbook $^{\mathrm{TM}}$ : Life Science" by Optical Data Corporation. For traditional whole-class instruction two 32" color TV monitors were utilized, one to show the video from the laserdisc player, the other TV used to display the computer screen for the whole class to observe how the authoring program is utilized to access visuals and their descriptive textual data; this computer to TV connection was done from a Power Macintosh $6100 \mathrm{AV}$ by means of a Focus Enhancements ${ }^{\circledR}$ external video converter.

The hardware described above was used interactively at what is known as Level 3: a HyperCard ${ }^{\mathrm{TM}}$ researcher-designed lesson (stack) dealing with the taxonomic relationships (anatomical, embryological, behavioral, and evolutionary) involved in classifying the diversity of animal life, linked to a videodisc authoring program (VideoCards ${ }^{\mathrm{TM}}$ v.3.0) in order to operate the videodisc player in a sequence specified by a biology unit on Animal Diversity. The authoring program VideoCards v.3.0 is a HyperCard-based program, but requires no more than familiarity with basic Macintosh procedures to produce sophisticated presentations.

The computers in the multimedia laboratory were all equipped with Apple At Ease ${ }^{\mathrm{TM}}$ v.2.0, a security program which allows the subjects access only to the applications and documents selected by 
the researcher. They were all set up so that only one button appears on the first screen that comes up after the computer is started, giving the subjects access only to 'The Five Kingdoms' stack. Selecting ('clicking' with the mouse) this button opens-up this introductory HyperCard stack which starts with a screen that illustrates the classification of life on earth based on the five-kingdom system (see Appendix C.01). Selecting the area for any one of the five kingdoms activates the sound of a voice which pronounces the name of each one of the kingdoms and allow access to the first introductory card for that particular kingdom. For the purpose of this study only the kingdom Animalia was linked to subsequent cards (screens) in order to discourage distractions from the intended unit on Animal Diversity. The sequence of cards in this stack are intended as an audio-visual tutorial of the embryological basis for classifying the diversity of animal life, one of the most difficult phylogenetic concepts for students to understand; it was reinforced each day the subjects entered the program since this introductory stack is the only way to enter the second part of the program, the 'Animal Kingdom' stack, on which the subjects spent most of their time learning about Animal Diversity.

The 'Animal Kingdom' stack can only be accessed from the 'Five Kingdom' stack by selecting ('clicking') a phylum from the last instructional card in the stack. This automatically links the user to a VideoCards authoring program stack entitled either 'Animal Kingdom Presentation' (Appendix C.02) or 'Animal Kingdom Cooperative Group' (Appendix C.03) depending on whether the user is the teacher 
in the traditional whole-class (presentation) group or a subject in one of the cooperative groups. These stacks differed for the two groups since the groups had different tasks to perform while utilizing these particular stacks.

Both the 'Animal Kingdom Presentation' stack and the 'Animal Kingdom Cooperative Group' stack are HyperCard-based stacks created from within the VideoCards authoring program. Every card in these two stacks is composed of a Console Workspace which contains not only Notes and Data Windows with textual information about the phyla and the visuals in the laserdisc, but also a Video Control Panel consisting of 14 buttons which manipulate the laserdisc and a column of 4 to 8 buttons used to manipulate Notes and Data Windows textual input functions as well as AV (audio-visual) Eventlinks (Appendix A.02). During this research study users of the stacks only needed to use the Mode button in order to insert AV Eventlinks identification numbers, the Adjust Windows button in order to enlarge the Notes Window, and the Next Note and Previous Note buttons in order to navigate between cards within the stack. Instruction on how to navigate and perform the necessary computer functions were taught in a brief tutorial session the day prior to the beginning of the 15 hours of instruction for the research study.

These two Animal Kingdom stacks were composed of cards containing descriptive information (characteristics) about each particular phylum in the lower Notes Window of each card, which can easily be enlarged by dragging an icon (see VideoCards Tutorial, Appendix A.02). The Notes Window in each of these cards is of the 
scroll type and can contain up to 30,000 characters (approximately 30 pages of double spaced text).

The characteristics of the phyla found on the Notes Window of these cards was the same information as that given to the subjects in the handout entitled 'Animal Kingdom Taxonomic Guide' (Appendix B.02). Following in the same Notes Window is a section titled 'AV Events' which contains a listing of all the visuals preselected by the researcher to be used for this biology unit, organized by taxonomic group and containing both the visual Eventlink number (frame address on the laserdisc) as well as the descriptive data for that visual. The descriptive information about the visuals found in this 'AV Events' portion was obtained from VideoCards' embedded data files, and it was identical to the information given to subjects in the 'Field Biologist Handbook' (Appendix B.05). This information was preselected by the researcher and placed on the Notes Window below the taxonomic information for the phylum, so that time consuming visual event selection and data retrieval did not have to be performed by the user.

The 'Animal Kingdom Presentation' stack and the 'Animal Kingdom Cooperative Group' stack are the same in every respect just described on previous paragraphs. They were however different in that the presentation stack has visual Eventlink numbers added at appropriate locations within the taxonomic descriptions for each particular phylum (see Appendix C.02). All the user (teacher) needed to do was select ('click') the Eventlink number as the taxonomic text is read or paraphrased, and the computer 
automatically searches and displays that particular visual on the TV for the whole class to view. The cooperative group stack lacks these Eventlink numbers embedded within the taxonomic text because it was one of the cooperative groups' task to preview, select, and insert the video Eventlinks in the appropriate location within the descriptive text for each of the eleven phyla that are part of this unit, so that each group could create their own presentational stack (Appendix C.03). To be able to preview the visuals, the subjects had to browse through the 'AV Events' portion of the Notes Window, 'clicking' Eventlink numbers, selecting and noting their most appropriate location within the taxonomic text of their handout 'Animal Kingdom Taxonomic Guide'. At the conclusion of the groups' selections and notations of visuals, subjects in the cooperative groups transferred Eventlink numbers to the appropriate part of the taxonomic text within the program (on Notes Window) for group presentational purposes. The ultimate aim of this process was for the subjects to produce a presentational stack similar to that produced by the researcher for use by the traditional whole-class instructional group.

\section{Design of the Study}

The design utilized to measure the subjects achievement and attitudes was a two-group posttest-only control group design (see Figure 1); this design was chosen because random assignment of the groups was possible, and because the administration of pretests was 
not advisable due to its potential interaction with the results of the posttest (a source of external invalidity). This combination of random assignment and control group design eliminated most of the sources of invalidity (internal and external). However, it did not control for the potential threat to internal validity caused by mortality, which did not prove to be a problem since all the subjects remained until the conclusion of the study.

\begin{tabular}{|c|c|c|c|c|}
\hline Group & Assignment & $\underline{\mathrm{n}}$ & Treatment & Posttest \\
\hline 1 & $\begin{array}{l}\text { Random, from two } \\
\text { preassigned } \\
\text { classes }\end{array}$ & 32 & $\begin{array}{l}\text { Cooperative Group } \\
\text { CBIV Instruction }\end{array}$ & $\begin{array}{l}\text { Researcher-designed } \\
\text { achievement test } \\
\text { (at 3-Cognitive levels); } \\
\text { Attitudes inventory. }\end{array}$ \\
\hline 2 & $\begin{array}{l}\text { Random, from two } \\
\text { preassigned } \\
\text { classes }\end{array}$ & 32 & $\begin{array}{c}\text { Traditional } \\
\text { Whole-Class CBIV } \\
\text { Instruction }\end{array}$ & $\begin{array}{l}\text { Researcher-designed } \\
\text { achievement test } \\
\text { (at 3-Cognitive levels); } \\
\text { Attitudes inventory. }\end{array}$ \\
\hline
\end{tabular}

Figure 1. Experimental design.

Sixty-four students (subjects) were selected by stratified random sampling techniques from two different pre-assigned class levels of biology (regular and honors) in order to assure heterogeneity of the experimental groups. This was done by using a table of random numbers and alternately selecting one from each level and randomly placing them into one of two experimental groups until they consisted of thirty two subjects each. Students not selected for the research study were given alternate individualized laboratory assignments dealing with the same unit of study as those participating in the study. The groups were randomly designated to receive either Traditional Whole-Class CBIV Biology Instruction or 
Cooperative Group CBIV Biology Instruction. The two groups were involved in learning the same biology unit 'Animal Diversity' by means of CBIV, the main difference being the type of instructional groupings, and thus their task and incentive structures (see Appendix B.06). All the subjects were posttested, for achievement at three cognitive levels as well as for attitudes, at the conclusion of the treatments.

\section{Procedures}

The unit on the Five Kingdoms of Life was developed during the summer of 1994. It was first utilized as a CBIV presentation in an AP Biology class in October of that same year, and soon thereafter it was used in cooperative groups for use by students who were absent during the regular class presentation. The items on the researcher-designed comprehensive achievement test were validated by field testing them on this same class.

\section{The Pilot Study}

At the end of the regular school year, in May and early June of 1995, a Pilot Study was conducted to obtain data to measure the achievement tests' concurrent validity and to determine any problems which students or researcher may encounter with the implementation of the program. The Pilot study was performed on two biology classes as a partial review for the final examination. 
To determine the concurrent validity of the 80 researcherdesigned test items, at the end of the pilot study the test items were administered simultaneously with the 80 quiz items obtained from several established test sources. Student scores obtained in the two test were compared and a concurrent correlation coefficient of +0.89 was calculated from this comparison, indicating an acceptable level of relationship between the instruments. To establish its internal consistency, a rationale equivalence reliability procedure was done by a computerized testing program LXR•TEST Version 4.1 .9 which utilized Cronbach's alpha formula to obtain a value of 0.97 , establishing its high degree of internal consistency.

At the end of the pilot study the attitudes inventory entitled 'Attitude Toward Science in School Assessment' (ATSSA) was administered simultaneously with the researcher-modified version entitled 'Attitude Toward Learning Science in School by means of Laserdiscs Assessment'. To determine the concurrent validity of the researcher-modified version of the attitudes inventory, subjects responses obtained from these two instruments were compared and a concurrent correlation coefficient of 0.98 was calculated from this comparison; since this comparison establishes the validity of the more specific researcher-modified version, it alone was utilized to measure attitudes in the research study. 


\section{The Research Study}

At the beginning of the 1995 summer school program at South Miami Senior High School, 68 biology high school students who either failed to achieve a passing grade during the regular school year or were taking honors biology as a way to advance academically, registered into two summer school classes, one regular the other honors. From these preassigned classes the subjects were selected utilizing stratified random sampling procedures and placed into each 1 of the 2 experimental groups, with the objective of obtaining two heterogeneous groups of 32 subjects, each with 16 form the regular class and 16 from the honors class. There also was randomized seating arrangements in both experimental groups, and stratified placement from the two levels of biology classes into each cooperative group in order to also assure heterogeneity at the cooperative group level (two subjects from each class level into each cooperative group). Four students not selected to participate in the research study due to a lack of sufficient equipment to accommodate them all, were given alternate individualized laboratory assignments by their regular teacher which covered the same biological content as the research study. Each subject which participated in the study received a Parent Permission Form (Appendix B.07) which was signed by the subject and parent, and returned to the researcher prior to their participating in the research study.

The subjects (students selected) received instruction for two and one half hours each day for six days of summer school, for a total 
of 15 hours of instruction. One of the experimental groups was scheduled to receive the traditional whole-class instructional treatment by the CBIV teacher in the morning, returning to their regular teacher in the afternoon, at which time the other experimental group received the alternate cooperative group instructional CBIV treatment; the regular teacher did not cover or discuss material closely related to that covered by the unit in the research study. To control the time of day variable, an alternating schedule of morning and afternoon was used for both groups according to the experimental group arrangement schedule shown in Figure 2.

\begin{tabular}{|c|c|c|c|c|c|c|}
\hline & 1 st Day & 2 nd Day & 3 rd Day & 4 th Day & 5 th Day & 6 th Day \\
\hline $\begin{array}{l}\text { Morning } \\
\text { Session } \\
(2.5 \text { hrs. })\end{array}$ & $\begin{array}{l}\text { Whole- } \\
\text { class } \\
\text { group }\end{array}$ & $\begin{array}{l}\text { Coopera- } \\
\text { tive } \\
\text { groups }\end{array}$ & $\begin{array}{l}\text { Whole- } \\
\text { class } \\
\text { group }\end{array}$ & $\begin{array}{l}\text { Coopera- } \\
\text { tive } \\
\text { groups }\end{array}$ & $\begin{array}{l}\text { Whole- } \\
\text { class } \\
\text { group }\end{array}$ & $\begin{array}{l}\text { Coopera- } \\
\text { tive } \\
\text { groups }\end{array}$ \\
\hline $\begin{array}{l}\text { Afternoon } \\
\text { Session } \\
(2.5 \text { hrs.) }\end{array}$ & $\begin{array}{l}\text { Coopera- } \\
\text { tive } \\
\text { groups }\end{array}$ & $\begin{array}{l}\text { Whole- } \\
\text { class } \\
\text { group }\end{array}$ & $\begin{array}{l}\text { Coopera- } \\
\text { tive } \\
\text { groups }\end{array}$ & $\begin{array}{l}\text { Whole- } \\
\text { class } \\
\text { group }\end{array}$ & $\begin{array}{l}\text { Coopera- } \\
\text { tive } \\
\text { groups }\end{array}$ & $\begin{array}{l}\text { Whole- } \\
\text { class } \\
\text { group }\end{array}$ \\
\hline
\end{tabular}

Figure 2. Experimental groups arrangement schedule.

The test and quizzes were not be taken by the subjects during the fifteen hours of instruction allocated for the research study, but were instead administered during the time of their regular biology classes.

Each subject, regardless of group, received the following instructional materials: (a) 'The Five Kingdoms of Life' and 'Animal Kingdom Taxonomic Guide' (Appendices B.01 and B.02), which contains most of the biological information required for subjects to learn during the course of the research study; most knowledge-level 
questions in the achievement posttest were directly derived from information contained in these documents; (b) 'Questions for Animal Diversity' (Appendix B.03), which is a set of 29 higher-level questions which were to be answered by the subjects utilizing all of the resources provided during the course of the research study, which includes all those previously mentioned in addition to the laserdisc visuals and the CBIV teacher; (c) 'Terminology for Animal Diversity' (Appendix B.04), which consists of a list of 177 terms used throughout the unit with their Greek and Latin roots defined; this was to be used as a study aide to help subjects build-up a biological vocabulary; (d) 'Field Biologist Handbook', containing descriptive information (data) for each visual retrieved from the laserdiscs' VideoCards data files which are included within the program (Appendix B.05); this data was retrieved and printed out in order to speed-up the data retrieval process which is very slow when done from within the authoring program VideoCards. In addition to the above, the subjects in cooperative groups also received 'Student Instructions for Cooperative Groups' (Appendix B.06) which contains detailed information about their responsibilities (tasks) and rewards (incentives) while engaged in cooperative group instruction in the unit on Animal Diversity.

The day prior to the beginning of the research study, the two groups met separately with the researcher and received detailed instructions about their task and incentive structures, and a tutorial on the use of the computer programs. 
One group of 32 subjects received traditional whole-class instruction by means of computer-based interactive video (CBIV) technology. They were taught a researcher-designed biology unit on Animal Diversity, developed by selecting audio-visual information from a set of laserdiscs entitled "The Living Textbook: Life Sciences", in an instructional sequence that correlates with the textual information found in the 'Five Kingdoms of Life' \& 'Animal Kingdom Taxonomic guide'. The purpose of this unit was to expose the subjects to a dynamic audio-visual presentation complementing the textual information required for them to learn, with teacher recitation of relevant information from the 'Field Biologists' Handbook'.

The other 32 subjects were taught the same unit on Animal Diversity by working in cooperative groups. Eight groups, consisting of four subjects each, worked cooperatively to produce a videodisc presentation lesson by selecting audio-visual instructional sequences by means of the authoring program VideoCards, accessing and organizing audio-visual information and their imbedded information (data set). The group members divided their tasks into four categories: taxonomist, field biologist, computer specialists, and research manager. The taxonomist utilized the 'Animal Kingdom Taxonomic Guide' (Appendix B.02) containing brief descriptions of eleven major phyla of the Animal Kingdom, in order to organize the groups' multimedia presentation, and also keep a written record of the groups' decision by marking the reference number of the visual selected to represent the characteristic of the group of organism 
being described, on the particular location of text in the taxonomic guide. The field biologist informed the group about the details of each visual utilizing 'The Field Biologist Handbook', a print-out of the imbedded data for the visuals selected for this particular unit (Appendix B.05). The computer specialist utilized the HyperCardbased computer program accessed from the Animal Kingdom Cooperative Group stack (Appendix C.03) which contains within it both the 'Animal Kingdom Taxonomic Guide' as well as the data for the visuals contained in the 'The Field Biologist Handbook'; this subjects' task was to work with the other three subjects in choosing their group video sequence in preparing their own multimedia presentation lessons. The research manager managed the group in a leadership role searching and recording for the group answers to the higher level 'Questions for Animal Diversity' (Appendixes B.04 and B.03). The tasks mentioned above were assigned to subjects on a daily rotating basis.

Two different adaptations of the program were utilized. The CBIV teacher in traditional whole-class group used the presentational version of the program entitled 'Animal Kingdom Presentation', a stack in which the Eventlink numbers have been preselected by the researcher for use in the presentational mode. The subjects in the cooperative groups used the version entitled 'Animal Kingdom Cooperative Group', a stack in which the Eventlink numbers are not found imbedded in the text, but are found in a section called 'AV Events' which immediately follows the text (Appendix B.06). 


\section{$\underline{\text { Summary }}$}

The fifteen hours of instruction (unit) focused on the subjects' learning the evolution, development and anatomical characteristics of the diversity of life within the Animal Kingdom. Subjects in the two groups were given identical achievement and attitudinal posttest at the conclusion of the treatments. All of the tests given for this unit were administered during the non-research session of their daily schedule, so that the fifteen hours used in this study were exclusively instructional. The research study took place at South Miami Senior High School from Tuesday, July 11, 1995, and lasted until Tuesday, July 16. On Wednesday, July 17 all subjects took the researcher-designed comprehensive achievement test on the Animal Diversity unit and the attitudes toward science instruction by means of laserdisc inventory. The data listed in Appendix $\mathrm{E}$ and analyzed in the following chapter, was a result of this research study. 


\section{CHAPTER IV}

Results of the Study

\section{$\underline{\text { Statistical Procedures }}$}

The data pertaining to the establishment of the validity and reliability of the researcher-designed comprehensive achievement test was obtained during the course of the school year 1994-95 from an A.P. Biology class. Most of this data was analyzed by the computerized testing program LXR•TEST ${ }^{\mathrm{TM}}$ Version 4.1 .9 (1990), which has statistical capabilities for item and test analysis. The data pertaining to both the pilot and research studies was gathered from May to July of 1995 . This data was analyzed by the computerized statistical program SPSS ${ }^{\circledR}$ Graduate Pack $^{\mathrm{TM}}$ Advanced Version for the Power Macintosh 6.1.1 (1994).

Determining the Validity and Reliability of the Instruments

The unit on Animal Diversity was developed during the summer of 1994 and was first utilized on an A.P. Biology class early in the school year when it was taught by CBIV traditional wholeclass instruction. This class was given a test on the 240 items originally written to cover the 80 objectives developed for the unit. Reliability ratings based on the point biserial and discrimination index (r) were obtained for each test item, and the one test item for 
each particular objective which achieved the highest reliability rating was selected for the final test version. Objectives for which all three items received low validity ratings had the items rewritten and reevaluated in subsequent tests until at least one item per objective was selected which achieved a point biserial value of at least +.500 and a discrimination index ( $r$ ) of at least .600. The result of this process was an 80 item multiple choice comprehensive achievement test with items at three different cognitive levels, and comprising the 80 objectives intended by the researcher.

Determination of the values for point biserial and discrimination index were both performed by the computerized testing program LXR TEST. Point biserial is a measure of the reliability of a particular question; its' formula compares the mean score on the exam of those subjects who select the correct answer, to the mean score of all the subjects. The discriminating index measures the correlation between the way that a set of students perform on a particular question and the way that the students performed in the entire test; its value can range from +1 (question answered correctly by examinees who scored high on the entire test, missed by low-scoring examinees), to -1 (question answered correctly by examinees who scored low on the entire test, missed by high-scoring examinees) (Bredehoft, J., Dewart, S., and Tindall, R., 1991).

To establish the internal consistency reliability of the entire achievement test, a rationale equivalence reliability procedure was followed that estimated internal consistency by determining how all 
items on a test relate to all other items and to the total test. This calculation was also performed by the computerized testing program LXR•TEST which utilizes Cronbach's alpha formula which can be used to compute the reliability of items that are scored dichotomously, i.e., correct or incorrect, as well as continuously (Cunningham, 1986). A Cronback's alpha reliability value of .97 was obtained for the researcher-designed achievement test, a value considered acceptable for any test (Gay, L. R., 1996). In order to authenticate its content (face) validity, the final version of this test was sent to Assessment Department in Dade County Schools' Office of Educational Accountability where it was reviewed by experts in the fields of testing and biological sciences (Dawson, C. L., personal communications, 1995).

The pilot study, performed in May and early June of 1995, was done in part to collect data for the determination of the concurrent validity of the 80 researcher-designed test items. At the end of the pilot study the test items were administered simultaneously with the 80 quiz items obtained from several established test sources.

Student scores obtained in the test and quiz were compared and a concurrent correlation coefficient of +.8987 was calculated from this comparison, indicating an acceptable level of relationship between the instruments. This value was calculated by determining a correlation coefficient using the statistical program SPSS Graduate Pack.

The researcher-modified version of an attitudes inventory entitled 'Attitude Toward Learning Science in School by means of 
Laserdiscs Assessment' was administered simultaneously with an established, more general version; a concurrent correlation coefficient of .9897 was calculated from this comparison, establishing the validity of the more specific researcher-modified version, which was utilized to measure attitudes in the research study.

\section{Procedures for the Analysis of Posttest Data}

The research study took palace in the summer of 1995 . The two and one-half hours per day of instruction for each experimental group by means of CBIV began on Tuesday, July 11, and lasted until Tuesday, July 16. On Wednesday, July 17, all subjects took the researcher-designed comprehensive achievement test on the Animal Diversity unit and the questionnaire measuring attitudes toward science laserdisc instruction.

To analyze the achievement test data, the overall scores were compared and examined for potential differences by instructional group (cooperative and traditional whole-class), class level (honors and regular), and gender (female and male). This was done by performing factorial analysis of variance (ANOVA) procedures on the total (overall) scores. The scores for the questions at three cognitive levels (knowledge, comprehension, and application) were also compared and examined for potential differences by instructional group, class level, and gender; this was done by performing factorial multivariate analysis of variance (MANOVA) procedures on the achievement posttest data. Results obtained by using the statistical 
program SPSS Graduate Pack are summarized in the sections which follow.

To analyze data obtained for the measure of attitudes, the attitudes posttest scores were compared by using three-way factorial analysis of variance (ANOVA) procedures and examined for potential differences among group (cooperative and traditional), class level (honors and regular), and gender (female and male). Results obtained from the statistical program SPSS Graduate Pack are also summarized in the following sections.

\section{Results of Statistical Analysis on the Achievement Posttest Data}

The means $(\underline{\mathrm{M}})$ and standard deviations $(\underline{\mathrm{SD}})$ were calculated for all the groups and categories compared for the measures of achievement. The cooperative groups consistently outperformed the traditional whole-class group in achievement test scores, as shown in Table 1. This superior achievement did not only occur in total (overall) achievement test scores, but also at every cognitive level measured (knowledge, comprehension, and application).

The greatest difference between the groups' means (4.1 units) occurred in total (overall) achievement test scores, followed by scores in knowledge-level questions (2.4 units). In order to determine if the differences for total achievement test scores are significant, a three-way factorial ANOVA was performed. Results for this analysis are shown in Table 2. Since this is a two-tailed test the level of significance reported is twice that of a one-tailed test, so that 
Table 1

Achievement Posttest Means and Standard Deviations at Three-

Cognitive levels and Total Scores by Treatment (Instructional

Grouping).

Questions' Cognitive Level

Instructional

Grouping*

Knowledge Comprehen Application Total

-Level sion-Level -Level

(Overall)

$\begin{array}{cccccc}\text { Cooperative } & \underline{\mathrm{M}} & 14.6 & 8.7 & 6.3 & 29.6 \\ \text { Groups } & \underline{\mathrm{SD}} & 6.4 & 4.1 & 3.7 & 13.2\end{array}$

$\begin{array}{cccccc}\text { Traditional } & \underline{\mathrm{M}} & 12.2 & 7.7 & 5.5 & 25.5 \\ \text { Whole-Class } & \underline{\mathrm{SD}} & 6.6 & 4.3 & 3.1 & 12.7\end{array}$

$* \underline{\mathrm{n}}=32$ for each group.

when hypothesized results (in this case the group main effect) were interpreted for significance at $\mathrm{p}<.050$, any $\mathrm{p}<.100$ were considered significant. Thus a three-way interaction for class level by gender by group was found to be significant $(\mathrm{F}(1,56)=4.394, \mathrm{p}<.041)$. The gender main effect was also found to be significant $(F(1,56)=4.869$, $\underline{p}<.031$ ), as was the expected significant difference in total achievement for subjects form different class levels (honors and regular). Most importantly, the hypothesized group main effect (F 
$(1,56)=3.023, \mathrm{p}<.088)$ was found to be significant for total achievement test scores.

Table 2

Tests of Significance for Total Achievement Test Scores, selected output from Three-Way Factorial ANOVA.

Source of Variation

Sig. of F

Main Effects

Class Level

Gender

Group*

2-Way Interaction

Class Level x Gender

Class Level x Group

Gender x Group

3-Way Interaction

Class Level x Gender x Group
13.818

.000

33.857

.000

4.869

.031

3.023

.088

0.552

.649

0.811

.372

0.726

.398

0.394

.533

4.394

.041

4.394

.041

* Note. Since this is a two-tailed test, the level of significance reported is twice that of a one-tailed test, so that when hypothesized results were interpreted for significance at $p<.050$, any $p<.100$ were considered significant.

In order to determine if any of the existing differences between the experimental groups at the three cognitive levels were 
significant, a three-way factorial MANOVA was performed on the achievement test scores. Results for this analysis are shown in Table 3.

When the multivariate Wilk's test values obtained from this three-way factorial MANOVA were interpreted for significance at the $\underline{p}<.050$, the values reported by the program were not significant for any level of interaction effects; only the expected class level (honors and regular) main effect was found to be significant, and the hypothesized group main effect was not significant $(\mathrm{F}(1,56)=1.05$, p $<.378$ ). Since none of the multivariate Wilk's tests were significant, then the results of the univariate $\mathrm{F}$ test were of no consequence in the interpretation of differences at the three cognitive levels.

Thus, results from this factorial MANOVA for achievement test scores at the three cognitive levels (Table 3 ) did not prove to be significant. However, results from the three-way factorial ANOVA done for achievement total (overall) test scores (Table 2) did indicate that class-level, group and gender interacted to make a significant difference in total achievement score, but these results do not specify where the differences exist.

In order to decipher the interactions suggested by the factorial ANOVA performed on the total (overall) achievement test scores there is a need to take a close look at the total mean scores of females and males from the different class levels in the different groups, as shown in Table 4. 
Table 3

Tests of Significance for Achievement Test Data at Three-Cognitive levels, selected output from Three-Way Factorial MANOVA.

EFFECT

Multivariate

Wilks' Test

Exact $\mathrm{F}$ Sig. of $\mathrm{F}$
VARIABLE

(Cognitive
Univariate

F-Test Level)

F Sig. of F

\begin{tabular}{|c|c|c|c|c|c|}
\hline \multirow[t]{3}{*}{ Class Level x Gender } & 0.96 & .420 & Knowledge & 1.027 & .315 \\
\hline & & & $\begin{array}{l}\text { Compre- } \\
\text { hension }\end{array}$ & 0.016 & .899 \\
\hline & & & Application & 1.104 & .298 \\
\hline \multirow[t]{3}{*}{ Group x Gender } & 1.54 & .215 & Knowledge & 0.436 & .512 \\
\hline & & & $\begin{array}{l}\text { Compre- } \\
\text { hension }\end{array}$ & 0.396 & .531 \\
\hline & & & Application & 1.444 & .234 \\
\hline \multirow[t]{3}{*}{ Group x Class Level } & 1.18 & .326 & Knowledge & 0.014 & .906 \\
\hline & & & $\begin{array}{l}\text { Compre- } \\
\text { hension }\end{array}$ & 0.001 & .982 \\
\hline & & & Application & 1.757 & .190 \\
\hline \multirow[t]{3}{*}{ Gender } & 2.01 & .123 & Knowledge & 4.031 & .049 \\
\hline & & & $\begin{array}{l}\text { Compre- } \\
\text { hension }\end{array}$ & 2.150 & .148 \\
\hline & & & Application & 5.869 & .019 \\
\hline
\end{tabular}


Class Level

$9.84 \quad .000$

Knowledge $21.911 \quad .000$

Compre-

hension

$19.133 \quad .000$

Application $29.945 \quad .000$

\begin{tabular}{|c|c|c|c|c|c|}
\hline \multirow[t]{3}{*}{ Group* } & \multirow[t]{3}{*}{1.05} & \multirow{3}{*}{.378} & Knowledge & 3.112 & .083 \\
\hline & & & $\begin{array}{l}\text { Compre- } \\
\text { hension }\end{array}$ & 2.194 & .144 \\
\hline & & & Application & 1.571 & .215 \\
\hline
\end{tabular}

* Note. Since this is a two-tailed test, the level of significance reported is twice that of a one-tailed test, so that when hypothesized results were interpreted for significance at $\mathrm{p}<.050$, any $\mathrm{p}<.100$ were considered significant.

The means for the total achievement test scores of females and males from different class levels in the different instructional groups shown in Table 4 reveal ordinal interactions which are illustrated in Figure 3. It is clear from these graphs that female and male subjects were differently affected by the treatments (cooperative vs.

traditional CBIV) depending on their class (aptitude) levels. Honorslevel males performed much better when in cooperative groups, whereas for regular-level males group membership did not make much difference. Conversely, the regular-level females performed much better in cooperative groups than their counterparts in the traditional groups, but for the honors-level females group membership did not appear to make much difference. 
Table 4

Achievement Posttest Means and Standard Deviations at Three-

Cognitive Levels and Total Scores of Instructional Groupings by Class

Level (Honors, Regular) and Gender.

\section{Instructional Groupings}

Cooperative

Honors $\quad \underline{\text { Regular }}$
Traditional

Honors $\quad \underline{\text { Regular }}$
Questions'

Cognitive Level Female Male Female Male Female Male Female Male $(\underline{\mathrm{n}}=7) \quad(\underline{\mathrm{n}}=9) \quad(\underline{\mathrm{n}}=4) \quad(\underline{\mathrm{n}}=12)(\underline{\mathrm{n}}=7) \quad(\underline{\mathrm{n}}=9) \quad(\underline{\mathrm{n}}=6) \quad(\underline{\mathrm{n}}=10)$

$\begin{array}{llllllllll}\text { Know- } & \underline{M} & 18.6 & 17.8 & 13.2 & 10.2 & 19.7 & 12.0 & 9.0 & 9.2\end{array}$ $\begin{array}{llllllllll}\text { ledge } & \text { SD } & 6.9 & 6.8 & 4.4 & 3.0 & 7.8 & 6.4 & 1.5 & 3.0\end{array}$

Comprehension $\begin{array}{llllll}\text { M } & 11.3 & 11.1 & 9.0 & 5.2 & 11.0\end{array}$ $8.7 \quad 5.3$ 6.1 Level $\underline{\mathrm{SD}}$

3.7

3.3

3.4

$2.3 \quad 4.8$

4.4

3.9 2.9

Application M $\quad 8.9$

8.7

5.0

3.5

9.3

4.6

$4.5 \quad 4.1$

Level

SD 4.0

2.6

1.4

2.4

3.0

1.5

2.6

2.6

Total

M

(Overall)

SD

38.7

37.6

27.2

19.0

40.1

$\begin{array}{lll}25.3 & 18.8 & 19.4\end{array}$

$\begin{array}{lllll}6.6 & 15.2 & 10.2 & 5.3 & 7.7\end{array}$

The greatest differences in total achievement test scores (12.3 points) were between the honors level males involved in cooperative CBIV over those in the traditional whole class groups, followed by regular level females involved in those same groups (8.4 points). In 
order to determine if the differences between honors level cooperative group males was significantly higher than those of their traditional group counterparts, a t-test was performed comparing

Honors Level

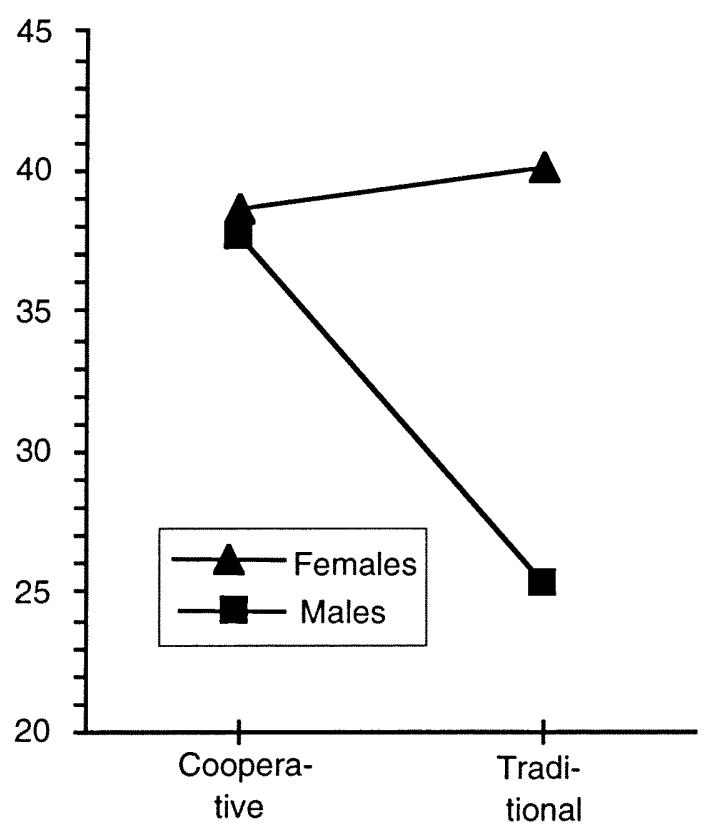

Regular Level

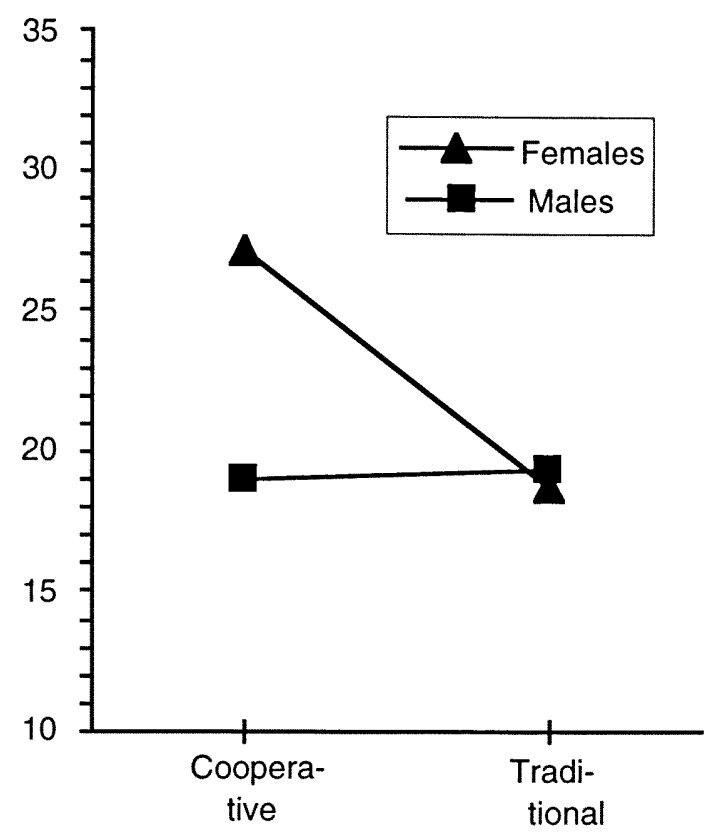

Figure 3. Ordinal interactions in Total (Overall) Achievement scores of Females and Males from Honors and Regular-Level Classes.

their mean achievement test scores. The results of this analysis are shown in Table 5; these results are for a two-tailed analysis and have to be interpreted at the one-tailed direction by dividing the reported significant $\mathrm{t}$ by one half. They show that these differences were very close to being significant at the alpha $=.01$ level with $\mathrm{t}(1,16)=2.32$, $\mathrm{p}<.034$. 
Table 5

Test of Significance for Total Achievement Posttest Data of Honors

Level Males, selected output form Univariate Two-Tailed t-Test

Achievement

Scores

t-value

2-Tail Sig. $t$

Power

Total: all

three-Cognitive

2.32

.034

.909

Levels combined

alpha $(\alpha)=.01$

A similar t-test analysis comparing regular level females in the two instructional groups, who differed by 8.4 points for total achievement scores, was not performed because their sample sizes were too small ( $\underline{n}=4 \& 6)$.

Analyzing the data for total achievement scores from the different groups by class level (Table 6), it is clear that subjects from the honors classes benefited the most from cooperative groups, outperforming their honors level counterparts in the traditional group by 6.3 points. Subjects from the regular level classes also performed better when in the cooperative groups, but in this case only by 1.9 points.

When comparing the total achievement scores from different CBIV instructional groups by gender (Table 6), the data reveals that 
Table 6

Achievement Posttest Means and Standard Deviations for Total

Scores by Instructional Groupings, Class Level and Gender.

\begin{tabular}{cccccc}
\hline $\begin{array}{c}\text { Instructional } \\
\text { Grouping }\end{array}$ & & \multicolumn{2}{c}{ Class Level } & \multicolumn{2}{c}{ Gender } \\
\hline Cooperative & $\underline{\mathrm{M}}$ & 38.1 & 21.1 & 34.5 & 27.0 \\
Groups & $\underline{\mathrm{SD}}$ & 12.6 & 6.9 & 11.4 & 8.9 \\
& $\underline{\mathrm{n}}$ & 16 & 16 & 11 & 21 \\
Traditional & $\underline{\mathrm{M}}$ & 31.8 & 19.2 & 30.3 & 22.2 \\
Group & $\underline{\mathrm{SD}}$ & 12.4 & 6.8 & 10.6 & 8.9 \\
Both groups & $\underline{\mathrm{M}}$ & 34.9 & 20.2 & 32.4 & 24.6 \\
combined & $\underline{\mathrm{SD}}$ & 12.5 & 6.8 & 11.0 & 8.9 \\
& $\underline{\mathrm{n}}$ & 32 & 32 & 24 & 40 \\
\hline
\end{tabular}

female subjects outperformed the male subjects, regardless of which group they were in, by an average score of 7.8 points $(9.7 \%$ higher). When females and males were compared for initial differences in G.P.A. and standardized test scores (mathematics and language Standford Achievement Test scores), the females used as subjects for this research study reported an average of $8.8 \%$ higher scores than the male subjects prior to the beginning of the study. Thus the $9.7 \%$ difference in achievement test scores between female and male subjects participating in this research study can be attributed to the fact that the female subjects had previously performed better by an 
average of $8.8 \%$ on other established measures of achievement, thus indicating that these gender differences in achievement scores are an unlikely consequence of the treatments received in this research study.

Results of Statistical Analysis on the Attitudes Posttest Data

The means $(\underline{M})$ and standard deviations ( $\underline{\mathrm{SD}})$ were also calculated for the measures of attitudes. This analysis reveals that subjects in the cooperative groups demonstrated more positive attitudes toward science laserdisc instruction than subjects in the traditional whole-class group, as shown in Table 7.

Table 7

Attitudes Posttest Means and Standard Deviations by Treatment (Instructional Grouping).

Instructional

Groupings*

Attitudes

Cooperative Groups $\quad \underline{M} \quad 50.9$

Instruction $\quad \underline{\mathrm{SD}} \quad 8.2$

Traditional Whole- $\underline{M} \quad 47.6$

$\begin{array}{lll}\text { Class Instruction } & \underline{\text { SD }} & 10.2\end{array}$

* $\underline{\mathrm{n}}=32$ for each group. 
In order to determine if any of the differences in attitudes scores for the different groups were significant, a three-way factorial ANOVA was performed on the attitudes data. Results for this analysis are shown in Table 8 . The three-way interaction for class level by group by gender was found to be significant $(F(1,56)=$ 8.266, $\mathrm{p}<.006)$. However, none of the main effects were found to be significant: class level $(\mathrm{F}(1,56)=3.014, \mathrm{p}<.088)$, gender $(\mathrm{F}(1,56)=$ $3.058, \mathrm{p}<.086)$, or group $(\mathrm{F}(1,56)=0.705, \mathrm{p}<.405)$.

Table 8

Tests of Significance for Attitudes data, selected output from ThreeWay Factorial ANOVA.

Source of Variation

Main Effects

2.139

.106

Class Level

3.014

.088

Gender

3.058

.086

Group

0.705

.405

2-Way Interaction

0.533

.661

Class Level x Gender

0.175

.677

Class Level x Group

1.020

.317

Gender x Group

0.472

.495

3-Way Interaction

8.266

.006

Class Level x Gender x Group

8.266

.006 
When the means and standard deviations of the instructional groups were calculated at different levels of the other independent variables (class level and gender) in order to detect the nature of the interactions between these factors, the results shown in Table 9 were obtained.

Table 9

Attitudes Posttest Means and Standard Deviations from a Three-Way Factorial ANOVA: Instructional Grouping (Cooperative \& Traditional), Class Level (Honors \& Regular), Gender (Female \& Male).

Instructional

\begin{tabular}{cc} 
Class Level $/$ Gender \\
\hline Honors & Regular
\end{tabular}

Groupings* Females Males Females Males

$\begin{array}{lccccc}\text { Cooperative Groups } & \underline{\mathrm{M}} & 52.7 & 52.7 & 40.7 & 52.0 \\ & \underline{\mathrm{SD}} & 4.7 & 11.7 & 5.3 & 5.1 \\ & \underline{\mathrm{n}} & 7 & 9 & 4 & 12\end{array}$

$\begin{array}{cccccc}\text { Traditional } & \underline{\mathrm{M}} & 43.4 & 53.4 & 49.3 & 44.2 \\ \text { Whole-class Group } & \underline{\mathrm{SD}} & 12.6 & 6.1 & 6.2 & 11.7 \\ & \underline{\mathrm{n}} & 7 & 9 & 6 & 10\end{array}$

$* \underline{\mathrm{n}}=32$ for each group.

These results disclose both ordinal and disordinal interaction between the factors of class level and gender in the two instructional 
groups (see Figure 3). Honors-level females and regular-level males in the cooperative groups demonstrated more positive attitudes toward science laserdisc instruction ( $\underline{\mathrm{M}}=52.7 \& 52.0$, respectively) than their counterparts in the traditional whole-class group $(\underline{\mathrm{M}}=$ $43.4 \& 44.2)$. Group membership did not appear to make a difference for honors level males in cooperative and traditional groups $(\underline{\mathrm{M}}=52.7 \& 53.4$, respectively), and regular-level females demonstrated more positive attitudes toward science laserdisc instruction when they were in the traditional whole-class groups $(\underline{M}$ $=49.3)$ than when in cooperative groups $(\underline{M}=40.7)$. Notice that for attitudes the interaction of factors in females and males from

Honors Level

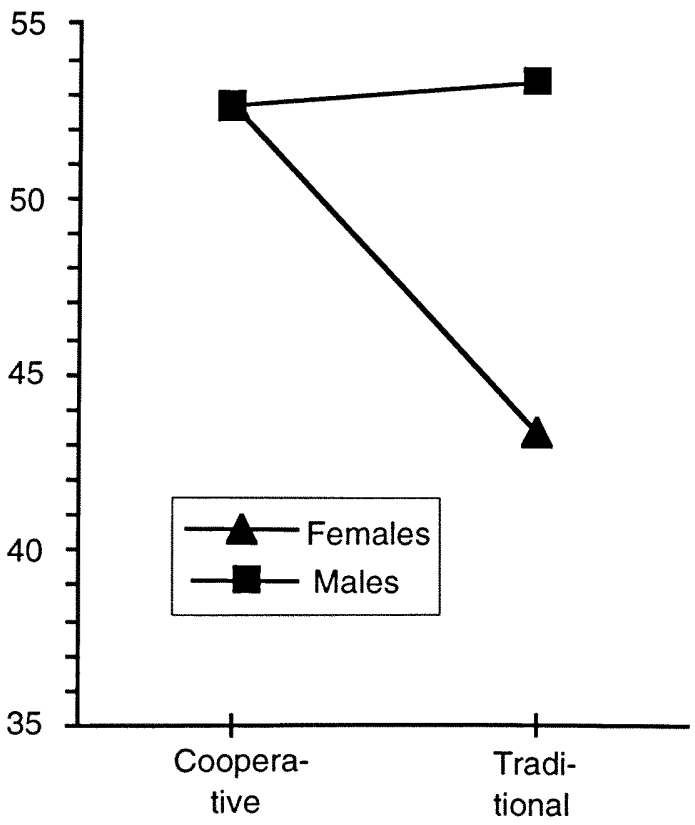

Regular Level

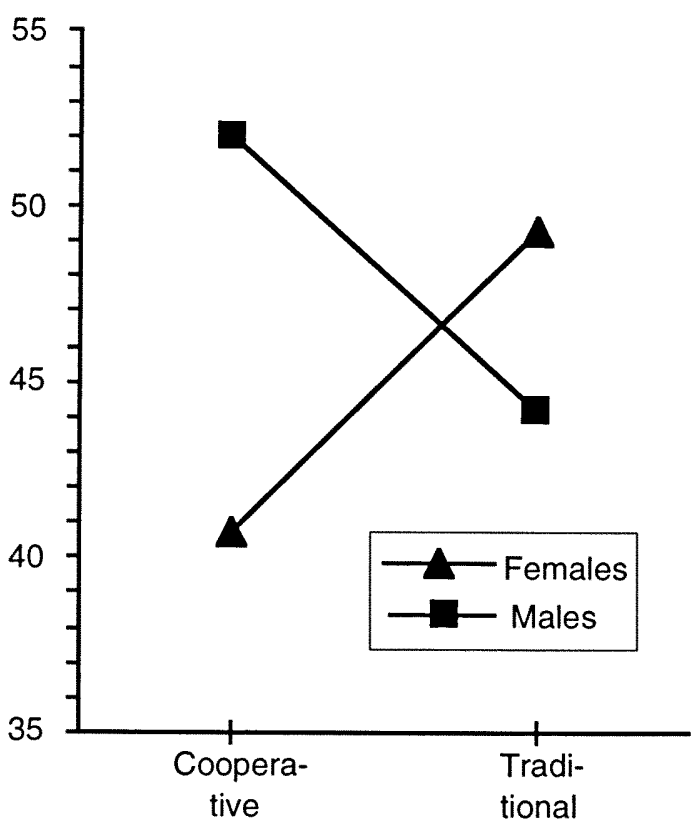

Figure 4. Ordinal and disordinal interactions in Attitudes of Females and Males from Honors and Regular Level Classes. 
different class levels had almost the exact opposite effect as achievement (compare Figure 3 to Figure 4).

The greatest differences in attitudes between the two instructional groups were exhibited by honors level females (9.3 units), followed by regular level females (8.6 units). However, t-tests analyses did not find these differences to be significantly different, with the honors level females demonstrating a $\mathrm{t}(1,21)=1.87, \mathrm{p}<$ .076 when interpreted at the $\alpha=.01$ level. Males in the regular level class differed by 7.8 units, whereas honors level males differed by only 0.7 units from one instructional group to the other (see Table 9). Results from the analysis of attitudes data are almost the exact opposite of those reported for the total (overall) achievement data, except for the fact that differences in attitudes between the two instructional groups were not sufficiently different to be significant in interactions or main effects.

In order to determine the effect of gender and class level independently of each other, their separate means and standard deviations were calculated for each instructional group, and the results are shown in Tables 10 and 11 .

The analysis shown in Table 10 reveals that subjects from the honors-level class had more positive attitudes by an average of 3.2 points than those from the regular-level class; this was true regardless of the CBIV group in which the subjects received instruction. It also reveals that subjects from both the honors and the regular level classes demonstrated more positive attitudes, by an average of 3.4 points, when they were involved in cooperative group 
instruction as opposed to traditional whole-class instruction. The greatest difference in attitudes was of 6.6 points, between honors level subjects in the cooperative groups $(\underline{M}=52.7)$ and the regular level subjects in the traditional group $(\underline{\mathrm{M}}=46.1)$.

Table 10

Attitudes Posttest Means and Standard Deviations from a Two-Way Factorial ANOVA: Instructional Grouping by Class Level.

\begin{tabular}{|c|c|c|c|}
\hline \multicolumn{2}{|l|}{ Instructional Grouping } & \multirow{2}{*}{$\begin{array}{c}\begin{array}{c}\text { CLASS } \\
\text { Honors }\end{array} \\
52.7\end{array}$} & \multirow{2}{*}{$\begin{array}{l}\text { LEVEL } \\
\text { Regular } \\
49.2\end{array}$} \\
\hline Cooperative Group Instruction & $\underline{M}$ & & \\
\hline$(\underline{\mathrm{n}}=32)$ & $\underline{\mathrm{SD}}$ & 8.6 & 5.2 \\
\hline Traditional Whole-Class Instruction & $\underline{M}$ & 49.1 & 46.1 \\
\hline$(\underline{\mathrm{n}}=32)$ & $\underline{\mathrm{SD}}$ & 8.2 & 9.6 \\
\hline Totals for both Experimental Groups & $\underline{\mathrm{M}}$ & 50.9 & 47.7 \\
\hline Combined $(\underline{n}=64)$ & $\underline{\mathrm{SD}}$ & 9.8 & 8.7 \\
\hline
\end{tabular}

The analysis shown in Table 11 reveals that male subjects from either the honors-level or the regular-level classes had more positive attitudes than the females regardless of CBIV instructional group. This was particularly true for males involved in cooperative group instruction who scored 3.9 points higher than the females in the same group, and 6.1 points higher than the females in the traditional whole-class group. 
Table 11

Attitudes Posttest Means and Standard Deviations from a Two-Way Factorial ANOVA: Instructional Grouping by Gender.

Instructional Grouping

Cooperative Group Instruction

$$
(\underline{n}=32)
$$

Totals for both Experimental

Groups Combined $(\underline{n}=64)$

Traditional Whole-Class Instruction

$$
(\underline{\mathrm{n}}=32)
$$

GENDER

Females Males

$\underline{\mathrm{SD}}$

4.9

7.9

n $\quad 11$

21

M $\quad 46.2$

48.6

$\underline{\mathrm{SD}}$

9.6

9.0

$\underline{\mathrm{n}}$

13

19

$\begin{array}{lcc}\underline{\mathrm{M}} & 47.2 & 50.5 \\ \underline{\mathrm{SD}} & 7.5 & 8.4 \\ \underline{\mathrm{n}} & 24 & 40\end{array}$

Summary of Findings

The cooperative group consistently outperformed the traditional group in achievement scores. Factorial ANOVA on total (overall) achievement scores indicated that subjects in cooperative groups significantly outperformed those in the traditional group, and also that the instructional group, class level, and gender interacted in 
an ordinal fashion to make a significant difference in how female and male subjects were affected by the treatments depending on their class (aptitude) level. Regular level females and honors level males performed much better when in cooperative groups, whereas group membership did not appear to make a difference for either honors level females or regular level males. A t-test comparing honors level males revealed that cooperative groups were close to being significantly better in total achievement posttest scores than their traditional group counterparts. Factorial MANOVA comparing the instructional groups at three cognitive levels found no significant difference.

Analysis on the attitudes posttest data also revealed that subjects in cooperative groups demonstrated more positive attitudes towards science laserdisc instruction; however, these differences were not found to be significant. Significant interactions in attitudes of females and males from different class levels had the opposite effect as achievement: honors level females and regular level males demonstrated more positive attitudes towards science laserdisc instruction when in cooperative groups, whereas group membership did not appear to make a difference for honors level males; furthermore regular level females demonstrated the lowest attitudes ratings of any group when involved in cooperative groups. This contrast between achievement and attitudinal results suggests crossgender interaction in traditionally defined gender roles. 


\section{CHAPTER V}

Summary, Discussion, and Implications

This chapter delineates the purposes, procedures, statistical results, and inferences on the hypotheses proposed for this research study. This is followed by a discussion of findings and conclusions, as well as implications for future investigations.

\section{Summary}

This study examined the effect on student achievement and attitudes of two instructional groupings (cooperative and traditional whole-class) using computer-based interactive videodisc (CBIV).

A Pilot Study was first performed to determine any problems which subjects and/or researcher may have encountered with the implementation of the CBIV biology unit, as well as to validate the researcher-designed achievement test and the researcher-modified version of an established attitudes inventory.

A research study was subsequently performed in which 2 groups consisting of 32 subjects each, were engaged in 2.5 hours of instruction per day, for of 6 days, for a total of 15 hours of CBIV instruction. Subjects were randomly placed into two groups which received CBIV biology instruction by either cooperative or traditional whole-class methodologies. All the subjects were posttested for achievement at three cognitive levels (knowledge, comprehension, 
application) as well as for attitudes toward science laserdisc instruction.

\section{$\underline{\text { Purposes }}$}

The study encompassed three main purposes. They were to measure the effect of the two instructional groupings on:

1. student achievement at three cognitive levels on researcherdesigned biology tests from a unit dealing with the taxonomic relationships involved in classifying the diversity of animal life.

2. student attitudes towards science laserdisc instruction as a subject in school.

3. the comparative cost-effectiveness.

\section{Procedures}

A Pilot Study was first performed on two biology classes as a partial review for the final examinations at the end of the school year. Its purpose was to establish the concurrent validity of the researcher-designed achievement test, and to determine any problems which students and/or researcher may have encountered with the implementation of the CBIV biology unit. Also at the end of the pilot study a researcher-modified version of an attitudes inventory entitled 'Attitude Toward Learning Science in School by means of Laserdiscs Assessment' was administered simultaneously with an established, more general version; a concurrent correlation 
coefficient of .9897 was calculated from this comparison, establishing the validity of the more specific researcher-modified version, which was utilized to measure attitudes in the research study.

For the research study a two-group posttest-only control group design was utilized to measure the subjects achievement and attitudes (see Figure 1, p. 102). This design was chosen because random assignment of the groups was possible, and because the administration of pretests was not advisable due to its potential interaction with the results of the posttest.

During the summer of 1995, a group of 64 students were selected by stratified random sampling techniques from 2 different pre-assigned class levels of biology (regular and honors), with the objective of obtaining 2 heterogeneous groups of 32 subjects, each with 16 subjects form the regular class and 16 from the honors class. There also was randomized seating arrangements in both experimental groups, and stratified placement from the two levels of biology classes into each cooperative group in order to also assure heterogeneity at the cooperative group level (two subjects from each class level into each cooperative group).

The groups were randomly designated to receive either traditional whole-class CBIV biology instruction or cooperative group CBIV biology instruction. The two groups were involved in learning the same biology unit 'Animal Diversity' by means of CBIV, the main difference being the type of instructional groupings, and thus their task and incentive structures. 
The subjects received instruction for 2.5 hours each day for 6 days of summer school, for a total of 15 hours of instruction. One of the experimental groups received the traditional whole-class instructional treatment by the CBIV teacher in the morning, returning to their regular teacher in the afternoon, at which time the other experimental group received the alternate cooperative group instructional CBIV treatment. To control the time of day variable, an alternating schedule of morning and afternoon was utilized for both groups (see Figure 2, p. 106). All the subjects were posttested, for achievement at three cognitive levels as well as for attitudes towards science laserdisc instruction, at the conclusion of the treatments.

\section{Statistical Results}

The cooperative group consistently outperformed the traditional whole class group in achievement posttest scores at every cognitive level (see Table 1, p. 116). However, form a total of four research hypotheses considered in regards to this superiority in achievement, only the one following was supported by the findings. $\mathrm{H}_{1}(1)$ : Students receiving cooperative-group instruction will have significantly better total (overall) achievement scores than those receiving traditional whole-class instruction in a CBIV biology unit. Results from a three-way factorial ANOVA done for achievement total (overall) test scores (see Table 2, p. 117), not only indicated that the main effects for instructional group, class level, and gender, were significant at the $\alpha=.05$, but that class-level, group 
and gender interacted to make a significant difference in the total achievement score. Further analysis of the results indicated that the instructional group, class level, and gender interacted in an ordinal fashion to make a significant difference in total achievement posttest scores: female and male subjects were differently affected by the treatments depending on their class (aptitude) level. Regular level females and honors level males performed much better when in cooperative groups, whereas group membership did not appear to make a difference for either honors level females or regular level males (see Figure 3 on p. 122). However, a subject of concern is the generalizability of the three-way interaction results. The group sizes at the 3rd level of interaction were quite small, ranging from 4 subjects for the regular level females to 12 for the regular level males in the cooperative groups (see Table 4, p. 121). For samples that small, the power of the $F$ tests performed for the three-way interaction are unacceptably low (below 0.5), so these interactions results are not generalizable to subjects outside of the sample used for this research study.

The other three hypotheses dealing with achievement, $\mathrm{H}_{1}(2)$ through $\mathrm{H}_{1}(4)$, predicted significantly better achievement test scores at the three cognitive levels for subjects in cooperative groups over those receiving traditional whole-class instruction in a CBIV biology unit. Results from a factorial MANOVA (see Table 3, pp. 119-120) indicated that only the expected class level effect made a significant difference, and not the hypothesized instructional grouping or the three-way interactions. 
The last hypothesis, $\mathrm{H}_{1}(5)$, had predicted that students receiving cooperative-group instruction would have significantly better attitudes towards science laserdisc instruction than those receiving traditional whole-class instruction in a CBIV biology unit. Results from the statistical analysis on the attitudes posttest data revealed that subjects in cooperative groups demonstrated more positive attitudes towards science laserdisc instruction. A three-way factorial ANOVA performed on the attitudes data revealed that the main effects of class level, gender, and the hypothesized group main effect were not significant, so hypothesis $\mathrm{H}_{1}(5)$ had to also be rejected. It also revealed a significant interaction for class level by group by gender; interestingly, this unhypothesized interaction of factors in females and males from different class levels showed almost the exact opposite effect as the interactions in achievement scores: honors level females and regular level males demonstrated more positive attitudes towards science laserdisc instruction when in cooperative groups, whereas group membership did not appear to make a difference for honors level males, and regular level females demonstrated the lowest attitudes ratings of any group when involved in cooperative groups. However, the small sample size problem which plagued the generalizability of the three-way interaction effect for achievement, also affects the attitudes results in the same way. Thus, these interactions results are not generalizable to subjects outside the sample utilized for this research study. 


\section{Conclusions}

The hypothesis supported by the findings of this research study confirms the effectiveness of cooperative groups, as has recent research literature. What was distinctive of this study was the use of cooperative instructional grouping while the subjects utilized computer-based interactive videodisc (CBIV) technology to learn a biology unit.

The length of time over which this research study was conducted, was the least amount of time recommended for allowing the cooperative groups to become sufficiently interdependent to make a significant difference as compared to other instructional techniques. If the study would have been conducted over a longer period of time, as other research shows, cooperative groups would have been more effective in improving student achievement; thus, there would have been greater opportunity to support all four research hypotheses pertaining to achievement gains. This study did not attempt to measure anything about the hands-on computer skills learned by the subjects participating in cooperative groups.

Attitudes are a more complex issue. First of all, studies have shown that their relationship to achievement is moderate at best, with correlation coefficients averaging .16 while in the early years of high school, dropping thereafter. There seems to be a higher correlation for achievement causing attitude than for attitude causing achievement. Achievement in science seems to be more highly related to interest in science than to psychologically scaled attitude, 
so perhaps science curricula should concentrate on improving achievement and let the effect follow without curricular emphasis (Wilson, 1983).

The cost effectiveness of improving student achievement is both a financial and a value judgment. How much are we willing to invest in improving our children's' cooperative skills, computer skills, and scientific literacy? What impact would it have on our economy if we continue to fall behind in the production of high quality scientific human resources? Would the investment in ten computers with multimedia capabilities similar to those utilized in this study, to be used cooperatively by small groups of students for special lessons, be more than we can do to invest in our future? Since no technological innovation can replace other well established instructional techniques, cant we invest in just sufficient number to create a multimedia learning center which can be shared by several teachers within a school or department? The answer to these questions would indicate our commitment to education and reveal our determination to have our schools better serve the needs of its citizens in meeting the challenges of the future.

More interesting than the verification of the hypothesized results, are the unhypothesized interactions that were found, specially in the interactions between group, class level, and gender: female and male subjects were differently affected by the treatments depending on their class (aptitude) level. Regular level females and honors level males performed much better when in cooperative groups, whereas group membership did not appear to 
make a difference for either honors level females or regular level males. Unfortunately the sample sizes at the third level of interaction were too small for these results to be generalizable to populations outside of the sample studied. However, the results obtained can be explained by other studies, as is explained in the following paragraphs.

The fact that honors level males performed much better when in cooperative groups may be explained by research on group dynamics in educational and noneducational settings which has consistently shown that males dominate the activity in mixed-sex groups (Webb, 1984). Lockheed \& Hall (1976) found that female and male high school students were equally active only when group members had prior experience with the material; when students had no prior experience, males tend to dominate group activity. Studies generally support the gender stereotype of greater competence among males; this perception becomes particularly strong in middle and late adolescence, and is especially true in mathematics and science, which are sex typed as 'male domain' (Kahle \& Meece, 1994). This may explain why regular level males, even though they did not improve in achievement while in cooperative groups, did improve in attitudes over their traditional group counterparts. It may also explain why regular level females in the cooperative groups demonstrated the lowest attitude ratings while participating in maledominated small group activities.

Tobin and Garnett (1987) report that whole-class activities tend to be also dominated by high-achieving males. It is apparent 
that compared with females, males are more likely to initiate teacher interactions, to volunteer to answer teacher questions, to call out answers, and to receive praise, criticism, or feedback to prolong teacher interactions (Kahle \& Meece, 1994). This may explain why the high achieving (honors level) males had positive attitudes regardless of which group they were in, but results from this study show that cooperative group males performed significantly better (for total achievement) than their counterparts in traditional wholeclass instruction.

The fact that the more confident honors level females performed well regardless of which group they were in, and that regular level females performed much better when in cooperative groups, may be explained by research which consistently shows that most females prefer and take a more active role in cooperative, rather than competitive, learning activities (Johnson \& Johnson, 1989). Studies have also reported that females are more responsive to request for help, regardless of sex, whereas males responded to other males more often than to females; this response is accentuated in groups with only one female (Webb, 1984).

Compared with males, females often have less confidence in their academic abilities, lower achievement expectations, less interest in challenging achievement activities and more debilitating causal attribution patterns (Dweck, 1986). However, findings also reveal that gender attitudes differences are not homogeneous across measures, age groups, and content areas, making it difficult to draw any general conclusions (Kahle \& Meece, 1994). 
Females may be more successful in obtaining help and contributing to group interaction in all-female groups than in mixedsex groups. However, Barbieri and Light (1992) showed that the advantage of males over females was independent of the group's gender composition. Rennie and Parker (1987) reported that singlesex grouping may be beneficial to females' science education in cases where teachers have a low level of awareness and skills in relation to creating and maintaining a non-sexist learning environment. Another solution may be training in cooperative skills, so that male students learn to be more responsive to other students' request for help, and female students trained to persevere until their requests are answered.

\section{Implications for Future Investigation}

Regardless of specific design factors, learning seems to be affected more by relevant cognitive activity than by particular instructional systems (Hannafin \& Hooper, 1993). Even though multimedia programs present a new set of considerations for educators and researchers, it is imperative that the proven methods of increasing knowledge be integrated to this new technology.

Since the use of cooperative learning groups has been found to increase achievement, future investigations should continue to use this instructional grouping technique in order to investigate the most effective strategies for implementing computer-based multimedia technologies. Cooperative learning has proven itself to be an 
effective and efficient way to maximize the limited number of resources in many learning situations.

Design considerations in the development of multimedia systems should incorporate the use of proven instructional strategies which increase students' problem solving, critical thinking, and decision making skills. This can be accomplished by the use of inquiry-based instructional designs which provide a more open ended approach that encourages student to use and develop important science process skills. These skills should include observing, classifying, measuring, inferring, formulating hypotheses, experimenting, interpreting data, and formulating models. There is a tremendous scarcity of science educational materials which follow this inquiry model, specifically in computerized multimedia systems; most of what is available has good visual and informational data, but its content and design do not encourage the use or development of science process skills. Much work still needs to be done on the part of designers and producers of science multimedia educational materials.

Navigation and learner control provide branching options which are essential components of the ability to search and compare information and sources, facilitating the development of inquiry and higher order intellectual skills. Careful consideration should be given to learning styles when designing branching structures, as too little choice can be restrictive and too much can be confusing. Research specifically addressing multimedia navigation and learning styles is almost nonexistent. 
As this research study suggests, gender differences should not be ignored, especially in the sex-typed 'male domain' fields of science and technology. The inculcation of this cultural stereotype can be alleviated by training teachers with the skills necessary to create and maintain a non-sexist learning environment; another solution may be training in cooperative skills, so that male students learn to be more responsive to other students' request for help, and female students trained to be more assertive and competitive. 
Aldridge, Bill (1989). Fire Up Secondary School Science. $\underline{\text { School }}$ Administrator, $\underline{46}(7), 18-20$.

American Association for the Advancement of Science (1989). Science for All Americans: Project 2061. New York: Oxford University Press.

American Association for the Advancement of Science (1993). Benchmarks for Science Literacy: Project 2061. New York: Oxford University Press.

American Chemical Society (1988). ChemCom: Chemistry in the Community. Dubuque, Iowa: Kendall/Hunt Publishing Company. Ashman, Anthony (1985, June). Chemistry in Schools--Past, Present and Future. Part 1. School Science Review, 66 (237), 696-704.

Atkins, M., \& Blissett, G. (1989). Learning activities and interactive videodisc: An exploratory study. British Journal of Educational Technology, 20(1), 47-56.

Baez, J. L.(1982). General Science: A Conceptual Approach. New York: MaGraw Hill.

Bangert-Downs, Robert L.; Kulik, James A.; and Kulik, Chen-Lin C. (1985, Summer). Effectiveness of Computer-Based Education in Secondary Schools. Journal of Computer Based Instruction, 12(3), 5968.

Barbieri, Maria S., \& Light, Paul H. (1992). Interaction, Gender, and Performance on a Computer-Based Problem Solving Task. Learning and Instruction, 2, 199-213. 
Bejar, I. (1992, June). Videodiscs in Education. Byte, 7, 35-47.

Berger, Carl F., Lu, Casey R., Belzer, Sharolyn J., \& Voss, Burton E. (1994). Research on the uses of Technology in Science Education In D. L. Gabel (Ed.), Research on Science Teaching and Learning (pp. 466-490). New York: Macmillan Publishing Company.

Blissett, Gillian \& Atkins, Madeleine (1993, July-Sept.). Are they thinking? Are they learning? A Study of the Use of Interactive Video. Computers and Education, 21(1-2), 31-39.

Bloom, B. S. (Ed.) (1956). Taxonomy of educational objectives. Handbook I: Cognitive Domain. New York: David McKay.

Blosser, P. E. (1981). A Critical Review of the Role of the Laboratory in Science Teaching. Columbus, Ohio: The Ohio State University. (ERIC Document Reproduction Service No. ED 206 445).

Bohren, Janet L. (1993). Science Learning and Interactive Videodisc Technology. (ERIC Document Reproduction Service No. ED 363 286).

Borror, Donald J. (1960). Dictionary of Word Roots and Combining Forms. Palo Alto, California: Mayfield Publishing Company.

Bosco, James (1986, May). An Analysis of Evaluations of Interactive Video. Educational Technology, 26, 7-17.

Bossert, S. (1977). Task, group management, and teacher control behavior: A study of classroom organization and teacher style. School Review, $\underline{85}$, 552-565. 
Bowers, Denis \& Tsai, Chia (1990, February). HyperCard in Educational Research: An Introduction and Case Study. Educational Technology, 19-24.

Branch, C. E., Ledford, B. R., Robertson, B. T., \& Robertson, L. (1987). The validation of interactive videodisc as an alternative to traditional teaching techniques: auscultation of the heart. Educational Technology, 27(3), 16-21

Bredehoft J., Dewart, S., \& Tindall, R. (1991). LXR・TEST ${ }^{\circledR}$ (Version 4.1.9) User's Guide for Professional and Scoring Editions. [Computer software manual]. Rancho Cucamonga, California: Logic eXtension Resources.

Bunderson, C. V., Baillio, B., \& Olsen, J. B. with Lipson, J. I. \& Fisher, K. M. (1984). Instructional effectiveness of an intelligent videodisc in biology. Machine-Mediated Learning, (2), 175-215.

Bunderson, C., Olsen, J., \& Baillio, B. (1981). Final Report: Proofof-concept demonstration and comparative evaluation of a prototype intelligent videodisc system. (ERIC Document Reproduction Service No. ED 228 989).

Campbell, D. T., \& Stanley, J. C. (1966). Experimental and quasiexperimental designs for research. Chicago, IL: Rand McNally.

Campbell, Neil A. (1993). Biology (3rd Ed.) (pp. 598-659).

Redwood City, California: The Benjamin/Cummings Publishing Company.

Carlson, H. L. (1991). Learning styles and program design in interactive multimedia. Educational Technology Research and Development, 39(3), 41-48. 
Carlson, H. L. \& Falk, D. R. (1989). Effective use of interactive videodisc instruction in understanding and implementing cooperative group learning with elementary pupils in social studies and social education. Theory and Research in Social Education, 17(3), 241-258.

Charney, D. (1989). Comprehending non-linear text: The role of discourse cues and reading strategies. Hypertext ' 87 proceedings. New York: Association for Computing Machinery.

Charp, Sylvia (1981). Effectiveness of Computers in Instruction. Viewpoints in Teaching and Learning, 57(2), 13-22.

Clark, R. E. (1983). Reconsidering Research on Learning from Media. Review of Educational Research, 53 (4), 445-459.

Clark, R. E. \& Sugrue, B. M. (1988). Research on instructional media, 1987-1988. In D. Ely (Ed.), Educational Media and Technology Yearbook (pp. 19-36). Englewood, CO: Libraries Unlimited.

Cronin, M. W. \& Cronin, K. A. (1992). A critical analysis of the theoretic foundation of interactive instruction. Journal of ComputerBased Instruction, 19(2), 37-41.

Cunningham, George K. (1986). Educational and Psychological Measurement. Macmillan Publishing Company, N.Y., New York.

Cushall, Harvey and Brovey (1987). Research on Learning from Interactive Videodiscs: A Review of the Literature and Suggestions for Future Research Activities, (pp. 4-9). (ERIC Document Reproduction Service No. ED 285 530).

Dade County School Board (1989). Biology Item Test Bank. [Computerized item test bank, readable by LXR TEST computer program]. 
Dade County School Board (1994, March). South Miami Senior High, Ten Year Faculty Self-Study 1993-1994, (pp. 3-5). Miami, FL: Southern Association of Colleges and Schools.

Dalton, D. W. (1986). The efficacy of computer-assisted video instruction on rule learning and attitudes. Journal of ComputerBased Instruction, 13, 122-125.

Dalton, David W., \& Hannafin, Michael J. (1987, Autumn). The Effects of Knowledge Versus Context-Based Design Strategies on Information and Application Learning from Interactive Video. Journal of Computer-Based Instruction, 14(4), 138-141.

Dalton, David W., Hannafin, Michael J., \& Hooper S. (1989). Effects of individual and cooperative computer-assisted instruction on student performance and attitudes. Educational Technology Research and Development, 37(2), 15-24.

Dawson, George (1991). ScienceVision: An Inquiry-Based Videodisc Science Curriculum. Florida State University (ERIC Document Reproduction Service No. ED 336 257).

Daynes, R., (1982, June). The Videodisc Interfacing Primer. Byte, $\underline{7}, 48-58$.

Dreshimer, C., \& Rasmussen, P. (1990). Seeing through chemistry. Computer multimedia package. Ann Arbor: Office of Instructional Technology, University of Michigan.

Dweck, C. S. (1986). Motivational processes affecting learning. American Psychologist, 41(10), 1040-1048. 
Evans, Alan D., (1986). Interactive Video Research: Past Studies and Directions for Future Research. International Journal of Instructional Media, 13(4), 241-248.

Fisher, George H. (1986). A Short Note on the Long History of

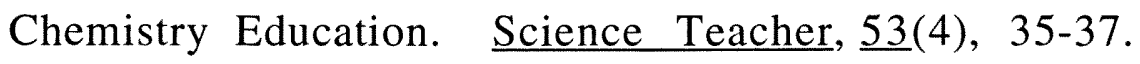

Fowler, H. Seymour (1977). Some Comments on the History of Science Education in the United States. In Robert L. Steiner (Ed.) Science Education: Past or Prologue. (pp. 81-103). Columbus, OH: Eric Clearinghouse for Science, Mathematics and Environmental Education. (ERIC Document Reproduction Service No. ED 150 019)

Friedlander, L. (1989). Moving images into the classroom: Multimedia in higher education. Laserdisk Professional, 2(4), 33-38.

Gay, Geraldine (1986). Interaction of Learner Control and Prior Understanding in Computer-Assisted Instruction. Journal of Educational Psychology, 78(3), 225-227.

Gay, L. R. (1996). Educational Research: competencies for analysis and application, 5th Ed. Columbus, OH: Charles E. Merrill.

Gayeski, D. M. (1993). Multimedia for learning. Englewood Cliffs, NJ: Educational Technology Publications.

Germann, Paul J. (1988). Development To The Attitude Toward Science In School Assessment And Its Use To Investigate The Relationship Between Science Achievement And Attitude Toward Science In School. Journal of Research in Science Teaching, 25(8), 689-703. 
Goldman, M. (1965). A comparison of individual and group performance for varying combinations of initial ability. Journal of Personality and Social Psychology, 1(3), 210-216.

Gomez-Rodriquez, Manuel (1989, November) Science and Mathematics Curriculum Reform Center of Puerto Rico (NSTA-SSC Project). Plan of Action. San Juan, P.R: University of Puerto Rico.

Good, H. G. (1956). A History of American Education. New York: The Macmillan Co.

Gray, R. A. (1989). HyperCard utilization in education:

Possibilities and challenges. Tech Trends, $\underline{34}$, 39-40.

Gronlund, Norman E. (1993). How to make Achievement Tests and Assessments, 5th Ed. New York, N. Y.: Allyn and Bacon.

Hallada, M. (1990). ChemTutor (Macintosh computer program). Ann Arbor, MI: University of Michigan.

Hannafin, Michael J., \& Colamaio, MaryAnne E. (1987, Winter). The Effects in Lesson Control and Practice on Learning from Interactive Video. Educational Communication and Technology Journal, $\underline{35}(4), 203-212$.

Hannafin, M. J., \& Hooper, S. R. (1993). Learning Principles. In M. Fleming and W. Levie (Eds.) Instructional Message Design; Principles for the Behavioral and Cognitive Sciences (pp. 191-231). Englewood Cliffs. NJ: Educational Technology Publications.

Hannafin, M. J., Phillips, T. L., \& Tripp, S. D. (1986). The effects of orienting, processing, and practicing activities on learning from interactive video. Journal of Computer Based Instruction, 13(4), 134139. 
Harcourt Brace Jovanovich (1992). HBJ Biology. Orlando, FL: Harcourt Brace Jovanovich, Inc.

Hazan, Charlene C. (1994). The Development of an Interactive Videodisc Program on Protein Synthesis. Columbus, OH: Eric Clearinghouse for Science, Mathematics and Environmental Education. (ERIC Document Reproduction Service No. ED 371 710).

Hegeson, Stanley L., \& Kumar, David D. (1993). Technological Applications in Science Assessment. Columbus, OH: Eric Clearinghouse for Science, Mathematics and Environmental Education. (ERIC Document Reproduction Service No. ED 361 207).

Hill, G. (1982). Group versus individual performance: Are N+1 heads better than one? Psychological Bulletin, 91, 517-539.

Hofstein, A. \& Yager, R. (1982). Societal Issues as Organizers for Science Education in the 80's. School Science and Mathematics, 82, 539-547.

Holmes, Ernest J. (1982, Winter) Teaching Biology in the Thirties. Journal of Biological Education, 16,(4), 242-246.

Hooper, S., \& Hannafin, M. J. (1988). Cooperative CBI: The effects of heterogeneous versus homogeneous grouping on the learning of progressively complex concepts. Journal of Educational Computing Research, 4(4), 413-424.

Hooper, S., \& Hannafin, M. J. (1991). The effects of group composition on achievement, interaction, and learning efficiency during computer-based cooperative instruction. Educational Technology Research and Development, 39(3), 27-40. 
Howson, Betty Ann and Davis, Hilarie (1992) Enhancing Comprehension with Videodiscs. Media and Methods, 28 (3), 12-14.

Hurd, Paul DeHart (1958). Science literacy: Its meaning for American Schools. Educational Leadership, 16, 13-16.

Hurd, Paul DeHart (1961). Biological Education in American Secondary Schools 1890-1960. Washington, D. C.: American Institute of Biological Sciences, Biological Sciences Curriculum Study, No. 1. (ERIC Document Reproduction Service No. ED 010 991).

HyperCard ${ }^{\mathrm{TM}}$ (Version 2.2) [Computer Software]. (1993). Cupertino, California: Apple Computer, Inc.

Johnson, David W., \& Johnson, Roger T. (1974). Instructional structure: Cooperative, competitive or individualistic. Review of Educational Research, 44, 213-240.

Johnson, David W., \& Johnson, Roger T. (1986). Computerassisted cooperative learning. Educational Technology, 26(2), 12-18.

Johnson, David W., \& Johnson, Roger T. (1989). Cooperation and competition: Theory and Research. Edina, MN: Interaction Book Company.

Johnson, David W., \& Johnson, Roger T.(1991). Classroom Instruction and Cooperative Learning. In Waxman, Hersholt C. \& Walberg, Herbert J. (Eds.), Effective Teaching: Current Research, pp. 277-293. Berkeley, CA: McCutchan Publishing Corporation.

Johnson, David W., Johnson, Roger T., \& Holubec, Edythe (1990). Circles of Learning. Edina, MN: Interaction Book Co.

Johnson, D. W., Maruyama, G., Johnson, R. T., Nelson, D., \& Skon, L. (1981). Effects of cooperative, competitive, and individualistic goal 
structures on achievement: A meta-analysis. Psychological Bulletin, $\underline{89}, 47-62$.

Johnson, D. W., Skon, L., \& Johnson, R. T. (1980). Effects of cooperative, competitive, and individualistic conditions on children's problem solving performance. American Educational Research Journal, 17(1), 83-93.

Johnson, Philip G. (1977). Some Revolutionary Changes in Science Education: 1850-1950 In Robert L. Steiner (Ed.), Science Education: Past or Prologue, (pp. 118-151). Columbus, OH: Eric Clearinghouse for Science, Mathematics and Environmental Education. (ERIC Document Reproduction Service No. ED 150 019)

Kahle, J. B. \& Meece, J. (1994). Research on Gender Issues in the Classroom. In D. L. Gabel (Ed.), Research on Science Teaching and Learning (pp. 542-557). New York: Macmillan Publishing Company.

Kinzie, M. B. \& Sullivan, H. J. (1989). Continuing motivation, learner control, and CAI. Educational Technology Research and Development, $\underline{37}(2), 5-14$.

Klein, M. Frances, (Ed.) (1991). The Politics of Curriculum Decision-Making: Issues in Centralizing the Curriculum. New York: SUNY Press.

Kliebard, Herbert M. (1987). The Struggle for the American Curriculum, 1893-1958. New York, NY: Routledge.

Kneedler, Peter E. (1993, February). California Adopts Multimedia Science Program. T. H. E. Journal, 73-76. 
Kritch, Kale M. (1995). Level of Interactivity of Videodisc Instruction on College Students' Recall of AIDS Information. Journal of Applied Behavioral Analysis, 28 (1), 85-86.

Kumagai, Jean (1990, October). NSTA's New Curriculum Integrates Science in Secondary Schools. Physics Today, 43, 87-89.

Lawson, Anton E. (1990, May). An Inquiry Approach to Nonmajors Biology. Journal of College Science Teaching, 19(6), 340346.

Leonard, William H. (1989). A Comparison of Student Reactions to Biology Instruction by Interactive Videodisc or Conventional Laboratory. Journal of Research in Science Teaching, 26 (2), 95-104.

Leonard, William H. (1992). A Comparison of Student Performance Following Instruction by Interactive Videodisc Versus Conventional Laboratory. Journal of Research in Science Teaching, $\underline{29}(1), 93-102$.

Lippincott, W. Thomas \& Bodner, George M. (1984, October) Chemical Education: Where We've Been; Where We Are; Where We're Going. Journal of Chemical Education, 61(10), 843-844.

Litchfield, Brenda C. (1993). Design Factors in Multimedia Environments: Research Findings and Implications for Instructional Design. Columbus, OH: Eric Clearinghouse for Science, Mathematics and Environmental Education. (ERIC Document Reproduction Service No. ED 363 268).

Lockheed, M. E., \& Hall, K. P. (1976). Conceptualizing sex as a status characteristic: Applications to leadership training strategies.

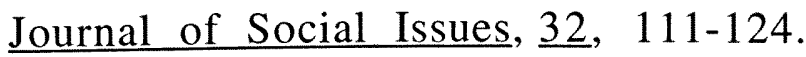


LXR・TEST ${ }^{\circledR}$ Version 4.1.9. [Computer Software]. (1990). Rancho Cucamonga, California: Logic eXtension Resources, Inc.

Marchionini, G. (1989). Information-seeking strategies of novices using a full-text electronic encyclopedia. Journal of American Society for Information Science, 40, 54-66.

Martorella, Peter (1989). Interactive Video and Instruction:

What Research Says to the Teacher. Columbus, OH: Eric Clearinghouse for Science, Mathematics and Environmental Education. (ERIC Document Reproduction Service No. ED 339 356).

Malouf, D. B., MacArthur, C. A., \& Radin, S. (1986). Using Interactive videotape-based instruction to teach on-the-job social skills to handicapped adolescents. Journal of Computer-Based Instruction, 13, 130-133.

McCarthy, Cameron (1990, June). Multicultural Education, Minority Identities, Textbooks, and the Challenge of Curriculum Reform. Boston University Journal of Education, 172(2), 23-27.

McCarthy, R. (1989). Multimedia: What the excitement is all about. Electronic Learning, $\underline{8}(8), 26-31$.

McNeil, B. J. \& Nelson, K. R. (1991). Meta-analysis of interactive video instruction: A 10 year review of achievement results. Journal of Computer-Based Instruction, 18(1), 1-6.

Michaels, J. (1977). Classroom reward structures and academic performance. Review of Educational Research, 47(1), 87-88.

Milheim, William D., \& Evans, Alan D. (1987, June). Using Interactive Video for Group Instruction. Educational Technology, 27, 35-37. 
Miller, L., \& Hamblin, R. (1963). Interdependence, differential rewarding, and productivity. American Sociology Review, 28, 768778.

Morais, Herbert M. (1970). The History of the Negro in Medicine. New York, NY: Publishers Company, Inc.

Mueller, Daniel J. (1986). Measuring social attitudes: A handbook for researchers and practitioners. New York, NY: Teachers College Press.

Muñoz, Sandra P. (1980, Spring). Reports: The Growth and Development of STS Education--Three Examples. Science, Technology $\underline{\text { \& Human Values, }} \underline{31}, 31-35$.

Noell, J. and Carmine, D. (1989). Group and individual computer-based video instruction. Educational Technology, 29(1), 36-37.

Olivas, Michael A. (1986). Latino College Students. New York, NY: Teachers College Press, Columbia University.

Reeves, Thomas C. (1992). Evaluating Interactive Multimedia. Educational Technology, $\underline{32}(5), 47-52$.

Renner, John W. (1988, January). The Necessity of Each Phase of the Learning Cycle in Teaching High School Physics. Journal of Research in Science Teaching, 25(1), 39-58.

Rennie, L. J., \& Parker, L. H. (1987). Detecting and Accounting for Gender Differences in Mixed-sex and Single-sex Groupings in

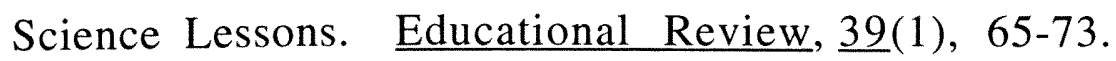

Savenye, W., \& Strand, E. (1989). Teaching Science Using Interactive Videodisc: Results of the Pilot Year Evaluation of the 
Texas Learning Technology Group Project. Dallas, TX: Association for Educational Communication and Technology. (ERIC Document Reproduction Service No. ED 308 838).

Scope Sequence \& Coordination Project Staff (1991, May 8). The Content Core, A Guide to Curriculum Designers. Washington, D.C.: National Science Teachers Association.

Sealey, Jean (1985). Curriculum Development Projects of the Sixties. Columbus, OH: Eric Clearinghouse for Science, Mathematics and Environmental Education. (ERIC Document Reproduction Service No. ED 272 378).

Schaffer, Lemuel C., \& Hannafin, Michael, J. (1986, Summer). The Effects of Progressive Interactivity on Learning from Interactive Video. Educational Communication and Technology Journal, 34(2), 89-96.

Schubert, William H. (1986). Curriculum: Perspective, Paradigm, and Possibility. New York, NY: Macmillan Publishing Company.

Sherwood, Robert D., Hasselbring, Ted S., \& Marsh, E. Jean (1990). An Evaluative Study of a Level One Videodisc Program. Columbus, OH: Eric Clearinghouse for Science, Mathematics and Environmental Education. (ERIC Document Reproduction Service No. ED 272 378).

Simsek, Ali (1992). The Impact of Cooperative Group Composition on Student Performance and Attitudes During Interactive Videodisc Instruction. Columbus, $\mathrm{OH}$ : Eric Clearinghouse 
for Science, Mathematics and Environmental Education. (ERIC Document Reproduction Service No. ED 320 772).

Simsek, Ali \& Hooper, Simon (1992). The Effects of Cooperative versus Individual Videodisc Learning on Student Performance and Attitudes. International Journal of Instructional Media, 19(3), 209218 .

Slavin, R. E. (1977). Classroom reward structure: An analytic and practical review. Review of Educational Research, 47, 633-650.

Slavin, R. E. (1990). Cooperative learning: Theory, research, and practice. Englewood Cliffs, NJ: Prentice-Hall.

Slavin, R. E. (1991). Synthesis of research on cooperative learning. Educational Leadership, 47(4), 52-54.

Slavin, R. E. (1992). When and Why Does Cooperative Learning Increase Achievement? Theoretical and Empirical Perspectives. In Rachel Hertz-Lazrowitz. \& Norman Miller (Eds.). Interaction in Cooperative Groups: The Theoretical Anatomy of Group Learning. Cambridge University Press.

Slee, Elisa (1989). A Review of the Research on Interactive Video. Columbus, OH: Eric Clearinghouse for Science, Mathematics and Environmental Education. (ERIC Document Reproduction Service No. ED 308 818).

Smith, Eric E. (1987). Interactive Video: An Examination of Use and Effectiveness. Journal of Instructional Development, 10(2), 2-10.

Smith, Michael K., \& Wilson, Charles (1993). Integration of student learning strategies via technology. Technology and Teacher Education Annual--1993. (pp. 283-285). Columbus, OH: Eric 
Clearinghouse for Science, Mathematics and Environmental Education. (ERIC Document Reproduction Service No. ED 355 937).

Strauss, Richard T., \& Kinzie, Mable B. (1994). Student Achievement and Attitudes in a Pilot Study Comparing Interactive Videodisc Simulation to Conventional Dissection. American Biology Teacher, $\underline{56}(7), \quad 398-402$.

SPSS ${ }^{\circledR}$ Graduate Pack ${ }^{\mathrm{TM}}$ Advanced Version for the Power Macintosh (Version 6.1.1). [Computer Software]. (1994). Chicago, IL.: SPSS Inc.

Swing, S. R., \& Peterson, P. L. (1982). The relationship of student ability and small group interaction to student achievement. American Educational Research Journal, 19(2), 259-274.

The Living Textbook ${ }^{\mathrm{TM}}$ : The Life Sciences (1986). [Laser videodisc]. Warren, New Jersey: Optical Data Corporation.

Ting, Selene, \& Walker, Tim (1993). The Living Textbook ${ }^{\mathrm{TM}}$ Video Cards $^{\mathrm{TM}}$ (version 3.0) [Computer software manual]. Warren, NJ: Optical Data Corporation.

Tobin, K., \& Dawson, G. (1992). Constraints to curriculum reform: Teachers and the myths of schooling. Educational Technology Research and Development, 40(1), 81-92.

Tobin, K. \& Garnett, P. (1987). Gender related differences in science activities. Science Education, 71, 91-103.

Yager, Robert E.(1982, September). The Crisis in Biology Education. American Biology Teacher, 44(66), 328-336.

VideoCards $^{\mathrm{TM}}$ (Version 3.0) [Computer program]. (1993). Warren, NJ: Optical Data Corporation. 
Ware, Sylvia A. (1988, February, 15). Chemistry in the Community. Chemical and Engineering News, 66(7), 42-52.

Webb, N. M. (1988). Peer interaction and learning with computers in small groups. Computers in Human Behavior, $\underline{3}$, 193209 .

Webb, N. M. (1984). Sex Differences in Interactions and Achievement in Cooperative Small Groups. Journal of Educational Psychology, 76 (1), 33-44.

Williamson, Stanley E. (1977). Science Education in the Twentieth Century. In Robert L. Steiner (Ed.), Science Education: Past or Prologue, (pp. 265-279). Columbus, OH: Eric Clearinghouse for Science, Mathematics and Environmental Education. (ERIC Document Reproduction Service No. ED 150 019)

Wilson, Victor L. (1983). A Meta-Analysis of the Relationship between Science Achievement and Science Attitude: Kindergarten through College. Journal of Research in Science Teaching, 20(9), 839850 .

Wollman, J. (1981, November/December). The Videodisc: A New Educational Technology Takes OFF. Electronic Learning, 1, 3840 . 


\section{APPENDICES}

\section{Appendix A \\ Computer and Software Tutorials}

Two computer programs, HyperCard ${ }^{\mathrm{TM}}$ and Video Cards ${ }^{\mathrm{TM}}$, were utilized to develop and present this multimedia lesson using Apple Macintosh computers. They are both described in this appendix. Similar programs exist for the DOS/Windows environment, namely Linkway $^{\mathrm{TM}}$ or SuperCard ${ }^{\mathrm{TM}}$ and the Windows version of Video Cards.

\section{A.01 HyperCard}

HyperCard is a unique information environment for the Apple Macintosh Operating Systems. It is used to look for and store information--text, complex databases, charts, diagrams, sounds, photographs, and movies. It works quite differently from most other programs in the sense that it works like a deck of cards (screen windows) containing information (text, charts, audio-visual) which can be connected to each other and to any other piece of information by the use of interconnecting buttons which can be easily created and placed within easy access for the user.

There are several major elements that the casual user of HyperCard has to be aquatinted with, they are cards, stacks and buttons. Cards are individual computer screen windows containing information provided by the designer; they may contain text and diagrams. A stack is a collection of cards, usually (but not 
necessarily) of similar design and based on the same theme.

Browsing is a term utilized for moving through cards and stacks, which can easily be performed by clicking buttons, which also allow connections to other programs and to audio-visual information.

HyperCard designers have control over a set of five user levels invisible to the untutored user. Each level adds powers to the abilities of the previous level. The five levels and their respective powers are as follows: (a) Browsing, where the user can only view existing cards and the information they contain, (b) Typing, where the user is allowed to enter and edit textual information on cards, (c) Painting, where the user is also allowed access to painting tools, (d) Authoring, where the users gains access to tools which allow for the creation of cards, stacks, buttons, and design their own working lessons, and (e) Scripting, which adds access to HyperTalk, the HyperCard program language that allows the user to write their own programs called scripts.

For use in this research study subjects in the whole-class traditional groups where shown lessons by the teacher using only the browsing level. Subjects in cooperative groups were allowed access by the HyperCard-based authoring program Video Cards at both the browsing and typing levels in order to allow them to type the reference number of the visuals which they select for their multimedia presentations. The researcher/designer used the authoring level in order to create the Five Kingdoms stack and link it to the Animal Kingdom stack. The Animal Kingdom stack was also created by the researcher as a copy of the HyperCard-based 
videodisc authoring program Video Cards which normally allows users to use only up to the typing level, which was all that was required in order to search for data about each visual and to import textual information about each phylum of the animal kingdom.

For further information concerning the use of the HyperCard and the authoring program Video Cards, refer to appendixes A.02 Video Cards, B.05 Field Biologist Handbook, C.01 Five Kingdoms HyperCard Stack, C.02 Animal Kingdom Presentation Stack, and C.03 Animal Kingdom Cooperative Group Stack.

\section{A.02 Video Cards}

This program, was produced by Optical Data Corporation for use with The Living Textbook ${ }^{\mathrm{TM}}$, an extensive collection of 20 science videodiscs for secondary schools. Video Cards allows for the user to incorporate Level 3 usage and to conduct data searches for visuals in the videodisc collection, as well as generate customized barcoded lessons. It is a HyperCard based program, which means that it was created as several interconnected HyperCard stacks with specialized ready-made laserdisc operational capabilities.

Following is a functional list of the major components of Video Cards program. Most of the features described were not utilized by the subjects during the course of the research study; they were used by the researcher in developing the multimedia unit, so are provided here as a guide for the teacher/researcher attempting to use the program to develop their own lessons utilizing this software. 
Key Video Cards components: (all stored in the folder named

\section{VC FOLDER)}

VideoCards ${ }^{\mathrm{TM}}$ : program controlling and coordinating all activities, both visible and behind-the-scenes.

VC Console Master: user interactive card, allowing videodisc control, data retrieval and design of presentations. A personalized stack of the console is created by the user for each lesson created. VC DATA (folder): contains a stack with data sets, which is the information for each visual event on a particular videodisc volume. The data is accessed by, and displayed on VC Console Workspace. VC TOURS (folder): a set of predesigned multimedia lessons particularly suitable for student browsing. Each tour corresponds to a different biological topic. Using tours, the student can display a sequential lesson on the TV monitor by pointing and clicking on objects in an illustrated background on the computer screen. VC FILES (folder): contains predesigned lesson text files that appear in the Lesson Guide binders provided with the videodiscs by Optical Data Corporation. These files can be imported into the Console, and customized to suite user needs as the basis for presentations.

\section{Video Cards Tutorial}

Following is a summary of the tutorial presented to both groups of subjects the day prior to the beginning of the research study.

Launching The Diversity of Life Lesson: 
(1) Turn on your Macintosh computer and double-click the only button that appears in your screen named 'Five Kingdoms of Life'. Turn on your videodisc player and color TV monitor.

(2) Double click the Video Cards icon to start the program. While waiting for introductory sequence, load videodisc into player with side 3 facing up, and close player drawer. When a different side of the disc was used, it was requested in the literature utilized by the subjects.

(3) A dialog box will appear with a list of videodisc player. Click Pioneer LD-V2200, then click OK.

(4) The computer program will now attempt to communicate with the videodisc player. Several status messages will appear on the screen, the final message indicating whether a data set for the videodisc volume is available. (Ask teacher for assistance in case of any negative messages!)

(5) When a dialog box appears, Click OK.

(6) \{First time users only! Otherwise skip this step and go to step 7\} If you are starting to design your lesson for the fist time, click New. You are now asked to type the name your lesson (Console). Click Save. Your lesson will now exist under the name you have given it. Always refer to it by this name.

(7) If you have previously created a lesson (Console) and wish to open it, click Existing. A dialog box appears asking you to locate the Console to open. Open your lesson by double-clicking the name of your lesson (Console).

Using Video Cards Console: 
(1) The lesson (Console) opens to a primary screen called the 'Workspace', with two scrolling windows: the 'Data window' (at the top) for viewing information retrieved from the data sets, and the 'Notes window' (at the bottom) for jotting notes, writing lessons and reports, and assembling visual sequences and presentations. Along the bottom of the Workspace is the 'Control Panel', a series of buttons used to control the videodisc player.

(2) The Data window open with a "welcome" message indicating two Help features: Screen Help and Overview Help. Use 'Screen Help' to review key features found on the Console screen; it works by displaying information as you point to different objects in the Console screen or Menus; it is turned "on" by pulling down VideoCards menu and choosing Screen Help, turned "off" by clicking the close box in upper left corner of screen. 'Overview Help' is a detailed tutorial with a variety of possible learning paths; it is turned "on" pull down the VideoCards menu and choose Overview Help and follow instructions; to turn it "off" click close box in upper left corner. Overview Help offers you three options: (1) Learning Path button offers introductory information about the entire Video Cards program; (2) Features button offers an alphabetical index about specific functions of the program; (3) Map button allows you to view a diagram introducing the Video Cards Console in action.

For further information concerning the use of the HyperCard and the authoring program Video Cards, refer to appendixes A.01 HyperCard, B.05 Field Biologist Handbook, C.01 Five Kingdoms 
HyperCard Stack, C.02 Animal Kingdom Presentation Stack, and C.03 Animal Kingdom Cooperative Group Stack. 


\section{Appendix B}

\section{$\underline{\text { Student Materials }}$}

Included in this appendix are 7 items that were distributed to every subject participating in this research study. The first five (B.01 to B.05) are pertinent to the biology unit on the Diversity of Animal Life. The 6th (B.06) is a set of instructions for the subjects participating in cooperative groups. The last one (B.07) is a parent permission form required by Dade County Public Schools for any research performed on their students.

\section{B.01 Animal Kingdom Taxonomic guide}

Following is the taxonomic information provided by the researcher to all the subjects. This information was utilized as a schematic guide to The Five Kingdoms of Life unit, as an introduction to taxonomic principles used in classifying the diversity of animal life. Its content and format is identical to that used by the subjects, except for 3 copyrighted diagrams from other sources which have been omitted and are only described. Notice that some of the information found in this guide is also found in the introductory 'Five Kingdoms' HyperCard stack (appendix C.01) which the subjects must go through each time they begin a lesson. Several test items were written from the information found in this guide, particularly in the sections that are also in common with the 'Five Kingdoms' stack. 


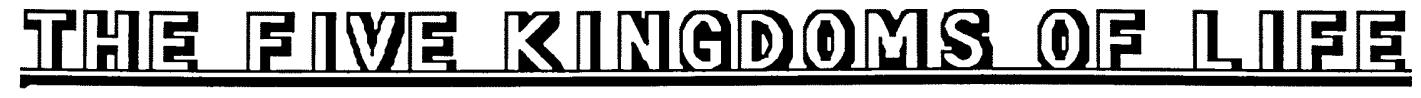

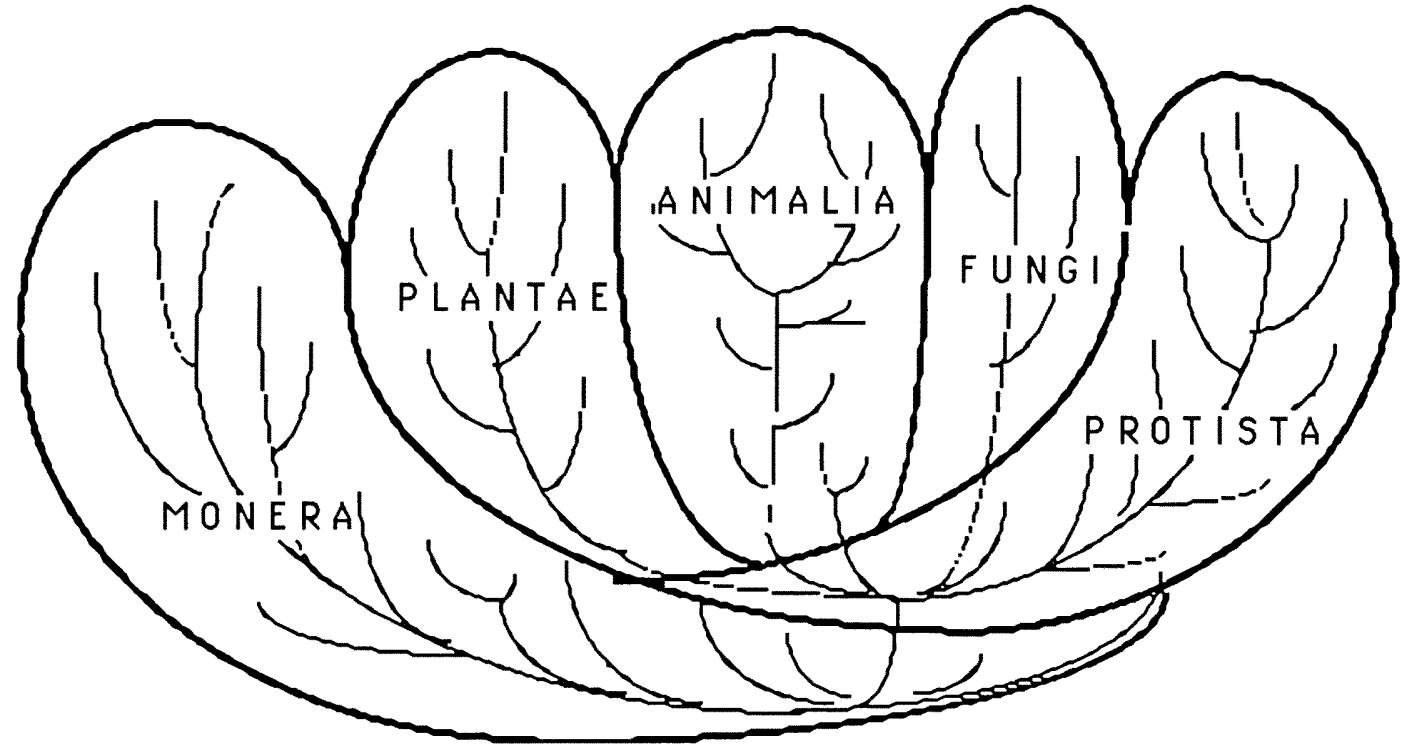

TAXONOMY: naming and classifying the diverse forms of life
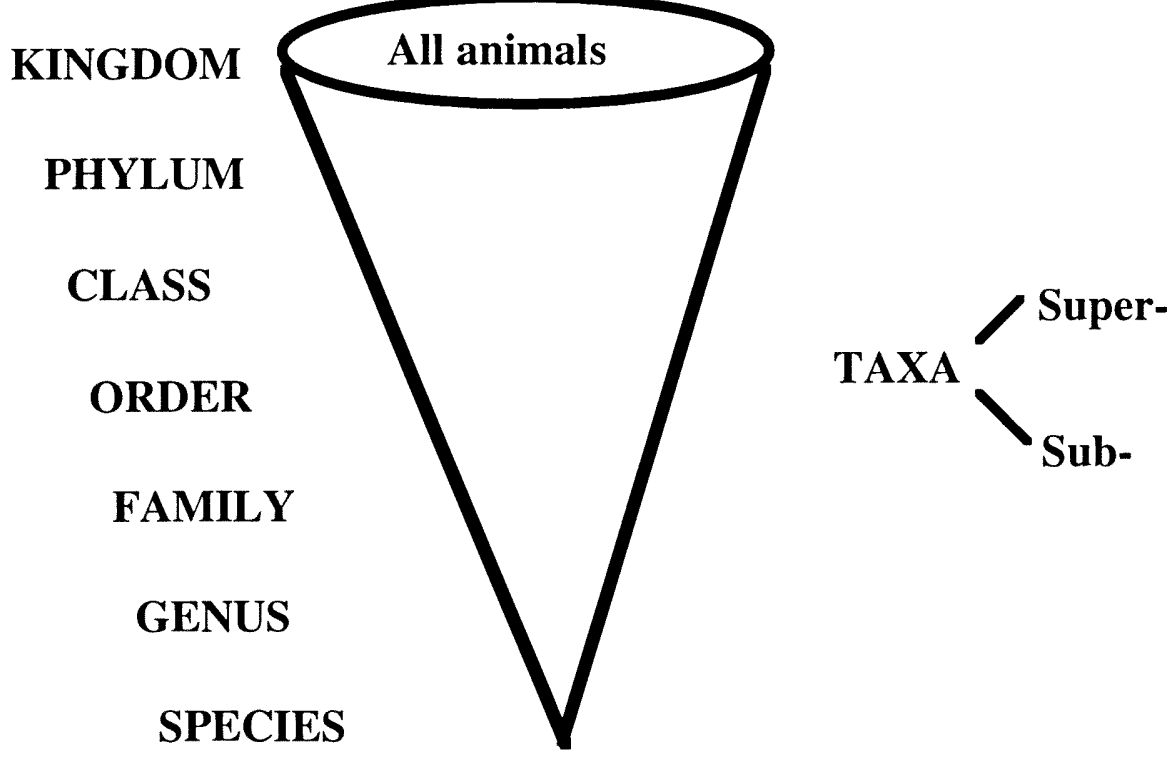

one

particular

type 
BINOMIAL NOMENCLATURE: system for naming species developed by Linnaeus, in the 18 th century, assigning to each species a two part Latin name, the first denoting the genus and the other the species. i.e., Felis leo, Felis lynx, Homo sapiens.

The goal of TAXONOMY: to group organisms according to similar anatomical structures (homologies), shared embryological development, and shared inheritance, in order to develop a "natural" classification system based on evolutionary history.

HOMOLOGY: similar anatomical structures based on shared descent. Not necessarily having the same functions.

Example: arm of human, foot of cat, fin of whale, wing of bat.

Diagram comparing the skeletal structure of forelimbs of 4 vertebrates: man, cat, whale, and bat. (From C. A. Vilee, Biology, 4th ed., W. B. Saunders Co., Philadelphia, 1962.)

ANALOGY: structures that carry out similar functions and have superficial resemblance, but are anatomically very different. Not based on shared descent, but evolving because of adaptation to similar environments.

Examples: wings of bird \& insect. 
PHYLOGENY \{G., phylon, tribe; genesis, origin \} the evolutionary history of a group of related species, based on taxonomic principles. Illustrated by a PHYLOGENETIC TREE

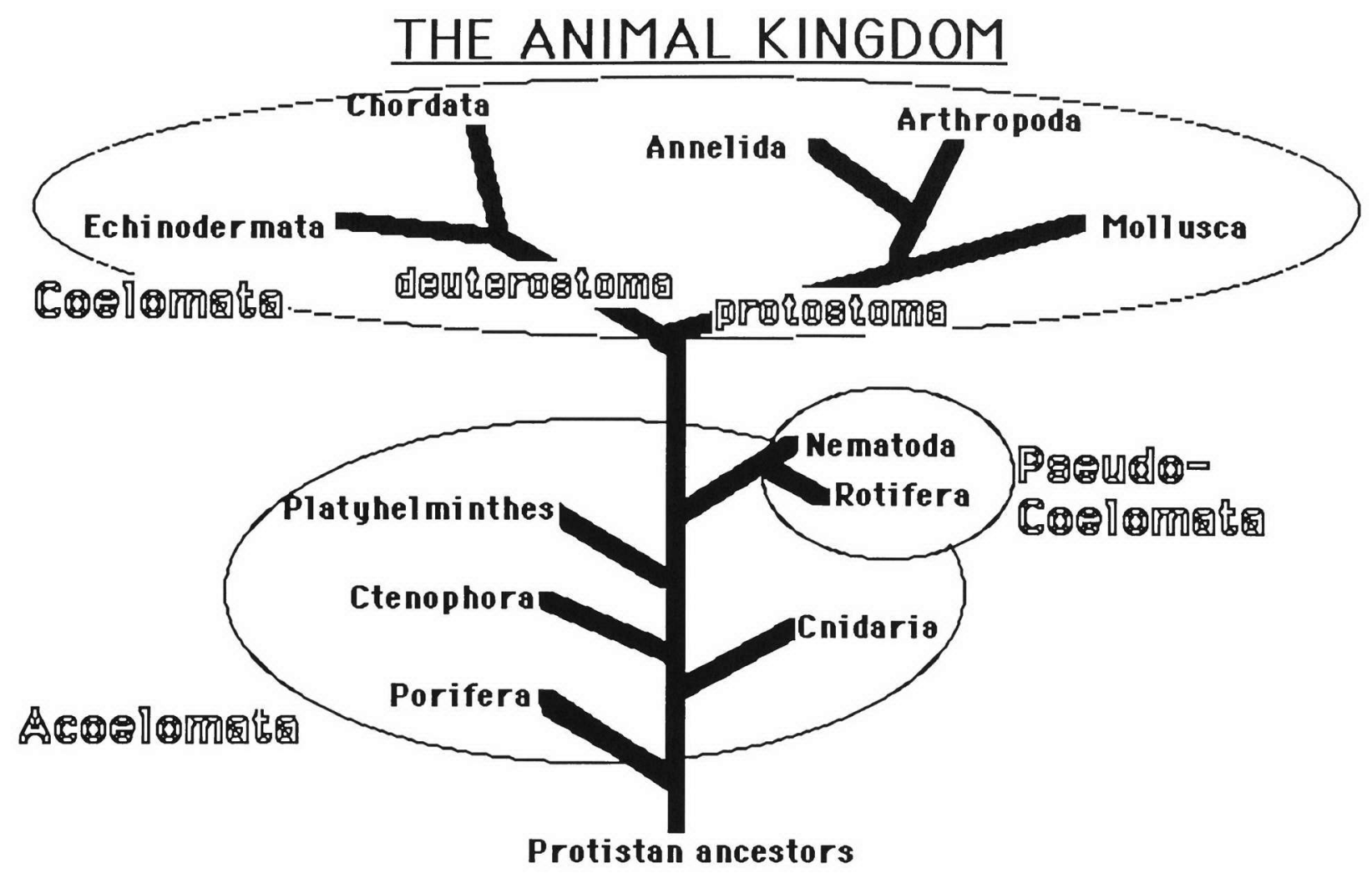




\section{CILLULAR CHABACTERISTICS}

\section{PROKARYOTES}

$\{\mathrm{G} .$, pro, before;

karyon, kernel or nucleus\}

\section{EUKARYOTES}

$\{\mathrm{G} ., e u$, true\}

Diagrams of typical prokaryotic and eukaryotic cells, based on electron microscopy, with parts labeled. (From L. Margulis and K. Schwartz, Five Kingdoms, 2nd ed., W. H. Freeman and Co., 1982.)

1. Smaller cells $(1-10 \mu \mathrm{m})$

2. One circular chromosome (haploid nucleoid)

3. No membrane-bound organelle

4. No sex cells (gametes)

5. Flagella of globular protein
1. Larger cells $(10-100 \mu \mathrm{m})$

2. Chromosomes in homologous pairs (diploid).

3. Membrane bound organelles: nucleus, mitochondria, chloroplasts

4. May reproduce sexually haploid (1n) gametes

5. Cilia and Flagella of microtubules (undulipodium: $9+2$ ) 


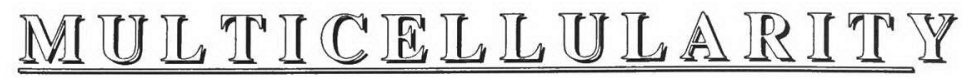

\section{CELL--> TISSUE--> ORGAN---> ORGAN SYSTEM---> ORGANISM}

\section{CELL (GERM) LAYERS:}

DIPLOBLASTIC: body composed of two cell layers

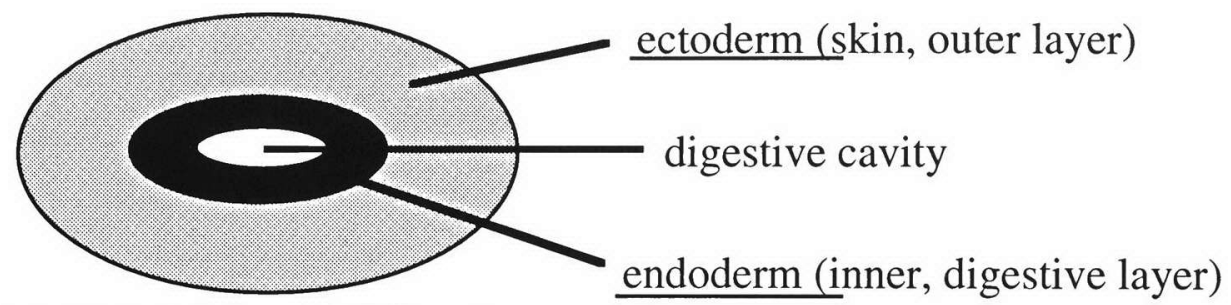

TRIPLOBLASTIC: three cell layers

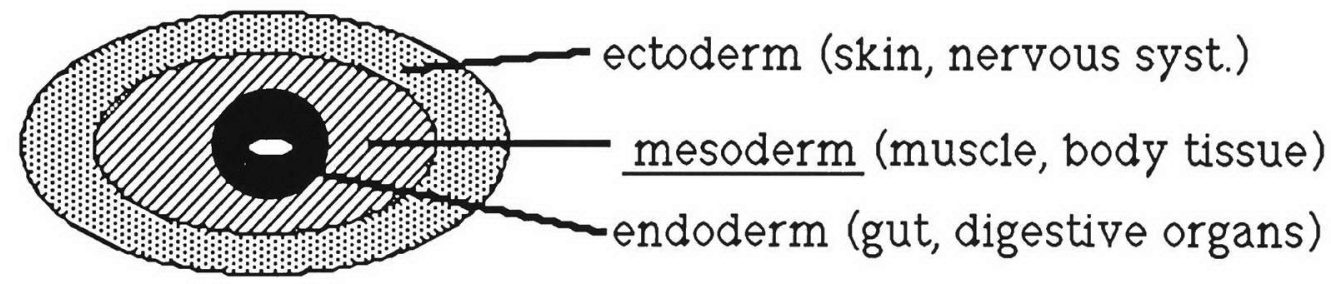

\section{DEVELOPMENT OF A BODY CAVITY (COELOM):}

ACOELOMATA: 1ack cavity between gut and outer body wall.

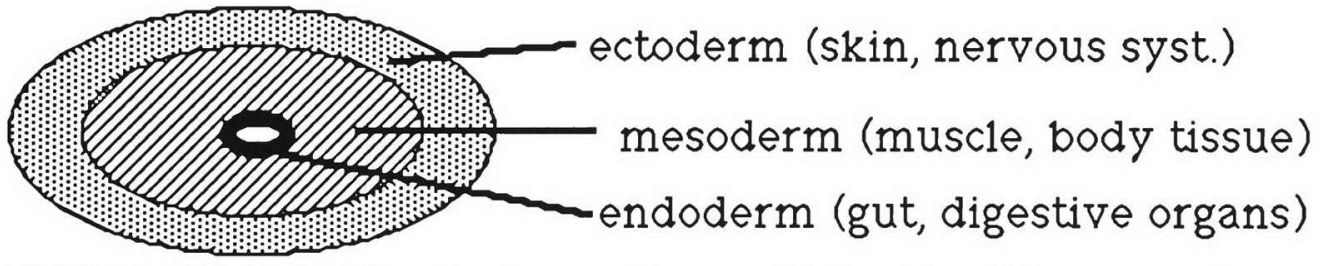

PSEUDOCOELOMATA: body cavity_partialy, lined by mesodermal tissue

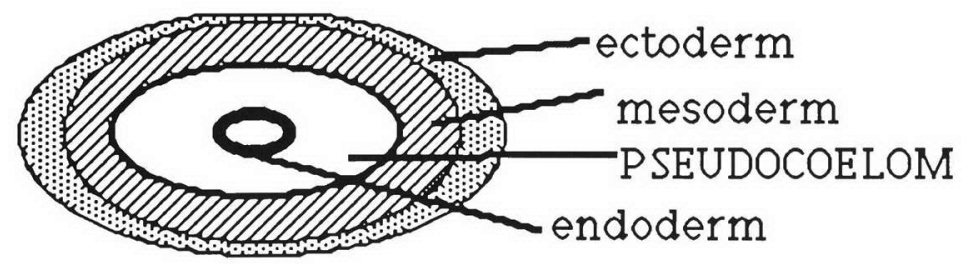

COELOMATA: have true coelom, a body cavity completely, lined by

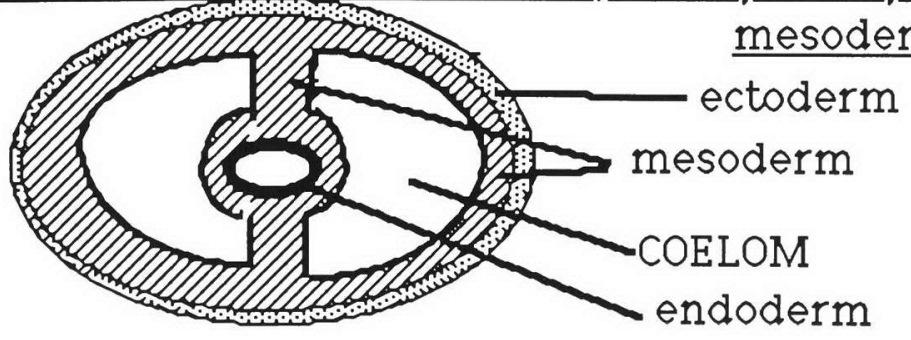




\section{NUTRIENT PROCURIMENT}

HETEROTROPHS: $\{$ G., hetero, other; troph, feed $\}$ organisms which must obtain their nutrients from others. Many of them oxidize the food they obtain by the process of cellular respiration, summarized in the following equation:

$$
\begin{array}{ccc}
\text { CARBO- } \\
\text { HYDRATE }
\end{array}
$$

AUTOTROPHS $\{\mathrm{G}$., auto, self; troph, feed $\}$ organisms capable of feeding themselves by producing their own nutrients from raw materials and light or chemical energy. Many produce their food by means of photosynthesis, summarized in the following equation:

$$
\begin{aligned}
& \text { CARBON } \\
& \text { DIOXIDE }
\end{aligned}+\text { WATER } \underset{\text { HYDRATE }}{\text { CARBO- }}+\text { OXYGEN }
$$

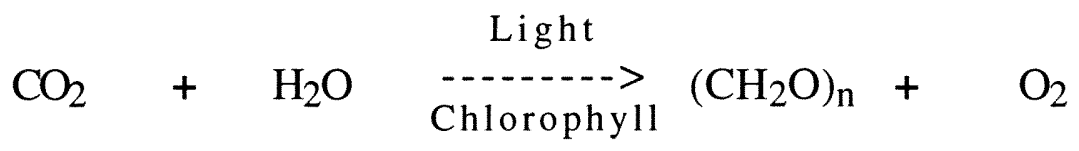

\section{FOOD CHAIN:}

$\begin{gathered}\text { PRODUCER } \\ (\text { Autotroph })\end{gathered} \cdots+\begin{aligned} & 1^{\circ} \text { CONSUMER } \\ & (\text { Herbivore })\end{aligned} \cdots+\begin{gathered}2^{\circ} \text { CONSUMER } \\ \left(1^{\circ} \text { Carnivore }\right)\end{gathered} \cdots+\begin{array}{r}3^{\circ} \text { CONSUMER } \\ \left(2^{\circ} \text { Carnivore }\right)\end{array}$




\section{RIPIODUCIION}

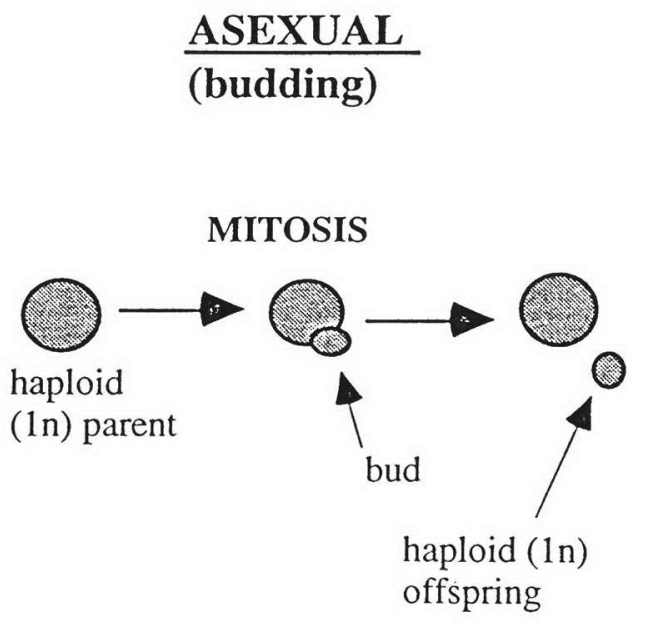

VS.

SEXUAL

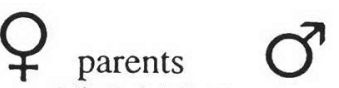

(diploid 2n)

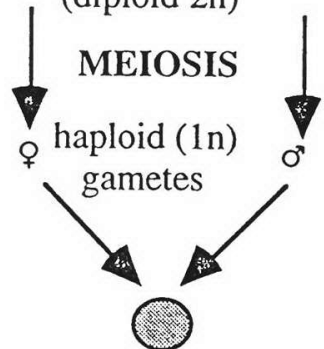

diploid (2n)

offspring

ASEXUAL: reproduction from one parent only, the offspring having the exact same hereditary information as the parent (CLONE).

SEXUAL: reproduction from two parents, each contributing half the hereditary information.

GAMETES: sex cells (sperms and eggs); have only half the hereditary material of the parent.

HAPLOID: organism having one complete set (1n) of hereditary material; common in asexual organisms and in gametes.

DIPLOID: organism having two complete sets $(2 n)$ of hereditary material

MITOSIS: process by which cells reproduce by making and exact copy of their hereditary material.

MEIOSIS: process by which cells reproduce by dividing their hereditary material in half. $\{$ From diploid $(2 \mathrm{n})$ to haploid( $(\mathrm{n})\}$. 


\section{ANIMAL DIETLOPMIRT}

\section{EMBRYONIC DEVELOPMENT IN PROTOSTOMA}

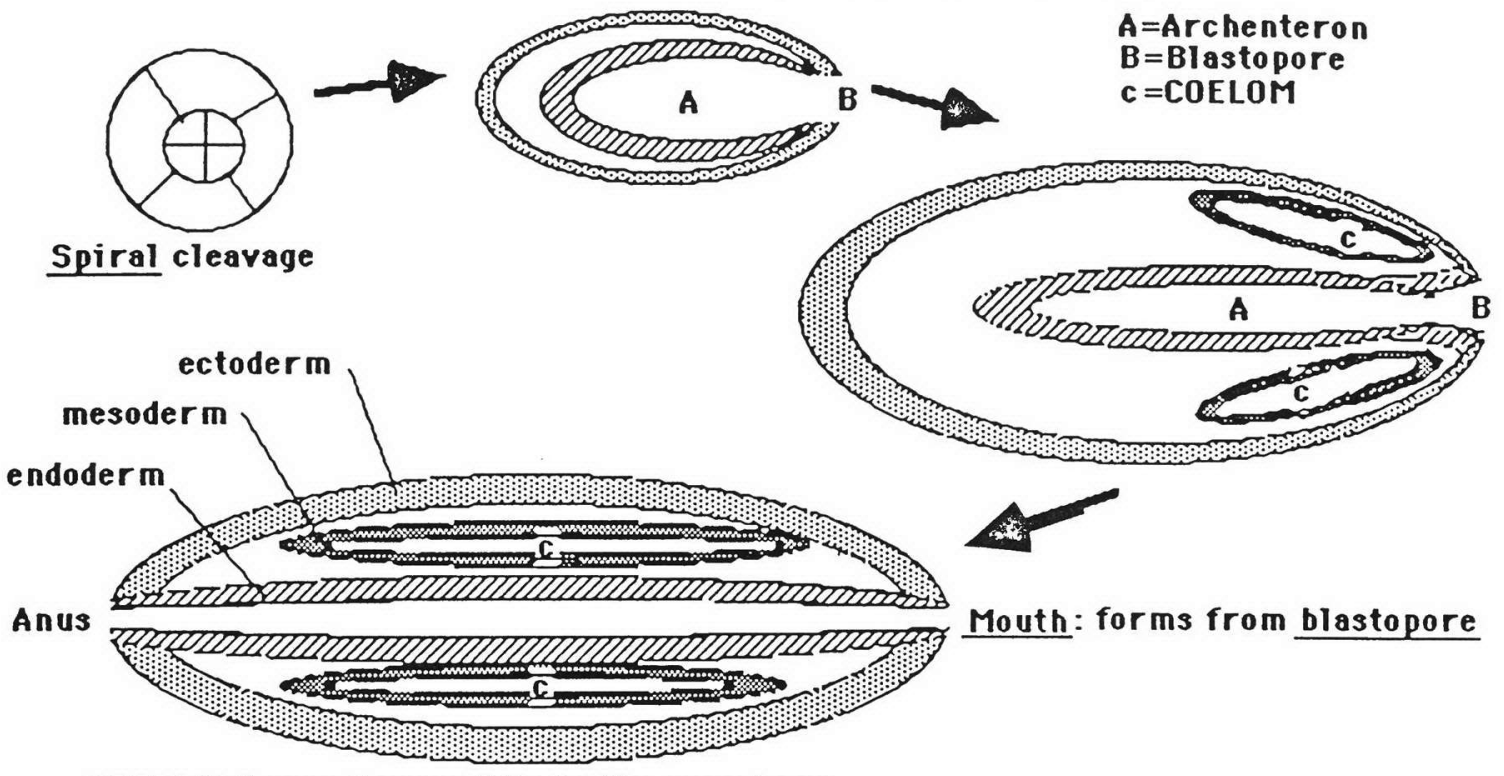

COELOM forms from splits in the mesoderm

EMBRYONIC DEVELOPMENT IN DEUTEROSTOMA

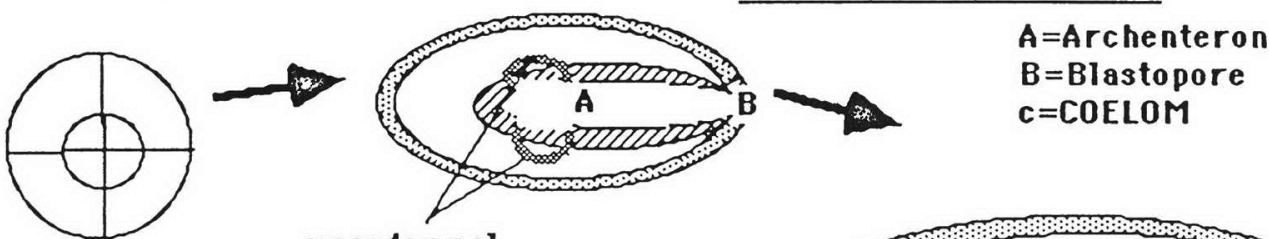

Radial cleavage mesodermal

out pockets

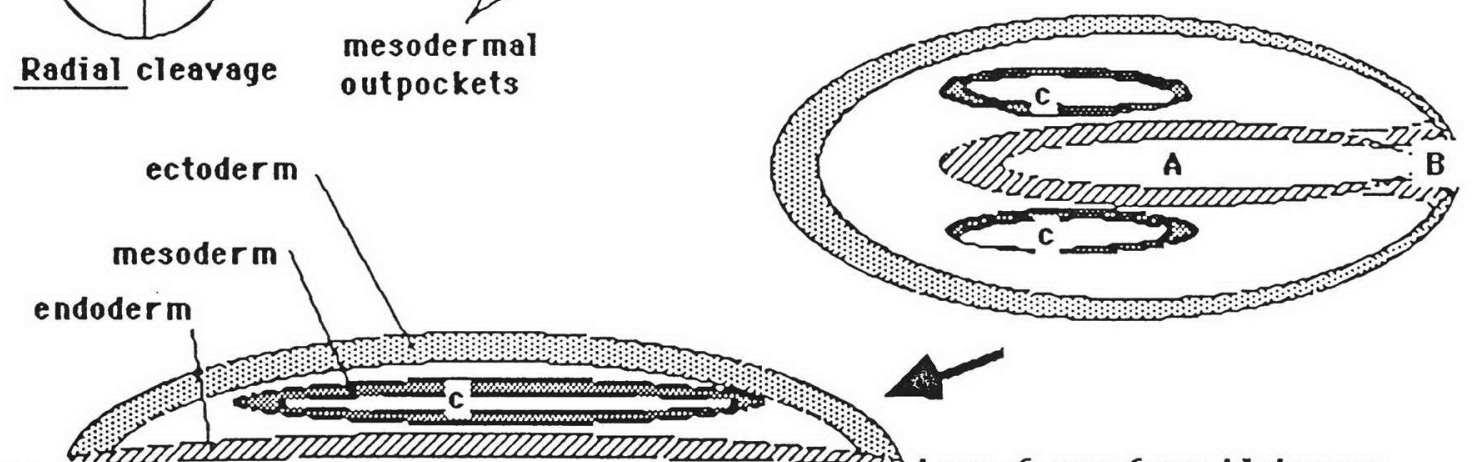

Mouth

Anus: forms from blatopore 


\section{BODY PLANS}

AS YMMETRY: lacking similarity of form on either side of a dividing line or plane (lack of balance in body structure).

SYMMETRY : similarity of form on either side of a dividing line or plane (balance in body structure)

(1) RADIAL: appears circular when viewed from above or below; structures radiate from outward in all directions from the center.

(2) BILATERAL: right and left sides are mirror images.

RADIAL

BILATERAL

Diagrams of a hydra and a crayfish, comparing radial and bilateral symmetry. (From N. A. Campbell, Biology, 3th ed., The Benjamin/Cummings Publishing Co. Inc., Redwood City, California, 1993.)

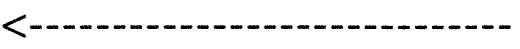

CEPHALIZATION

\{G., cephalo, head $\}$

development of a head with highly specialized sensory organs. 


\section{B.02 Animal Kingdom Taxonomic Guide}

In this section is the classificational information about the animal kingdom given to every subject participating in the research study. There are several differences on how the two groups used this information, but the goal was for the two groups was the same-to learn it. The traditional whole-class group was given lectures where this information was paraphrased by the teacher at the same time the visuals form the laserdiscs were shown. Subjects were encouraged to discuss the material in class by high level questions asked by the teacher (from appendix B.03), and additional relevant terminology (appendix B.04) and information from the 'Field Biologist Handbook' (appendix B.05) was also presented. Note that subjects in the traditional group were being presented by means of TVdisplayed information from the computer screen which was identical to that found in this guide (see Appendix C.02, Animal Kingdom Presentation Stack).

The cooperative groups also received the same written information given to the traditional whole-class group; they were not, however, given the same lectures and discussions. Instead each member of the cooperative group was given a task to perform which took the place of most of the functions of the presenter. The teacher, instead of presenting went around coaching the 8 separate cooperative groups, making sure they were all on tasks and providing general the guidance, whether technical, biological, social, strategic, or whatever was required to keep subjects learning as a cohesive group. Note that subjects in these cooperative groups were 
working from a computer screen containing information identical to that found in this guide (see Appendix C.03, Animal Kingdom Cooperative Group Stack).

Many questions written for the comprehensive achievement test also came from the information found in this Animal Kingdom Taxonomic Guide, particularly for items which were also represented visually in the laserdisc. 


\section{IRINGDOMI

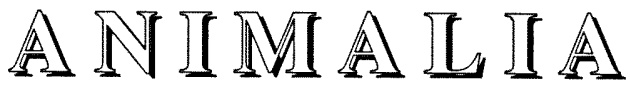

$\{$ L., anima, breath, soul $\}$

\section{CHARACTERISTICS:}

(1) MULTICELLULAR \{L., multi, many; cell, a small room\}

(2) HETEROTROPHIC \{G., hetero, other, different; trophi, nourish, food O Organisms that nourish themselves from eating others, as opposed to those that nourish themselves by producing their own food, such as plants (autotrophs).

(3) DIPLOID, DEVELOPING FROM TWO DIFFERENT HAPLOID GAMETES: contain two sets of the hereditary material (DNA), each set obtained from a different haploid (one set of DNA) gametes (sperm \& egg) from each of the parents. (Some primitive forms also have an asexual phase in their life cycle). 
PHYLUM 1: PORIFERA \{L., porus, pore; ferre, to bear\}

Sponges are immobile (sessile) animals whose sac-like bodies are perforated by elongated donut-shaped cells (POROCYTES). They draw water through their pores into a central cavity (SPONGOCOEL) and then out through a larger opening (OSCULUM). This current is propelled by flagellated cells lining the spongocoel. Sponges are filter-feeders, collecting food particles from the water circulated through their porous body.

Their bodies are composed of two cell layers (DIPLOBLASTIC): (1) an outer, protective EPIDERMIS, and (2) an inner layer of collar cells (CHOANOCYTES) that ingest food by PHAGOCYTOSIS and whose whiplike FLAGELLA cause water currents to circulate through its body. A gelatinous layer (MESOGLEA) between the cell layers contain specialized cells (AMOEBOCYTES) which move to obtain food from the collar cells and transport nutrients to the epidermis.

Amoebocytes also excrete tough fibers (SPICULES) within the mesoglea, to make up the 'skeleton' of sponges.

Three main classes are categorized by type of spicules:

(1) CALCAREA: spicules composed of the mineral calcite (calcium carbonate, $\mathrm{CaCO}_{3}$ ).

(2) HEXACTINELLIDA: six-rayed spicules composed of silicon oxides (glass).

(3) DEMOSPONGIAE: spicules composed of spongin (a flexible protein).

Broken or maimed sponges show remarkable powers of REGENERATION, not only to replace lost parts, but also to reproduce asexually from fragments; some species also reproduce asexually by means of small spherical structures (GEMMULES) that disperse and grow to form new sponges.

Most sponges are HERMAPHRODITIC, meaning that each individual sponge sexually function as both a male and a female, thus producing both eggs and sperms. Eggs are retained in the mesoglea and sperms are released into spongocoel and out the osculum. Fertilization occurs in the mesoglea where zygotes develop into flagellated larvae which leave the parent to settle in suitable environments, undergo metamorphosis and begin their sessile adult existence. 
Several species of sponges live in association with organisms from other groups (SYMBIOSIS), such as various species of algae and even shrimp.

Because of their stationary filter-feeding characteristics, sponges can be confused with corals and tunicates.

\section{PHYLUM 2: CNIDARIA (COELENTERATA)}

\{G., knide, nettle; koilos, hollow; enteron, intestines\}

Animals whose bodies consist of two cell layers (EPIDERMIS \& GASTRODERMIS) with a gelatinous MESOGLEA containing loose cell between them; these layers are folded into a sac with a central digestive compartment (GASTROVASCULAR CAVITY or COELENTERON) and have stinging tentacles which surround a single opening that functions as both a mouth and anus. The tentacles have specialized stinging cells (CNIDOCYTES), with poison-filled barbed threads (NEMATOCYSTS) used to immobilize their prey. Cells lining the gastrovascular cavity secrete enzymes into the cavity where partial extracellular digestion of food particles begins; digestion continues inside these same cells after engulfing the food (phagocytosis).

Cnidarians are RADIALLY SYMMETRICAL and have two general body forms: POLYP (anchored) and MEDUSA (free-swimming); some exist only as one form, others pass through both forms at different stages of their life cycle (ALTERNATION OF GENERATIONS). The medusa exists in male and female forms (reproduce sexually), while the polyps reproduce asexually by producing POLYP BUDS. Their body shape is maintained by HYDROSTATIC PRESSURE. Within the mesoglea they have contractile fibers of primitive muscle and a nerve net to coordinate their slow movement.

Several species of cnidarians engage in symbiotic associations; many species are COLONIAL.

Four major classes:

(1) HYDROZOA: freshwater hydras, colonial hydroids and fire corals. They reproduce asexually by producing polyp buds which are miniature, but genetically identical versions of their parents (CLONES); also reproduce sexually in the free-swimming medusa (most alternate between polyp and medusa forms during their life cycle--while in medusa stage, they resemble the true jellyfish) 
(2): true jellyfish (medusa form prevail)

(3) ANTHOZOA: sea fans, most corals, sea anemones (occur only as polyps); hard corals secrete calcareous $\left(\mathrm{CaCO}_{3}\right)$ exoskeletons.

(4) CUBOZOA: sea wasps and several other tropical and subtropical genera with cube-shaped medusa; several are lethal to humans.

\section{PHYLUM 3: CTENOPHORA \{G., kteis, comb; pherein,}

to bear\}

The comb jellies are transparent planktonic marine animals named for their eight rows--the combs--of heavily ciliated cells running along the length of its body that it uses for locomotion; they range in size from 1 to $10 \mathrm{~cm}$, making them the largest animals to use cilia for locomotion. Superficially they resemble cnidarian medusae; most have two retractable tentacles which are coated with a sticky substance and are capable of spiraling around prey; their digestive cavities are more complex than those of cnidarians, exhibiting more specialized functions such as enzyme secretion and the distribution of digested nutrients along a canal system that runs between the two cell layers that make up their bodies (diploblastic).

\section{PHYLUM 4: PLATYHELMINTHES \{G., platys, flat;} helmis, worm \}

The soft-bodied flat worms have BILATERAL SYMMETRY. Three germ layers (TRIPLOBLASTIC) with a mesoderm developing into true muscle tissue, but lacking a coelomic cavity (acoelomata). They have nerve cords running the length of their bodies with larger GANGLIA in the head region (CEPHALIZATION) and posses an incomplete digestive system that has on only one opening.

Three major classes:

(1) TUBELLARIA: include free-living (nonparasitic) planarians. Capable of reproducing asexually by regeneration, constricting in the middle and splitting in half; sexually by copulating, even though they are all hermaphroditic.

(2) TREMATODA: Flukes live as parasites within the bodies of other animals; they have suckers for attachment to their host, and a tough protective ectoderm. Most have complicated life cycles involving one or two hosts before reaching their final host (i.e., eggs from human feces--> snail--> fish--> humans). 
(3) CESTODA: Tapeworms are intestinal parasites on many vertebrates, including humans, which acquire it from ingesting contaminated beef. They are highly specialized to a parasitic way of life: lack digestive enzymes and organs, absorbing through their skins, food predigested by their host. Their head (SCOLEX) is armed with suckers \& hooks for attachment, followed by a long ribbon-like body composed of many reproductive units (PROGLOTTIDS).

\section{PHYLUM 5: ROTIFERA \{L., rota, wheel; ferre, to bear\}}

Mostly tiny fresh water animals having a complete digestive system (two openings). Have a crown of cilia ('wheel') that draws water into their mouths and a jaw-like organ that grinds ingested microorganisms. Their fluid-filled pseudocoelomate cavities helps in transporting nutrients throughout their bodies. Many reproduce PARTHENOGENICALLY: unfertilized eggs develop into adults (virgin births).

\section{PHYLUM 6: NEMATODA \{G., nema, thread\}}

Roundworms have cylindrical bodies with tapered ends and are covered with a tough transparent CUTICLE; they also have a fluidfilled pseudocoelom with longitudinal muscles allowing for whipping motion. Their digestive systems are complete and many are parasitic. Many free-living species live in the soil and play an important role in decomposition \& nutrient cycling. Reproduction usually sexual, sexes are separate.

Examples:

ASCARIS: eggs in food \& water --> ingested they pass through intestines \& lungs of pig, horse, human--> eggs excreted in feces. HOOK-WORMS: enter host through skin (feet) --> feed off blood in intestines.

TRICHINELLA: cysts in contaminated meat (pork) --> human intestines and muscles (cysts).

FILARIAL WORMS: passed to humans by mosquitoes; clog lymph vessels and may cause ELEPHANTIASIS, a severe inflammation and swelling of extremities. 


\section{PHYLUM 7: MOLLUSCA \{L., molluscus, soft\}}

Soft-bodied animals, often enclosed within hard calcareous $\left(\mathrm{CaCO}_{3}\right)$ EXOSKELETONS. Their coelomate (true cavity) bodies have three main parts: a muscular FOOT, a VISCERAL MASS containing most of the internal organs, and a MANTLE, a heavy fold of tissue covering the VISCERA and often excreting a hard shell. Many have strap-like rasping organ (RADULA) to scrape up food. Aquatic forms have gills extruding from the mantle; in terrestrial forms the vascularized mantle cavity exchanges gases with air.

All reproduce sexually and have separate sexes, except for some that are hermaphroditic. Fertilized eggs develop into a freeswimming trochophore larvae with a row of cilia encircling the body; in some classes these larvae develop into a second free-swimming stage, the veliger larvae which develops a ciliated velum; larvae eventually develop into familiar adults.

Four major classes:

(1) POLYPLACOPHORA (AMPHINEURA): Chitons are marine, eightplate shelled mollusks that inhabit rocky shores, ingesting algae with its radula.

(2) PELECYPODA (BIVALVIA): flattened shell with two valves; use muscular foot or flapping shells for locomotion. No radula; are SUSPENSION FEEDERS--siphon food particles with water. Some are hermaphroditic. Examples: scallops, have eyes in mantle \& move by flapping its shells; mussels, attached by means of byssal threads; clams \& oysters, use muscular foot for locomotion.

(3) GASTROPODA: most have bodies within coiled shells; are the invertebrates that have most successfully invaded land. Many are hermaphroditic. Examples: snails \& limpets, slugs \& sea slugs (nudibranch), sea butterfly (pteropods).

(4) CEPHALOPODA: head surrounded by prehensile tentacles; fast propulsion using siphon made from mantle. Are carnivorous predators that bite and inject poison into their prey. Have well developed nervous systems \& sense organs (eyes). Examples: squid, octopus, cuttlefish, nautilus.

\section{PHYLUM 8: ANNELIDA \{L., anellus, little ring\}}

Worms having segmented bodies with well developed and highly specialized organ systems. Their coelom is partitioned into segments 
of the body by a SEPTA, but their digestive, circulatory, and nervous systems run the length of the animal. Each segment has a pair of excretory NEPHRIDIA, and their highly vascularized and moist skin is used as the respiratory organ.

Three classes:

(1) OLIGOCHAETA: earthworms and various aquatic species.

(2) POLYCHAETA: each segment has pair of PARAPODIA, used for locomotion and gas exchange. Mostly marine, many build tube they inhabit. Examples: clam worms, tube worms, bristle worms, fan worms.

(3) HIRUDINEA: leeches. Most feed on small invertebrates. Some use either jaws or enzymes to perforate skin of vertebrate hosts and secrete an anesthetic (painkiller) and anticoagulant (to keep blood from clotting) until it sucks up to ten times its weight in blood.

\section{PHYLUM 9: ARTHROPODA $\{$ G., arthron, joint; pous,} foot $\}$

Animals whose bodies are enclosed in a tough, jointed EXOSKELETONS made from layers of protein and CHITIN (a polysaccharides); in order to grow they must shed their old exoskeletons and secrete a larger one (MOLTING). They have extremely well developed sense organs, including a COMPOUND EYE composed of many independent visual units; an open circulatory system, not confined to blood vessels; a wide variety of different organs for gas exchange (trachea \& book lungs); some have unique excretory structures known as MALPIGHIAN TUBULES, which remove wastes from the blood into the digestive tract. Their body segments have become specialized for a wide variety of functions and are often fused into functional assemblies: head, thorax (were legs are attached) and abdomen; head and thorax are sometimes fused into a CEPHALOTHORAX.

Considered the most successful phylum because they comprise $2 / 3$ of all living organisms and are represented in nearly all habitats of the biosphere.

(1) CRUSTACEA Mostly aquatic, with heavy exoskeleton (chitin impregnated with $\mathrm{CaCO}_{3}$ ). Have many appendages (legs, mouth parts) and two pairs of antennae. Small crustaceans diffuse gases across thin areas of cuticle, but larger forms have gills. 
DECAPODS: Lobsters, crayfish, crabs, shrimp.

ISOPODS: Mostly small marine.

COPEPODS: Mostly small, marine, and extremely numerous (PLANKTONIC).

BARNACLES: sessile, shelled, use appendages to capture plankton.

(2) ARACHNIDA Have four pairs (8) of walking legs; many have simple eyes (single lens); breathe by means of BOOK LUNGS; they excrete digestive juices; lack antennae, have simple eyes (single lens). Many string webs of silk from a protein excreted by abdominal glands.

Examples: horse-shoe crabs, scorpions, spiders, mites and ticks.

(3) DIPLOPODA (MILLIPEDES): HERBIVOROUS worm-like animals whose segmented bodies have two pairs of legs per segment.

(4) CHILOPODA (CENTIPEDES): CARNIVOROUS worm-like animals whose segmented bodies have one pair of legs per segment. Have poisonous bite.

(5) HEXAPODA (INSECTA): Have three pairs (6) of walking legs and one or two pairs of wings on thorax, one pair of antennae and compound eyes. Their bodies are segmented into : HEAD, THORAX and ABDOMEN (in some, head \& thorax are fused into a cephalothorax). Excretion of wastes by unique MALPIGHIAN TUBULES which are outpocketings of the gut. Gas exchange by a TRACHEAL SYSTEM of branched, chitin-lined tubes that infiltrate the entire body and are open to the outside through SPIRACLES. Capable of complex innate individual and social behavior. Their molting growth may be accompanied by developmental changes known as METAMORPHOSIS. Two types of metamorphosis: (1) INCOMPLETE (also GRADUAL): EGG --> NYMPH (INSTARS) --> ADULT, a series of molts each gradually looking more like an adult, and (2) COMPLETE: EGG --> LARVA --> PUPA --> ADULT, each morphologically and functionally different.

Are the most numerous and diverse of all organisms in land and air.

Classified into 26 orders; some examples:

THYSANURA: silverfish.

THYSANOPTERA: thrip.

ODONATA: dragonflies, damselflies.

ORTHOPTERA: locus, grasshoppers, katids, walking sticks, roaches, mantids.

ISOPTERA: termites.

MALLOPHAGA: lice. 
HEMIPTERA: true bugs; bedbug, chinch bug.

HOMOPTERA: treehoppers, cicada.

COLEOPTERA: beetles, weevils.

LEPIDOPTERA: moths, butterflies.

DIPTERA: flies, mosquitoes.

SIPHONAPTERA: fleas.

HYMENOPTERA: ants, bees, wasps.

TRICHOPTERA: caddis flies.

\section{PHYLUM 10: ECHINODERMATA \{G., echino,} spiny; derma, skin \}

Marine animals with calcareous (hard), spiny coverings. Radially symmetrical adults, often with five spokes, develop by metamorphosis from bilateral larvae. Locomotion by TUBE FEET, whose movements are regulated by their unique WATER-VASCULAR SYSTEMS, a network of hydraulic canals whose function also includes feeding \& gas exchange. Sexual reproduction is external, from two separate sexes; one species of sea stars can regenerate entire body from a single spoke (arm).

Six classes:

(1) ASTEROIDEA: sea stars

(2) OPHIUROIDEA: brittle stars

(3) ECHINOIDEA: sea urchins \& sand dollars

(4) CRINOIDEA: sea lilies

(5) HOLOTHUROIDEA: sea cucumbers

(6) CONCENTRICYCLOIDEA: sea daisies

\section{PHYLUM 11: CHORDATA \{L., chorda, cord}

Animals defined by the presence of three distinct features: (1) a NOTOCHORD, flexible rod composed of fibrous tissue extending through most of the length of the animal (replaced by vertebral column in vertebrates), (2) a NERVE CHORD, located DORSAL to the notochord (develops into brain and spinal chord), (3) PHARYNGEAL GILL SLITS in their throat (PHARYNX) at some stage of their life cycle, and (4) a muscular postanal tail. Most chordates develop extra cartilaginous or bony endoskeletons. 
CLASS UROCHORDATA (TUNICATA): mostly large, sessile (except larvae stage), suspension-feeding marine animals, cloaked in tunic of cellulose-like carbohydrate; some are small and planktonic, others are colonial. Also known as sea squirts because they feed by drawing water into mouth, filtering suspended food particles and trapping them in mucus, and squirting the water out through another opening. Reproduce sexually from separate sexes, producing a tadpole-like larvae stage exhibiting chordate characteristics; larvae swims and attaches by its head to a surface and undergoes metamorphosis during which it looses most of its chordate characteristics, forming a large sessile suspension-feeding adult.

CLASS CEPHALOCHORDATA: also known as lancelets, are tiny, scaleless, fish-like marine animals. They burrow body into sand, mouth exposed to surface, and draw water in for suspension-feeding.

SUBRIIYLUM VERTEBRATA: Cartilaginous or bony vertebral column replaces the embryonic notochord.

\section{Superclass Pisces (fish):}

CLASS AGNATHA (Cyclostoma) have circular mouths; lack jaws, scales and paired appendages. Examples: lampreys, hagfish.

CLASS CHONDRICHTHYES: CARTILAGINOUS fishes with PLACOID scales (dentine covered by enamel--like teeth); breathe by GILLS their entire life. Examples: sharks, skates, rays.

CLASS OSTEICHTHYES: Bony fishes with scales also composed of bony material; breathe by gills their entire life. Examples: betta, stickleback, trout, angler, flying fish, lionfish, catfish, eel, perch, flatfish, leaffish, puffer fish, clownfish, gar.

Superclass Tetrapoda:

CLASS AMPHIBIA: lay eggs in water and spend their larval stage in aquatic environment as a tadpole breathing with gills, then emerge and spend their adult life on land breathing by means of LUNGS and through their soft, scaleless glandular skins. Example: axolotl, Congo eels, newts, salamanders, toads, frogs.

CLASS REPTILIA: Well adapted to land: breathe by lungs, dry scales cover body; lay amniotic, calcareous shell-covered eggs. Like 
all the animals thus far discussed, they are 'cold-blooded' (ECTOTHERMS), that is, they acquire their body temperature from their environment. Some where ancestors to birds, others to mammals. Examples: turtles, lizards, iguanas, chameleons, skinks, geckos, worm lizards, snakes, alligators and crocodiles.

CLASS AVES (BIRDS): Have body covered with FEATHERS, have beaks instead of teeth, and are able to metabolically produce \& regulate their body temperature--'warm-blooded' (ENDOTHERMS). Most are well adapted for flight: well developed wings, hollow bones, and, connected to their lungs, a system of air sacs which fill their body cavities. Flightless birds include terrestrial as well as aquatic species. Examples: penguin, ostrich, swans, grouse, duck, flamingo, ptarmigan, hummingbird, parrot, owl.

CLASS MAMMALIA: Use MAMMARY GLAND milk for nourishment of their young. Have body covered with hair. Few lay eggs, most are VIVIPAROUS--give live births, development occurring in uterus. Three main SUBCLASSES:

SUBCLASS PROTOTHERIA (MONOTREMES): egg-laying, found in Australia. Examples: duck-billed platypus, spiny anteater (echidna). SUBCLASS METATHERIA (MARSUPIALS) : the young nurse from mammary glands within a pouch. Double uterus and vagina.

Examples: koala, kangaroo, wallaby, opossum, wombat.

SUBCLASS EUTHERIA (PLACENTAL): develop with a PLACENTA, a mass of blood vessels and membranes that attaches to the uterus in order to exchange materials between embryo and mother.

Twelve major orders:

(1) INSECTIVORA: insect-eating mammals. Moles, shrews, hedgehogs, pangolins.

(2) CHIROPTERA: adapted for flying. Bats.

(3) RODENTIA: continuously growing chisel-like incisor teeth. Squirrels, beavers, rats and mice, porcupines, hamsters, jerboa, agouti, capybara.

(4) LAGOMORPHA: chisel-like incisors, longer hind legs for jumping. Rabbits, hares, pikas.

(5) PRIMATES: opposable thumb; forward-facing eyes; well developed cerebral cortex; omnivorous. Prosimians, lemurs, monkeys, apes, humans.

(6) CARNIVORA: carnivorous with sharp canines. Dogs, wolves, jackal, bears, cats, lions, weasels, otters, seals, walruses.

(7) PROBOXCIDEA: long, muscular trunk; tusks (elongated upper incisors). Elephants. 
(8) PERISSODACTYLA: odd numbered toes on hooves; herbivorous. Horses, zebras, tapir, rhinoceroses, hippopotamus.

(9) ARTIODACTYLA: even numbered toes on hooves; herbivorous. Sheep \& goat, pigs, cattle \& bison, springbok \& deer, giraffes.

(10) CETACEA: marine with fish-shaped bodies, thick layer of insulating blubber. Whales \{blue, humpback, narwhal\}, dolphins, porpoises.

(11) EDENTATA: reduced or no teeth. Sloths, anteaters, armadillos.

(12) SIRENIA: aquatic herbivores; fin-like forelimbs, no hind limbs. Manatees. 
Every subject participating in the research study received a copy of the twenty nine questions found in this section. These questions were written to make the subjects think at higher cognitive levels than the knowledge level so often being the only level required for most of what students learn, including most of the information from this unit on Animal Diversity. These questions were also intended to stimulate discussions about more comprehensive biological principles and relationships, and distract them from some of the gruesome details involved in learning about taxonomic relationships.

Subjects in the traditional whole-class groups were read these questions by the teacher in an attempt to stimulate interesting discussions. The cooperative groups always had a group member whose task was to find answers to these questions from any of the resources available to the group, including teacher assistance. All subjects were made aware of the importance of these questions for passing the exams.

Many of the comprehension and application level questions written for the comprehensive achievement test were derived form these questions.

\section{QUESTIONS FOR ANIMAL DIVERSITY}

\section{Introduction: Basis of Animal Taxonomy}

1. When comparing the Five Kingdoms, which characteristic is the greatest most fundamental difference between them ? Explain why. 
2. What are the main differences between prokaryotes and eukaryotes?

3. What is the difference between taxonomy and phylogeny?

4. Give a functional definition of a species.

5. Using a phylogenetic tree of the Animal Kingdom, recognize occurrence of the following developmental (embryological) trends.

(a) Diploblastic $\rightarrow$ triploblastic

(b) Acoelomata $\rightarrow$ pseudocoelomata $\rightarrow$ coelomata

(c) Protostoma vs. deuterostoma

6. What are the differences between the two coelomata groups: protostoma and deuterostoma?

\section{Phylum 1: Porifera}

7. Describe the flow of water within a sponge and identify the parts involved. 
8. Describe the general reproduction characteristics and life cycle of poriferans.

9. What characteristics differentiate the classes of Porifera? Give representative examples.

\section{Phylum 2: Cnidaria}

10. Describe the body shapes, parts and germ layers of cnidarians.

11. Describe the general reproduction characteristics and life cycle of cnidaria.

\section{Phylum 3: Ctenophorans}

12. How are ctenophorans similar cnidarians? How do they differ?

\section{Phylum 4: Platyhelminthes}

13. What characteristics differentiate the classes of Platyhelminthes? Give representative examples. 


\section{Phylum 5: Rotifera}

14. What characteristics define the phylum Rotifera?

\section{Phylum 6: Nematoda}

15. Differentiate between the three phyla of worms: P4.

Platyhelminthes, P6. Nematoda and P8. Annelida.

\section{Phylum 7: Mollusca}

16. Describe the general characteristics of mollusks.

17. What characteristics differentiate the classes of mollusks? Give representative examples.

\section{Phylum 8. Arthropoda}

18. Describe the general characteristics of arthropods. 
19. What characteristics differentiate the classes of arthropods? Give representative examples.

20. Describe molting and metamorphosis in arthropods.

\section{Phylum 9: Annelida}

21. Describe physiological processes such as digestion, respiration, excretion in earthworms.

22. What characteristics differentiate the classes of annelida?

\section{Phylum 10: Echinodermata}

23. Describe the structural and physiological (defensive, digestive and locomotive) characteristics of this phylum.

\section{Phylum 11. Chordata}

24. Describe the general characteristics of chordates. 
25. What characteristics differentiate the mayor classes of chordates? Give representative examples.

26. What characteristics differentiate the subclasses of the class mammalia? Give representative examples.

27. Describe the characteristics of the different orders of Placental Mammals.

28. Describe the occurrence of the following physiological adaptations in chordates and give possible evolutionary adaptive advantages.
(A) gills vs. lungs.
(B) aquatic vs. terrestrial. 
(C) shell covered eggs.

(D) ectotherms vs. endotherms.

(E) feathers vs. hair.

(F) soft glandular skins vs. dry scales.

(G) egg-laying (oviparous) vs. 'live-births' (viviparous).

(H) egg-laying vs. marsupial vs. placental development.

29. Give at least six examples of symbiotic relationships, each from an animal of a different phylum. For each example describe the nature of the relationship (commensalistic, mutualistic, parasitic). 


\section{B.04 Terminology for Animal Diversity}

Every subject participating in the research study also received a copy of the 177 terms found in this section with their Greek and Latin roots and combining forms (Borror, D. J., 1960). These terms were provided as an aide to the biological terminology found throughout this unit. Additional space was provided in the list for subjects to write definitions, notes, or whatever information may assist in their studies. There was no particular assignment given from this list, and subjects were made aware that memorizing this list would not help their achievement very much, but that they should refer to it to clarify and unify confusing terminology. Note that the list is organized in the same order as the lesson, and that a few terms were defined for clarification purposes.

\section{TERMINOLOGY FOR ANIMAL DIVERSITY}

\section{Introduction: Basis of Animal Taxonomy}

TAXONOMY \{G., taxo, arrangement; nomy, the science of

MONERA \{G., moner, one single\}

PROTISTA \{G., protisto, the very first\}

FUNGI \{L., fungi, a mushroom, fungus\}

PLANTAE \{L., planta, plant $\}$

ANIMALIA \{L., anima, breath, soul $\}$ 
PHYLUM \{G., phylum, a tribe $\}$

SPECIES $\{$ L., speci, kind, special $\}$

TAXA \{G., taxo, arrangement

BINOMIAL \{L., bi, two, twice; nomio, law, custom $\}$

NOMENCLATURE \{L., nomen, a name $\}$

HOMOLOGY \{G., homo, same; logy, study of $\}$

ANALOGY \{G., analogy, proportion $\}$

PHYLOGENETIC \{G., phylo, a tribe; genet, ancestor\}

PROKARYOTE \{G., pro, before;karyon, kernel or nucleus\}

EUKARYOTE \{G., eu, true;karyon, kernel or nucleus\}

CHROMOSOMES \{G., chromo, color; soma, a body\}

HOMOLOGOUS \{G., homo, same, alike; logous, study of

ORGANELLE \{G., organ, organ; L., ella, small \}

MULTICELLULARITY \{L., multi, many; cell, small room\}

DIPLOBLASTIC \{G., diplo, double; blasto, a bud, sprout $\}$

TRIPLOBLASTIC $\{$ G., triplo, triple $\}$

ECTODERM \{G., ecto, out side; derma, skin\}

MESODERM \{G., meso, middle; derma, skin\}

ENDODERM \{G., endo, within, inner; derma, skin $\}$

ACOELOMATA \{G., $a$, without; coelo, hollow $\}$

PSEUDOCOELOMATA \{G., pseudo, false; coelo, hollow $\}$ 
COELOMATA \{G., coelo, hollow $\}$

HETEROTROPHS \{G., hetero, other, different; troph, nourish, food

AUTOTROPHS \{G., auto, self; troph, nourish, food \}

PHOTOSYNTHESIS \{G., photo, light; syn, with, together; thesis, arranging\}

HERBIVORE \{L., herbi, grass; vov, eat, devour\}

CARNIVORE \{L., carni, flesh; vov, eat, devour $\}$

PROTOSTOMA \{G., proto, first; stoma, mouth\}

ARCHENTERON \{G., arche, beginning, first; entero, gut, intestines\}

BLASTOPORE \{G., blasto, a bud, sprout; pore, passage\}

DEUTEROSTOMA \{G., deutero, second; stoma, mouth\} 
1. PORIFERA \{L., porus, pore; ferre, to bear

SESSILE $\{$ L., sessil, siting on, sedentary $\}$

POROCYTES \{G., porus, pore; cyte, cell\}

SPONGOCOEL \{G., spongo, sponge; coel, hollow

OSCULUM \{L., oscul, little mouth\}

EPIDERMIS \{G., epi, upon, over; derm, skin\}

CHOANOCYTES \{G., choano, funnel; cyte, cell\}

PHAGOCYTOSIS \{G., phago, eat; cyto, cell; sis, the act of \}

FLAGELLA \{L., flagellum, a whip\}

MESOGLEA \{G., meso, middle; glea, glue $\}$

AMOEBOCYTES \{G., amoeba, change; cytes, cells\}

SPICULES \{L., spicul, a spike, point\}

CALCAREA \{L., calcare, limestone\}

CALCIUM CARBONATE $\left(\mathrm{CaCO}_{3}\right)$ very common white powdery or crystalline substance. Found as calcite, oyster shells, chalk, limestone, marble, endo- and exoskeleton of many animals.

HEXACTINELLIDA \{G., hexa, six; acti, ray or beam; neli, merciless\}

SILICON OXIDE $\left(\mathrm{SiO}_{2}\right)$ colorless crystals or white powder; occurs widely in nature as sand, quartz, flint, diatomite; used to manufacture glass.

DEMOSPONGIAE \{G., demo, people; spongia, sponge\}

REGENERATION \{L., re, over again; gener, produce\}

GEMMULES \{L., gemmul, a bud\} 
HERMAPHRODITIC \{G., hermaphrodit, both male and female\}

SYMBIOSIS \{G., symbio, living together

2. CNIDARIA $\{$ G., knide, nettle $\}$

(COELENTERATA) \{G., koilos, hollow; enteron, intestines

GASTRODERMIS \{G., gastro, stomach; dermis, skin \}

GASTROVASCULAR \{G., gastro, stomach; vascular, little vessel\}

CNIDOCYTES \{G., knide, nettle; cytes, cells\}

NEMATOCYST \{G., nemato, a thread; cyst, bag, bladder

RADIAL SYMMETRY \{L., porus, pore; ferre, to bear

POLYP \{G., polyp, many footed $\}$

MEDUSA \{L., porus, pore; ferre, to bear $\}$

POLYP BUDS \{G., polyp, many footed

HYDROSTATIC \{G., hydro, water; static, standing, placed

COLONIAL

HYDROZOA \{G., hydro, water; zoa, animal $\}$

CLONE \{G., clon, a branch, twig\}

SCYPHOZOA \{G., scypho, a cup; zoa, animal $\}$

ANTHOZOA \{G., antho, a flower; zoa, animal\}

CUBOZOA \{G., cubo, a cube; zoa, animal \}

3. CTENOPHORA \{G., kteis, comb; pherein, to bear\} 
4. PLATYHELMINTHES \{G., platys, flat; helmis, worm \}

BILATERAL SYMMETRY \{L., bi, two; lateral, side\}

TRIPLOBLASTIC \{L., triplo, triple; G., blasto, a sprout, bud \}

(ACOELOMATA) \{G., $a$, not, without; coelo, hollow

GANGLIA \{G., ganglion, a knot\}

CEPHALIZATION \{G., cephalo, the head\}

TUBELLARIA $\{$ L., tubi, a tube $\}$

TREMATODA \{G., tremato, a hole\}

PARASITIC $\{$ G., parasito, near food $\}$

CESTODA \{G., cesto, a girdle $\}$

SCOLEX \{G., scolex, a worm\}

PROGLOTTIDS \{G., pro, before, in front; glotti, the tongue\}

5. ROTIFERA \{L., rota, wheel; ferre, to bear\}

PSEUDOCOELOMATA \{G., pseudo, false; coelo, hollow\}

PARTHENOGENESIS \{G., partheno, virgin; genesis, origin, birth\}

6. NEMATODA $\{$ G., nema, thread $\}$

CUTICLE \{L., cutic, skin $\}$

ASCARIS \{G., ascaris, intestinal worm \}

HOOK-WORMS

TRICHINELLA \{G., trichin, hairy\}

FILARIAL WORMS \{L., fili, a thread\} 
ELEPHANTIASIS \{G., iasis, formation of

\section{MOLLUSCA $\{$ L., molluscus, soft $\}$}

EXOSKELETON \{G., exo, outside; skelet, dried body, skeleton\}

VISCERA \{L., viscera, organs of body cavity

MANTLE $\{$ Sp., manto, a cloak $\}$

RADULA \{L., radula, a scraper $\}$

TROCHOPHORE \{G., trocho, a wheel; phore, to carry, bear\}

LARVAE \{L., larva, a ghost, specter

VELIGER \{L., veli, a veil, a sail; ger, to carry, bear\}

POLYPLACOPHORA \{G., poly, many; placo, plate; phora, carry

PELECYPODA \{G., pelecy, a hatchet, axe; poda, foot $\}$

BIVALVIA \{L., bi, two; valva, folding door

GASTROPODA \{G., gastro, the stomach, belly; pod, a foot $\}$

NUDIBRANCH \{L., nudi, nude, naked; branch, a fin, gill \}

CEPHALOPODA $\{$ L., cephalo, head; poda, foot $\}$

8. ANNELIDA $\{$ L., anellus, little ring $\}$

SEPTA $\{$ L., septum, a fence $\}$

NEPHRIDIA \{G., nephridi, the kidney\}

OLIGOCHAETA \{G., oligo, few, small; chaeta, a bristle, long hair

POLYCHAETA \{G., poly, many; chaeta, a bristle, long hair\} 
HIRUDINEA \{L., hirudin, a leech\}

9. ARTHROPODA \{G., arthron, joint; pous, foot $\}$

CHITIN \{G., chit, a tunic $\}$

MOLTING \{G., mol, with difficulty\}

METAMORPHOSIS \{G., meta, between; morphosis, form, structure\}

CRUSTACEA $\{$ L., crusta, crust $\}$

DECAPODS $\{\mathrm{G} .$, deca, ten; poda, feet $\}$

ISOPODS \{G., iso, equal; poda, feet $\}$

COPEPODS \{G., cope, an oar, handle; poda, feet $\}$

BARNACLES \{Fr., barnac, a goose $\}$

ARACHNIDA \{G., arachni, spider $\}$

BOOK LUNGS

DIPLOPODA \{G., diplo, double; podo, foot $\}$

HERBIVOROUS \{L., herba, grass; viv, living; orus, dig through\}

CHILOPODA \{G., chili, a thousand; podo, foot $\}$

HEXAPODA \{G., hexa, six; podo, feet $\}$

THORAX \{G., thorax, breast, chest $\}$

ABDOMEN \{L., abdomen, abdomen $\}$

CEPHALOTHORAX \{G., cephalo, head; thorax, chest $\}$

MALPIGHIAN TUBULES \{Malpighi, Italian scientist\}

TRACHEA \{L., trachea, windpipe $\}$ 
SPIRACLE \{L., spiracul, an air hole $\}$

COLEOPTERA \{G., coleo, a sheath; ptero, a wing \}

DIPTERA \{G., di, two; ptero, a wing $\}$

HEMIPTERA \{G., hemi, one half; ptero, a wing\}

HYMENOPTERA \{G., hymeno, a membrane; ptero, a wing\}

LEPIDOPTERA \{G., lepido, a scale; ptero, a wing\}

ODONATA $\{\mathrm{L} .$, odo, swollen;nata, birth $\}$ ?

ORTHOPTERA \{L., ortho, straight, upright; ptero, a wing\}

10. ECHINODERMATA \{G., echino, sea urchin; derma, skin \} TUBE FEET

WATER VASCULAR SYSTEMS \{L., vascula, a little vessel\}

12. CHORDATA $\{$ L., chorda, cord $\}$

NOTOCHORD \{G., noto, the back; chord, a string\}

NERVE CHORD

GILL SLITS

CARTILAGINOUS $\{$ L., cartilago, gristle\}

INVERTEBRATE $\{$ L., in, not; vertebra, a joint $\}$

TUNICA \{L., tunica, a covering, a cloak\}

CEPHALOCHORDATA \{G., cephalo, head; chorda, a string\}

AGNATHA \{G., $a$, not, without; gnatho, the jaw 
VERTEBRATA \{L., vertebra, a joint $\}$

PISCES \{L., piscis, fish $\}$

CHONDRICHTHYES \{G., chondro, cartilage; ichthy, fish

PLACOID $\{$ G., placo, plate, flat $\}$

OSTEICHTHYES \{G., oste, bone; ichthy, fish \}

AMPHIBIA \{G., amphi, on both sides

REPTILIA $\{$ L., reptil, creep, crawl $\}$

ECTOTHERMIC \{G., ecto, outside; thermo, heat

AVES \{L., avis, birds $\}$

ENDOTHERMIC \{G., endo, inside; thermo, heat $\}$

MAMMALIA \{L., mammalia, mammal $\}$

VIVIPAROUS \{L., vivi, living; parous, giving birth to

MONOTREMES \{G., mono, one; trema, a hole

PROTOTHERIA \{G., proto, first, original; theria, wild beast $\}$

MARSUPIALS \{G., marsupi, a bag, pouch\}

METATHERIA \{G., meta, between;theria, wild beast $\}$

PLACENTA $\{$ L., placenta, round flat cake $\}$

EUTHERIA \{L., eu, good; theria, wild beast $\}$ 


\section{B.05 Field Biologists' Handbook:}

This is a 91 page booklet provided to each subject and containing descriptive information about each one of the many visuals found in the laserdiscs for each particular phylum of the animal kingdom. It was collected from data files which are included with the program VideoCards. They were extracted, and customized by the researcher for use in this research study. The process was quite involved since the program does not allow full data retrieval in batch form from a subject search.

VideoCards has a simple and convenient system of locating visuals and data, called Automatic Text Search, which searches for any term or topic you specify. The results of such a search appear as a list of events in the Notes Window of a new Note. You can 'click' the Eventlinks in this list to view each individual visual and its data. The data list generated by this Automatic Text Search does not, however, result in a complete listing of all the information available for each particular visual. It only lists the Eventlink for each particular event, followed by the first few words of the event's data entry; this is sufficient to identify and view the audio-visual event, but to obtain and retain the entire description (data) for all the audio visual events gathered from such a search requires several additional time consuming steps. In order facilitate the subjects' time consuming task of gathering data for everyone of the hundreds of events, the researcher performed these searches, modified them to make them more useful, and included them in two places for the subjects to use: (a) a printed version in the 'Field Biologist Handbook', 
and (b) an electronic version within the 'Animal Kingdom Stacks'

(appendixes C.02 and c.03).

Following is a brief example of the researcher-modified version of an Automatic Text Search for Echinodermata, as it is found in the Field Biologist Handbook.

\section{Dise SIDE 3}

\section{PHYLUM ECHINODERMATA}

\section{Class 1. ASTEROIDEA (1229*): Sea Stars}

(1230*) Linckia lavigata; cobalt sea star. This brilliant blue starfish is found in the coral reefs of the Indo-Pacific. It grows up to sixteen inches in diameter. NOTICE: This starfish does not have suckers on the ends of its tube feet. Instead, the tube feet are pointed so they can force their way into the soft sand where this starfish lives. Each tube foot has a double ampulla to provide more force.

Q: What is the small, light blue spot in the center?

A: The madreporite (sieve plate)

Side 3 Movie: STARFISH (41933-43341*)

SUMMARY: Starfish locomotion and feeding; scallop's eyes and locomotor response to a starfish.

NARRATION: The tube feet of a starfish are arranged in rows under each of its arms. The tip of each foot can be contracted, using a system of muscles and water pressure to form a tiny suction cup. Hundreds of these provide the creature with a very firm grip on the sea bed.

The pale transparent bag appearing beneath the starfish is its stomach, which is turned inside out to digest food outside its body. Protruding from each half of the scallop's shell is a line of small, very sensitive tentacles. Between these, is a row of tiny, glistening spheres. Each one is an eye, equipped with lens, retina and nerve fiber. If the scallop senses danger, it can swim rapidly away, using a series of contractions to eject water from between the halves of its shell. 
The slightest touch of the starfish on a scallop's tentacle is enough to send it scuttling away.

$(2617 *)$ Diagram: Starfish

$\left(1231^{*}\right)$ Nardoa. Starfish have bony endoskeletons, a skeleton inside the body. Knob like, bony spines cover the aboral (side without a mouth) surface of this starfish. Microscopic gills fill the spaces between the spines. This starfish lives in the Indo-Pacific.

(1233*) Bipinnaria larva of starfish. Starfish have external fertilization and development that results in a free-living larva that lives in the plankton. The larva is called a bipinnaria, which means two-winged. It is covered with bands of cilia that bring food to the larva's mouth and propel it through the water.

\section{Class 2. OPHIUROIDEA (1235*): Brittle Stars}

(1236*) Ophiothrix; Brittle and serpent stars differ from starfish in several major ways. The central disc and slender arms are nearly separate structures in these animals. Their arms contain muscles and vertebrae that give them great lateral flexibilty.

NOTICE: Brittle stars have spiny arms. Serpent stars have smooth, snakelike arms. A favorite trick of biology teachers is to show students one arm of a serpent star and see if they can tell that it is not the tail of a snake.

Q: What does ophiuroid mean?

A: Ophiur=Serpent-tailed; oid=like

$(1237 *)$ Brittle Star; oral view. The underside of this brittle star shows how the arms lead to the mouth. Starfish have ambulacral grooves in the middle of each arm that contain the tubefeet and lead to the mouth. These grooves are not present in ophiuroids because they do not use their tubefeet for locomotion.

NOTICE: The tubefeet of this brittle star resemble its spines and are interspaced among them on the arms.

Class 3. ECHINODEA (1241*): Sea Urchins and Sand Dollars

$(1242 *)$ Echinus esculentus; edible sea urchin in laminaria bed. Sea urchins (sea hedgehogs) are globe-shaped echinoderms. The outer surface of the sea urchin is covered with spines and tubefeet. Some 
sea urchins have long venomous spines, but most sea urchins are harmless unless they are stepped on by mistake. This sea urchin gets its common name because sea urchin eggs (roe) are eaten and considered a delicacy by many peoples.

Q: A sea urchin is a starfish with its feet turned up?

A: Yes, generally

(1243*) Psammechinus miliaris; details of spines and tube feet. Tubefeet are hydraulic, muscular tubes with suction cups at the end. The sea urchin uses them to move and to sense its environment. Many can be seen extending from this urchin. The tubefeet respond to changes in pressure caused by the muscles that control the size of the bulb (ampulla) attached to each tubefoot inside the urchin. The tubefeet extend outward though holes in the bony body wall (test). Sea urchins move their spines with muscles, aiding their locomotion.

(1244*) Psammechinus miliaris; mouth of sea urchin. Sea urchins generally feed on vegetation, but they will eat many of the small, sessile organisms that live on the surfaces they inhabit. They do this with one of the most complex structures in the animal kingdom, Aristotle's lantern. It is a cone-shaped structure that ends in teeth that project out of the mouth. The teeth move in and out, grasping and scraping.

NOTICE: The teeth protrude through a circular membrane that protects the mouth. Many pedicellaria can be seen around the mouth of this sea urchin.

(2003*) Phylum Echinodermata; Class Echinoidea; sea urchin test. Echinoderms have bony endoskeletons. This test is the endoskeleton of the sea urchin Lytechinus variegatus.

(2011*) Phylum Echinodermata; Class Echinoidea; spines; top view. NOTICE the tubefeet and pedicellaria among this sea urchin's spines.

(2012*) Phylum Echinodermata; Class Echinoidea; spines; side view. NOTICE the suction cup tip of the tubefoot on the left and the pinchers of the pedicellaria in the lower center of the picture.

(2013*) Phylum Echinodermata; Class Echinoidea; sea urchin; Arbacia. Arbacia is found in the Atlantic and has medium-sized spines. 
B.06 Student Instructions for Cooperative Groups

Subjects selected for the cooperative groups were given the following instructions which were discussed with them in detail the day prior to the beginning of the research study. On three more occasions thereafter, they were reminded, as a group, of their group tasks and incentive structure as outlined below.

\section{Cooperative Group Instruction}

Purpose: To inform students of their responsibilities (tasks) and rewards (incentives) while engaged in cooperative group instruction in the unit on Animal Diversity.

\section{Group Tasks:}

(1) To work as a group to create a computerized multimedia presentation on Animal Diversity.

(2) To work as a group to instruct (tutor) each other.

Task Structure: students will work in groups of four, each student taking one of the following roles.

(1) Taxonomist: will inform and advise other group members about taxonomic information found in 'Animal Kingdom Taxonomy Guide' handout. Will also keep a written record of the groups' multimedia project decisions by marking the reference number of selected representative visuals. 
(2) Field Biologist: will inform and advise other group members about descriptive data found in 'Field Biologist Handbook'.

(3) Computer Specialist: will work with computer programs to manage audio-visual information found in laserdisc.

(4) Research Manager: will manage the group in a leadership role, searching for and recording for the group, answers to the higher level essay 'Questions for Animal Diversity'.

The tasks listed above were assigned to students on a daily rotating basis.

\section{Incentive Structure:}

Grade source

Grade assignment description

Total

grades

(1) Individual One letter grade given for each of the homework five homework's assigned. grade

(2) Individual Two grades for each one of the four test grades quizzes, and three grades for the final achievement test $(\mathrm{Q} 1=2, \mathrm{Q} 2=2, \mathrm{Q} 3=11$ 2, $\mathrm{Q} 4=2$, Final $=3$ ).

Total individual grades $=16$ 
(3) Group- A grade will be determined for all average test group members based on an average grades taken from their individual scores (Q1

$$
=0, \mathrm{Q} 2=1, \mathrm{Q} 3=1, \mathrm{Q} 4=2 \text {, Final = 4) } 8
$$

(4) Group Eight grades for each member of the 8 project grade group.

Total group grades $=16$

TOTAL GRADES FOR ENTIRE UNIT $=32$ 
B.07 Parent Permission Forms (Required for every subject by DCPS) To the parents/ guardians of

(student):

This is to inform you that the student named above has been selected to participate in a research study taking place in his/her Biology Class this summer.

The general purpose of this study is to determine the most effective instructional technique for utilizing a computer-based interactive biology videodisc. This would allow the student to learn their biology lesson utilizing the latest computerized multimedia technology. They will be involved in learning their biology through this new medium for approximately two-andone-half (2.5) hours a day for a period of approximately one-and-a-half (1.5) weeks. The rest of the time during the semester they will be receiving their regular biology instruction. Their attitudes toward science instruction as well as their learning (achievement) of the biology lesson will be assessed. Their overall G.P.A., as well as their Stanine scores will also be utilized in order to gauge their achievement gains.

Your signature below is to indicate approval or disapproval of his/her participation in this research study.

Give permission:

Refuse permission:

Thank you for your attention to this matter!

If you have any questions or need any additional information concerning this research study, please feel free to contact me:

Researcher:

Jorge L. Alonso

5856 S.W. 53 rd Street

Tel. \# 666-5871 (7 A.M. - 3 P.M.)

666-8273 (after 3 P.M.)

\section{Affiliated Institution:}

Florida International University

Luis A. Martínez-Pérez, Ph.D.

Major Professor 


\section{Appendix C \\ HyperCard Lesson Stacks}

Three HyperCard Stacks where created for this research study. The first (C.01), used by all subjects regardless of group, is an introductory lesson to five kingdom classification system, and it is included here in its entirety with accompanying explanation. The other two stacks (C.02 and C.03) were created using the authoring software Video Cards, one of them was designed for the traditional whole-class group and the other for the cooperative groups. Their contents differ slightly, to reflect the different tasks for which they were designed to be used; they are very extensive and only representative portions are shown for each.

\section{C.01 Five Kingdoms HyperCard Stack (Complete)}

The following are illustrations of the computer screens the user encounters when utilizing the electronic lesson designed for this research study; the accompanying explanations are provided for the reader to understand its functionality and its educational intent. The sequence of cards in this stack are intended as an audio-visual tutorial of the embryological basis for classifying the diversity of animal life, one of the most difficult phylogenetic concepts for students to understand; it was be reinforced each day the subjects entered the program, since this stack is the only path to the second part of the program, the 'Animal Kingdom' stack, on which the subjects spent most of their time learning about Animal Diversity. 


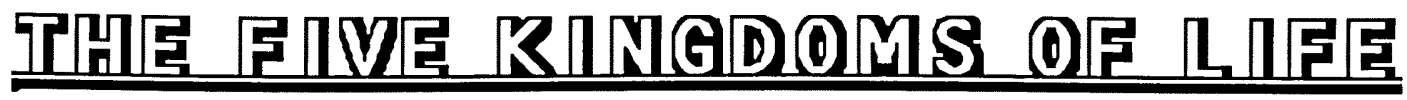

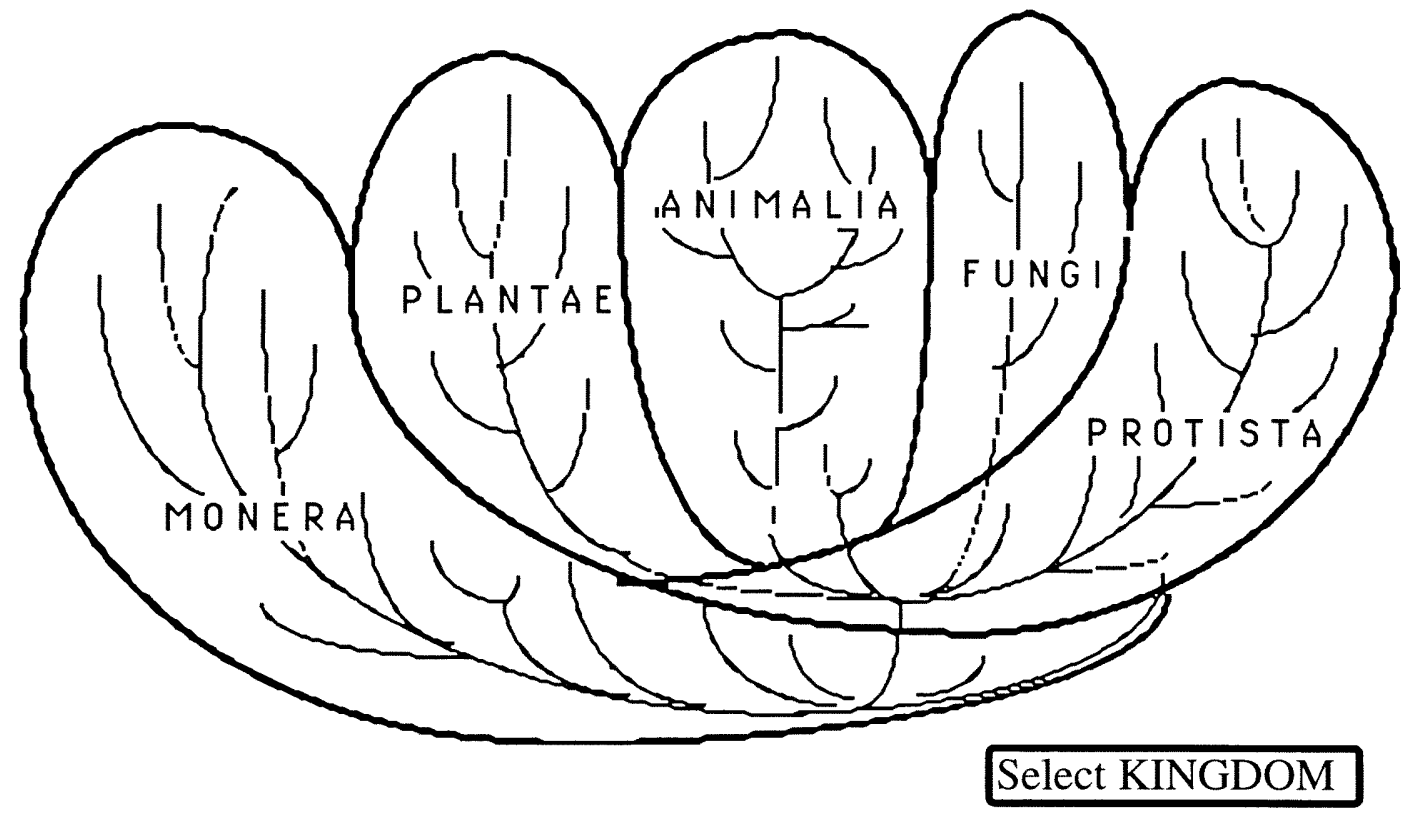

Figure 4. Five Kingdoms HyperCard Stack Screen 1: The Five Kingdoms of Life

When the user select 'The Five Kingdoms' button, the only one available in the start-up screen, the HyperCard program is activated and a screen window similar to Figure 4 appears. This introductory screen illustrates the classification of life on earth based on the fivekingdom system. The vein-like appearance of each kingdom represents branches in their phylogenetic trees. Selecting the area for any one of the five kingdoms will activate the sound of a voice which pronounced the name of each one of the kingdoms and allow access to the first introductory card for that particular kingdom. For the purpose of this study only the kingdom Animalia was linked to 
subsequent cards (screens); this was done in order to discourage distractions from the intended unit on Animal Diversity. The button at the bottom right activates the sound of a voice which reminds the user of their only possible option to "select a kingdom".

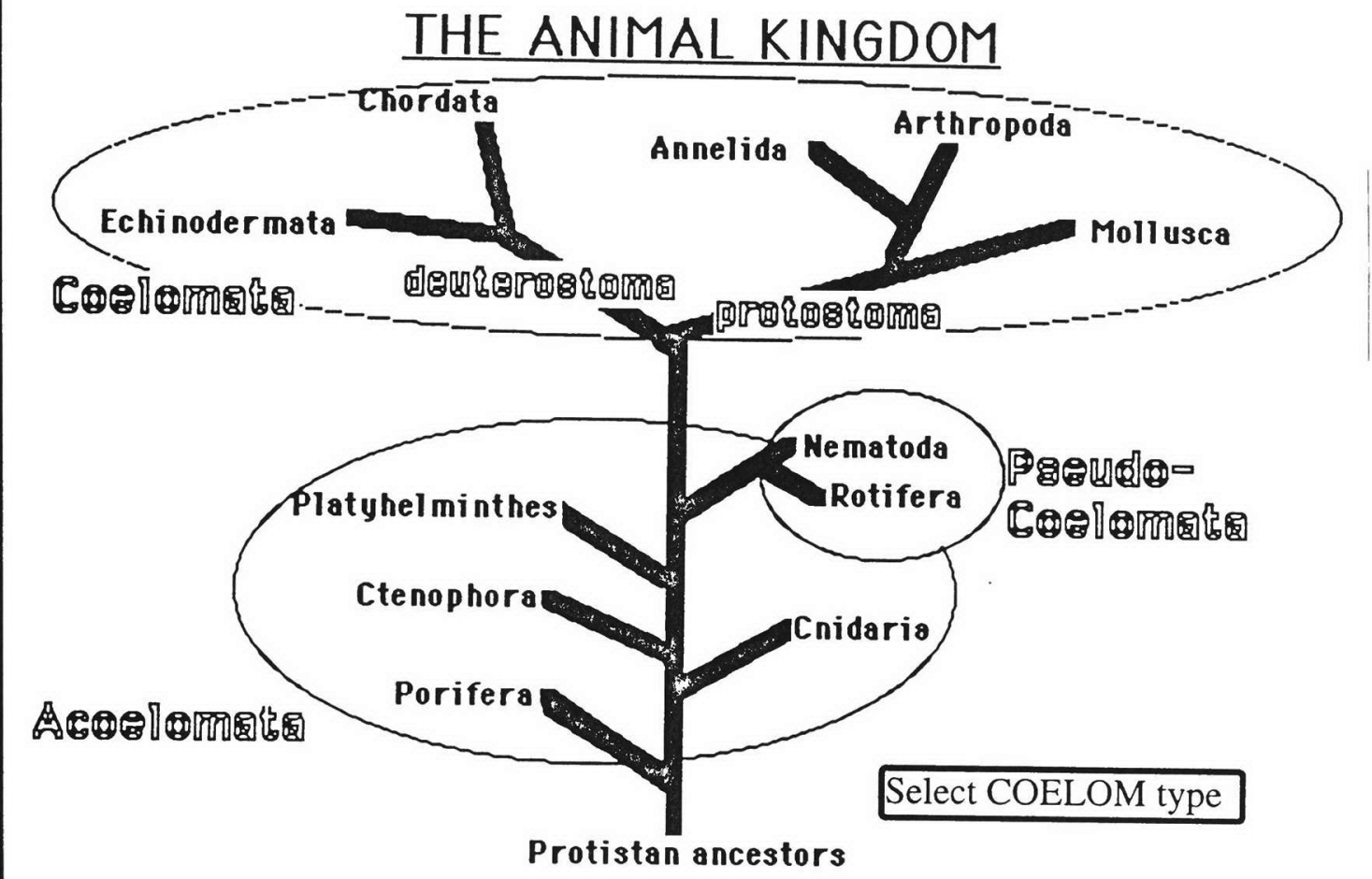

Figure 5. Five Kingdoms HyperCard Stack Screen 2: Body Cavities

When the user selects the 'Animalia' button, a screen window similar to Figure 5 appears. This screen illustrates a more detailed phylogenetic tree of the animal kingdom with the phyla classified by major embryological coelomate characteristics. Selecting within the area of any elliptical area for the coelomate groups activates the sound of a voice which pronounces the name of the particular 
coelomate group and links the user to Figure 6 which follow it. This screen (Figure 5) also contains a button in the bottom right hand corner which, when selected, reminds the user by means of a voice of their only possible option within this screen which is to "select a coelom type"

Selecting any of the buttons (the elliptical areas) in the computer screen window represented by Figure 5 will also automatically link the user to a screen window similar to Figure 6 . This screen (Figure 6) illustrates detailed diagrams of the body cavities and their corresponding germ (tissue) layers. Selecting anything within the area below each subheading will activate a voice which will again pronounce the name of the particular coelomate group selected. To move into the screen which follows, the user has to select the button on the lower right hand corner.

The next screen appearing, represented in Figure 7, is almost identical in appearance to Figure 5, but functionally it differs in several respects. First of all its request is to select a phylum, as shown by the audio button in the lower right. Selection of any of the lower phyla in the acoelomate or pseudodocoelomate groups will activate a voice which pronounces the name of the phylum and automatically link the user to a dialog box which lists all the eleven phyla and ask the user which one they would like to view; selecting any of the phyla from this dialog box will automatically link the user to one of the two Animal Kingdom HyperCard stacks created by Video Cards, depending on whether the user is the presenter 
(teacher) in the traditional whole-class group (appendix C.02), or a subject in a cooperative group (appendix C.03).

ACOELOMATA: 1ack cavity between gut and outer body wall.

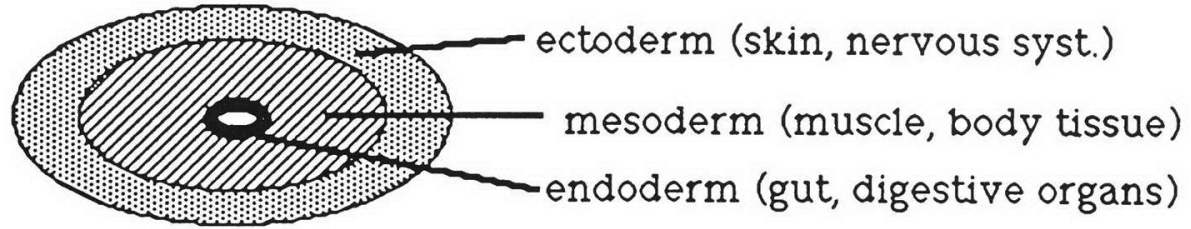

PSEUDOCOELOMATA: body cavity_partialy lined by mesodermal tissue

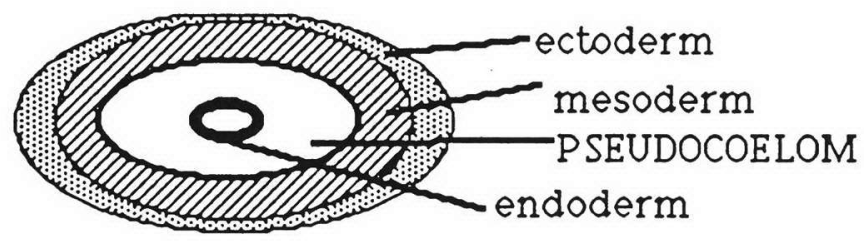

COELOMATA: have true coelom, a body cavity completely lined by

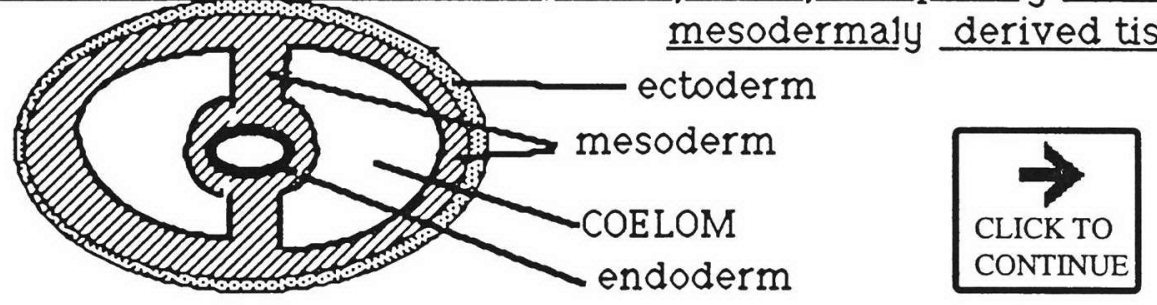

Figure 6. Five Kingdoms HyperCard Stack Screen 3: Germ layers

If the user selects anyone of the higher coelomate phyla they will follow a different path. First of all it depends on whether the coelomate phyla which exhibit protostoma (right side of screen) or deuterostoma development (left side of screen) are selected. If any of the phyla which exhibit protostoma development is selected, the button activates the sound of a voice that pronounces "protostoma" and links the user to a screen similar to Figure 8; if any of the phyla 
which exhibit deuterostoma development is selected, the voice pronounces "deuterostoma" and links the user to a screen similar to Figure 9.

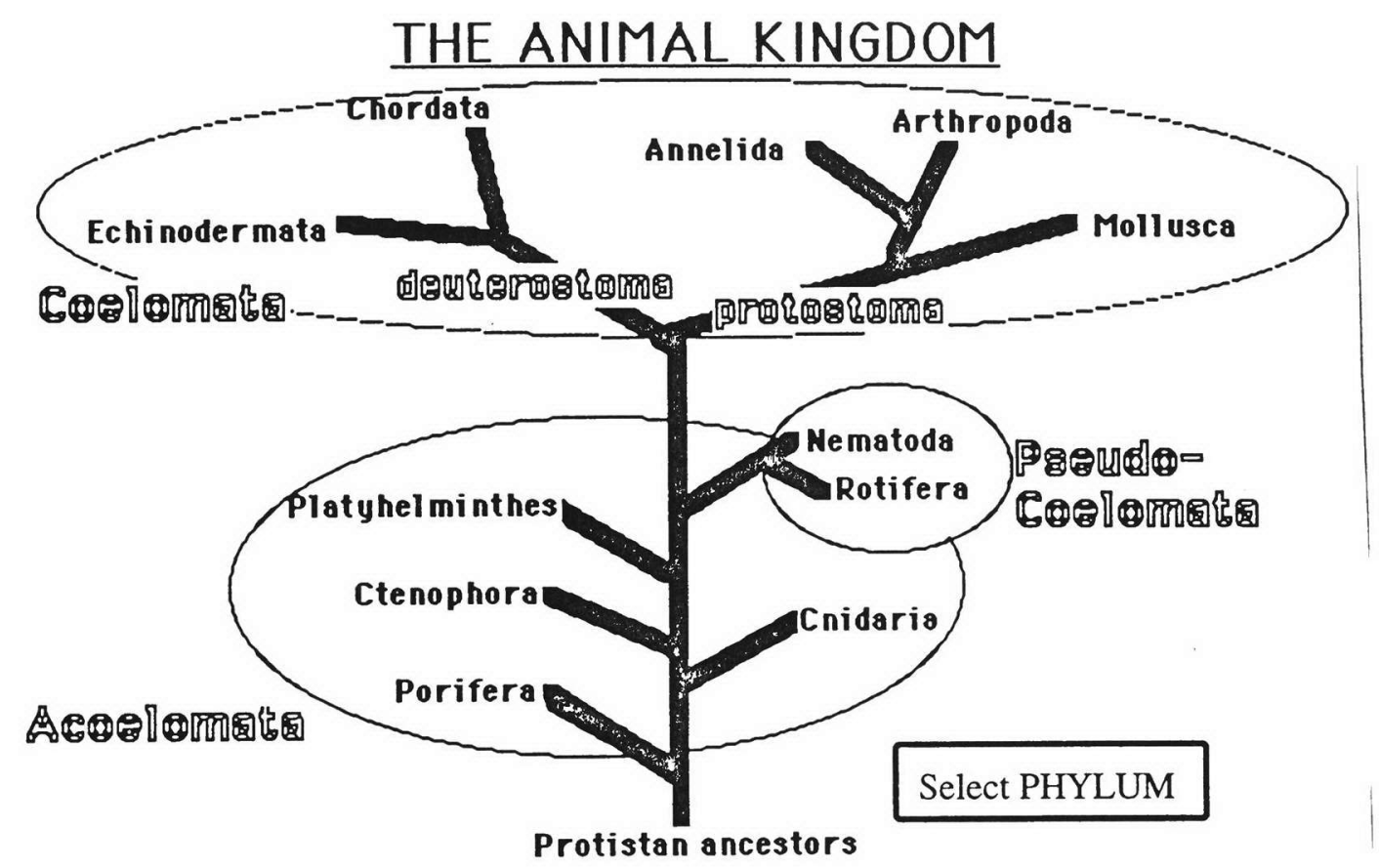

Figure 7. Five Kingdoms HyperCard Stack Screen 4: Acoelomata Phyla

The screen represented by Figure 8 shows a sequence involved in the embryological development of the protostoma ('mouth first') phyla. It contains several audio buttons in the central portion of the screen; the button labeled 'Info' activates a voice which informs the user to select one of the adjoining numbered buttons to obtain further information about the characteristics of protostoma 
development; the button labeled ' 1 ' activates a voice which mentions "spiral cleavage" as the first of these characteristics; the button labeled ' 2 ' mentions' that "coelom forms from splits in the mesoderm"; button ' 3 ' says "mouth from blastopore" as the third important developmental characteristic of the protostoma phyla. At the bottom of this screen a button labeled 'click to continue' links this screen to another similar to the one represented in Figure 9.

\section{EMBRYONIC DEVELOPMENT IN PROTOSTOMA}

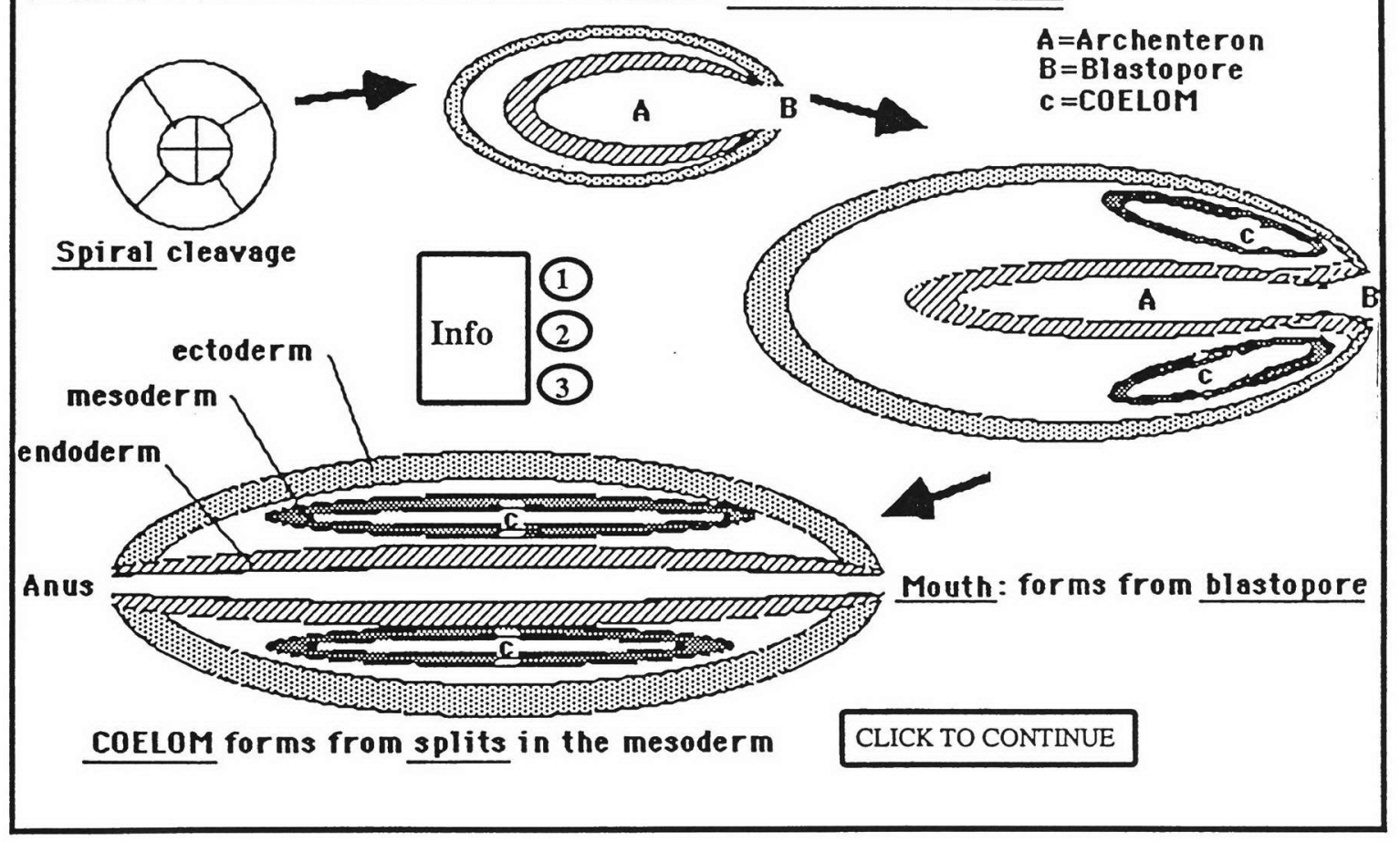

Figure 8. Five Kingdoms HyperCard Stack Screen 5: Protostoma

Figure 9 represents the 6 th screen in the Five Kingdoms stack. It is similar in form to the preceding screen, but its contents show a deuterostoma developmental sequence. Its information buttons 
mention "radial cleavage", "coelom from outpockets in mesoderm", and "anus form blastopore" as buttons '1', '2' and '3' are selected, respectively. The two buttons in the lower right either link to the previous card ('Protostoma' button), or to the next screen represented by Figure 10 ('Click to continue' button).

\section{EMBRYONIC DEVELOPMENT IN DEUTEROSTOMA}

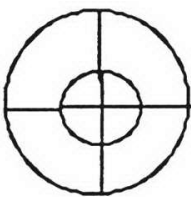

Radial cleavage

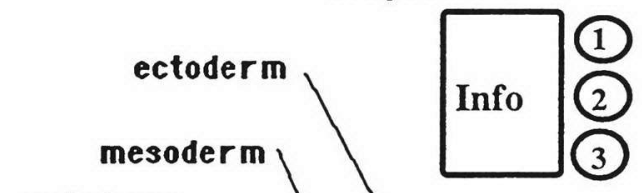

mesodermal outpockets

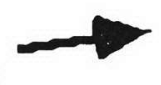

endoderm

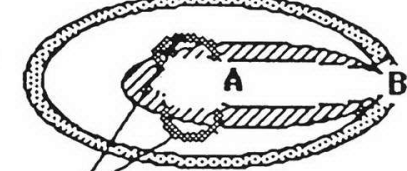

$\rightarrow$

$A=$ Archenteron

$B=$ Blastopore

$\mathrm{C}=$ COELOM

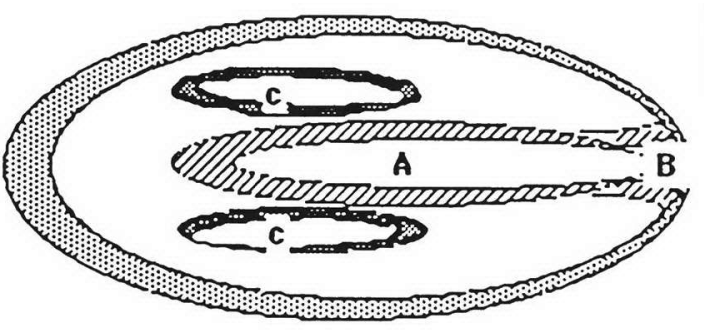

Anus: forms from blatopore

Mouth
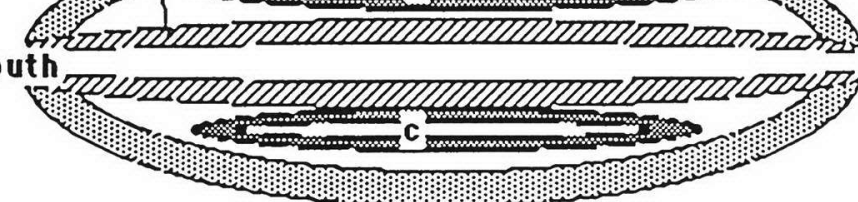

COELOM forms from outpockets in the mesoderm

Protostoma

CLICK TO CONTINUE

Figure 9. Five Kingdoms Stack, Screen 6: Deuterostoma

The next screen in the Five Kingdoms stack, represented by Figure 10, shows and enlarged phylogenetic tree of the coelomata phyla. This screen contains five buttons, one for each of the five phyla represented. The buttons for 'Echinodermata', 'Annelida', and 'Mollusca' will, as in the lower phyla of Figure 2, activate a voice 
which pronounces the name of the phylum and automatically link the user to a dialog box which lists all the eleven phyla and ask the user which one they would like to view; selection any of the phyla from this dialog box will automatically link the user to a dialog box which lists all the eleven phyla and ask the user which one they would like to view; selecting any of the phyla from this dialog box will automatically link the user to one of the two Animal Kingdom HyperCard stacks created by Video Cards, depending on whether the user is the presenter (teacher) in the traditional whole-class group (appendix C.02), or a subject in a cooperative group (appendix C.03).

\section{THE COELOMATA PHYLA}

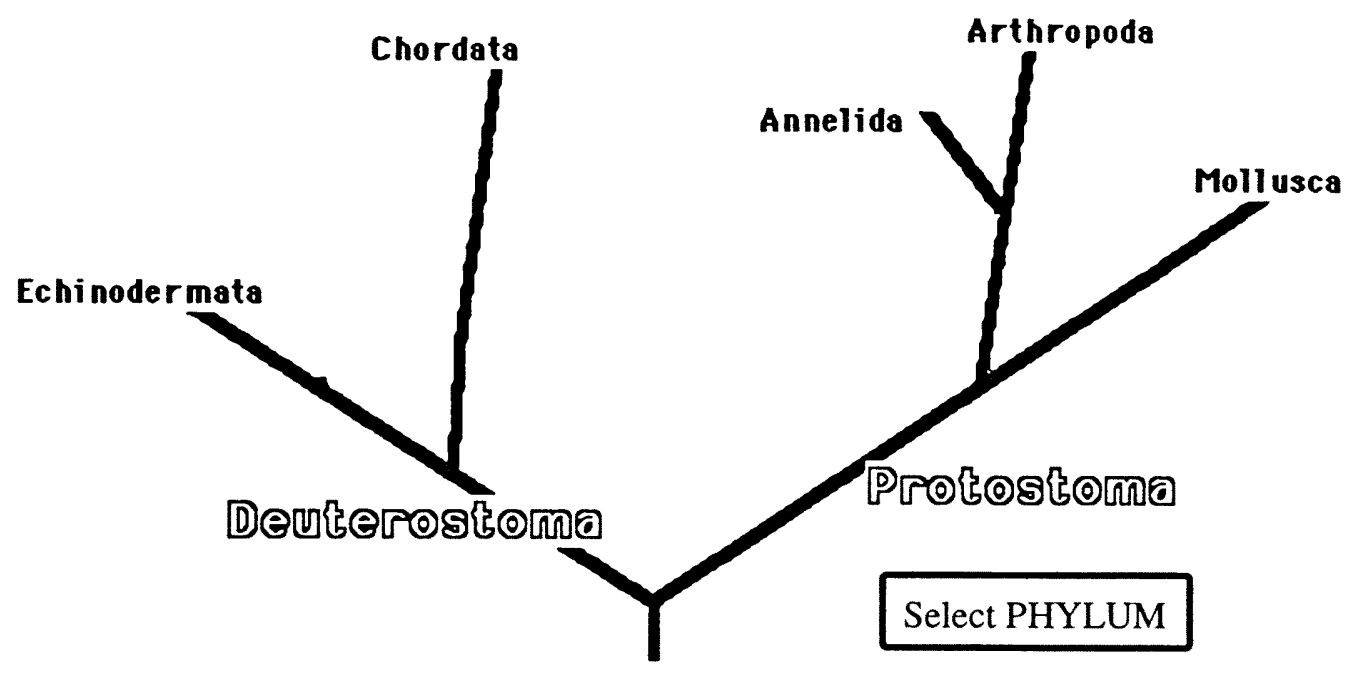

Figure 10. Five Kingdoms HyperCard Stack Screen 7: Coelomata Phyla 
The button for the phyla 'Arthropoda' and 'Chordata' will activate a voice that pronounce the names of the phyla and also link the user to screens represented by Figure 11 and 12, respectively.

The phylum Arthropoda is represented in this lesson (unit) by five classes. Since each of these classes has its own Note Window within the Video Cards stack, then it is appropriate to have a button with audio to pronounce the name of the selected phylum and link by means of a dialog box to the 'Video Cards stacks, in the same way that phyla were linked in previous screens.

\section{PHYLUM ARTHROPODA}

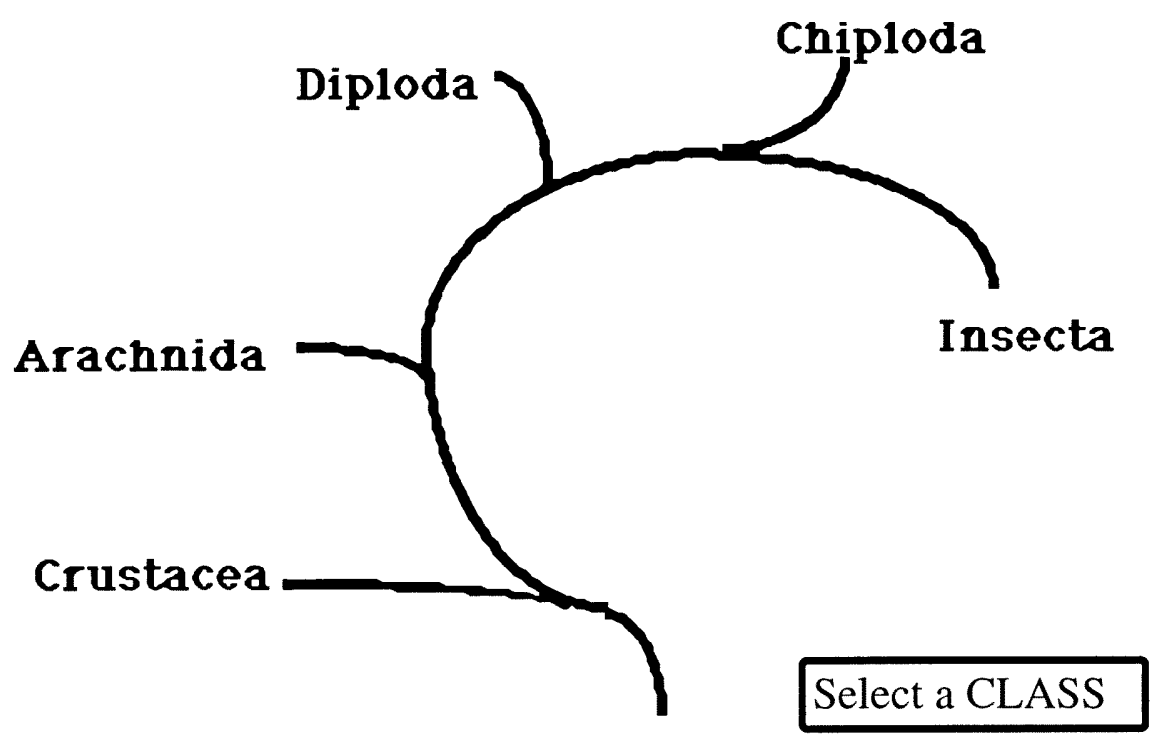

Figure 11. Five Kingdoms HyperCard Stack Screen 8: Arthropoda Classes 
The phylum Chordata is represented in this lesson by 9 classes. Since each of these classes has its own Note Window within Video Cards stack, then it is appropriate, as with Arthropoda, to have a button with audio to pronounce the name of the selected phylum and a link to the Video Cards stack by means of a dialog box. These links will take the user to the appropriate stack for the second part of the lesson which is explained in the following appendixes (C.02 and C.03).

\section{PHYLUM CHORDATA}

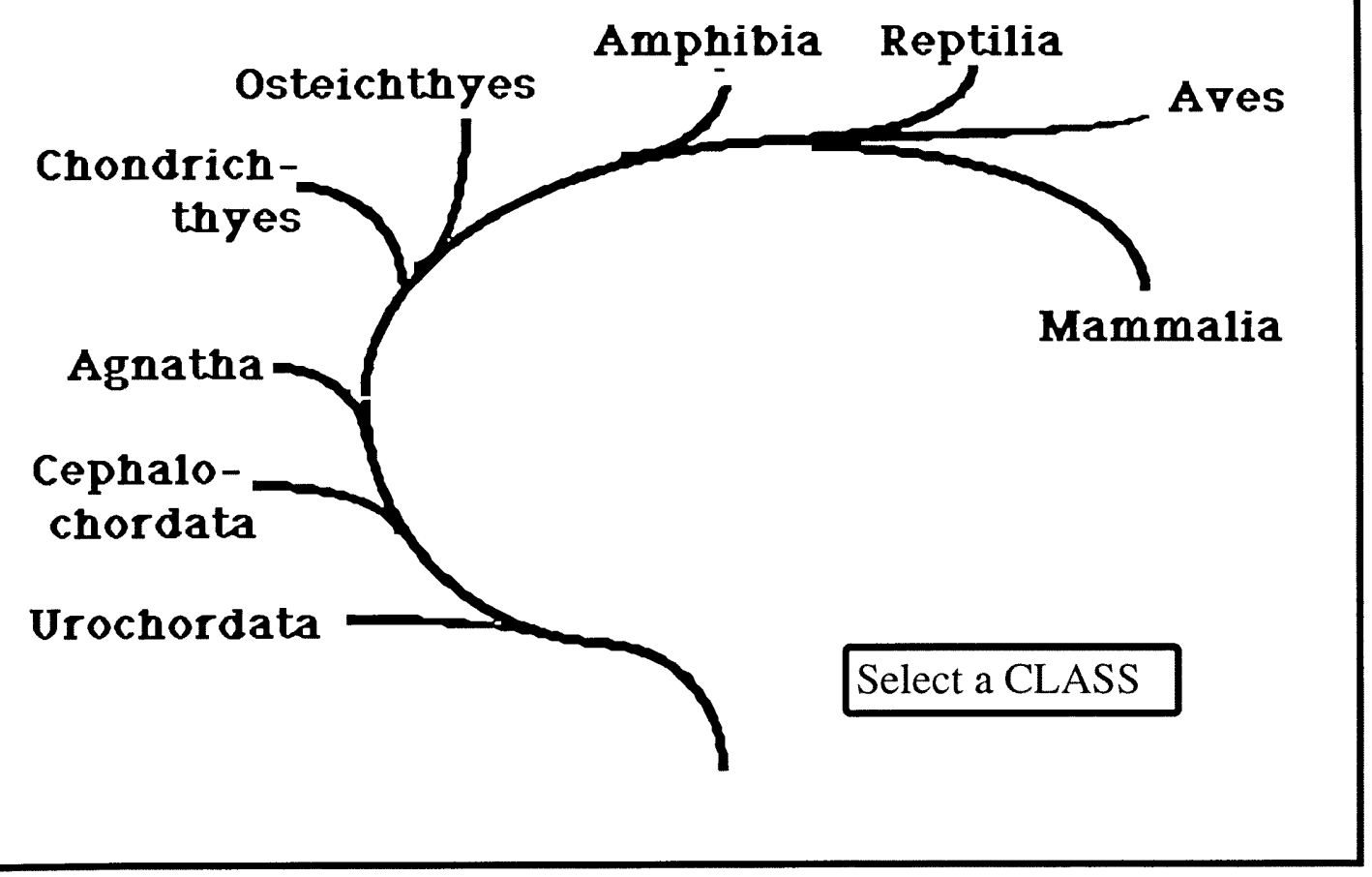

Figure 11 Five Kingdoms HyperCard Stack Screen 9: Chordata Classes 


\section{C.02 Animal Kingdom Presentation Stack}

This HyperCard stack was created using Video Card, the authoring software produced by Optical Data Corporation to be used with their videodiscs in The Living Textbook collection which includes over 20 volumes for secondary sciences. In this research study this stack was included in the computer used by the presenter for the traditional whole-class instructional group only; subjects in the cooperative groups used the modified version found in appendix C.03. Once the presenter went though the introductory 'Five Kingdom' stack and selected a phylum, the software automatically linked from this stack into the 'Animal Kingdom Presentation' stack were descriptions for the characteristics of the phylum can be found together with a collection of a eventlinks numbers interspersed with the text. The presenter only needs to read or paraphrase the contents of this stack as they are shown to the subjects through a TV monitor displaying the contents of the computer screen to the group, and select the eventlinks to view the audio-visual events being described. Notice that the taxonomic description found here are identical to that given to all the subjects in the 'Animal Kingdom Taxonomic Guide' handout.

Following the taxonomic description found in this stack, there is another section called 'AV Events' which contains a collection of the data for each visual utilized within the unit on Animal Diversity. This information is provided within this stack as a handy reference for the presenter, but are not otherwise necessary for the presentations done in this research study. Notice that the eventlinks description 
(data) found here is identical to that provided to all the subjects in 'Field Biologist Handbook'.

PHYLUM 10: ECHINODERMATA \{G., echino, spiny; derma, skin \} (2014*) Marine animals with calcareous (hard), spiny coverings. (1230*) Radially symmetrical adults, often with five spokes, (1233*) develop by metamorphosis from bilateral larvae. Locomotion by TUBE FEET, whose movements are regulated by their unique WATERVASCULAR SYSTEMS, a network of hydraulic canals whose function also includes feeding \& gas exchange (41933-43341*) (2617*). Sexual reproduction is external, from two separate sexes; one species of sea stars can regenerate entire body from a single spoke (arm).

Six classes:

(1) $(1229 *)$ ASTEROIDEA: $\left(1231^{*}\right)$ sea stars

(2) $\left(1235^{*}\right)$ OPHIUROIDEA: $\left(1236^{*}\right)\left(1237^{*}\right)$ brittle stars

(3) $\left(1241^{*}\right)$ ECHINOIDEA: $\left(1242^{*}\right)\left(1243^{*}\right)\left(1244^{*}\right)\left(2013^{*}\right)(2014 *)$

$\left(2003^{*}\right)$ sea urchins \& sand dollars

(4) $\left(1223^{*}\right)$ CRINOIDEA: $(1224 *)\left(1225^{*}\right)\left(1226^{*}\right)(1227 *)$ sea lilies

(5) $\left(1250^{*}\right)$ HOLOTHUROIDEA: $\left(1251^{*}\right)\left(1285^{*}\right)\left(2016^{*}\right)\left(2017^{*}\right)$

$\left(2018^{*}\right)\left(2033^{*}\right)$ sea cucumbers

(6) CONCENTRICYCLOIDEA: sea daisies

AV EVENTS

\section{PHYLUM ECHINODERMATA}

Class 1. ASTEROIDEA (1229*): Sea Stars

(1230*) Linckia lavigata; cobalt sea star. This brilliant blue starfish is found in the coral reefs of the Indo-Pacific. It grows up to sixteen inches in diameter. NOTICE: This starfish does not have suckers on the ends of its tube feet. Instead, the tube feet are pointed so they can force their way into the soft sand where this starfish lives. Each tube foot has a double ampulla to provide more force.

$\mathrm{Q}$ : What is the small, light blue spot in the center?

A: The madreporite (sieve plate)

Side 3 Movie: STARFISH (41933-43341*) 
SUMMARY: Starfish locomotion and feeding; scallop's eyes and locomotor response to a starfish.

NARRATION: The tube feet of a starfish are arranged in rows under each of its arms. The tip of each foot can be contracted, using a system of muscles and water pressure to form a tiny suction cup. Hundreds of these provide the creature with a very firm grip on the sea bed.

The pale transparent bag appearing beneath the starfish is its stomach, which is turned inside out to digest food outside its body. Protruding from each half of the scallop's shell is a line of small, very sensitive tentacles. Between these, is a row of tiny, glistening spheres. Each one is an eye, equipped with lens, retina and nerve fiber. If the scallop senses danger, it can swim rapidly away, using a series of contractions to eject water from between the halves of its shell.

The slightest touch of the starfish on a scallop's tentacle is enough to send it scuttling away.

$(2617 *)$ Diagram: Starfish

(168*) Starfish; oral view showing stomach. NOTICE: The starfish has a very thin-walled stomach that it can slide between the valves of a clam that has been wired shut. This starfish's stomach is in the center of the picture and is partly extruded.

$\left(2170^{*}\right)$ Starfish dissection showing ampullae (aboral end of tube feet).

NOTICE: The light-colored spheres in the center of the picture are the ampullae that control the tube feet seen in the bottom of the picture. The top of the ray and the surrounding internal organs have been removed.

(2183*) Preserved starfish showing ring canal.

(2184*) Preserved starfish showing radial canal and ampullae.

(1231*) Nardoa. Starfish have bony endoskeletons, a skeleton inside the body. Knob like, bony spines cover the aboral (side without a mouth) surface of this starfish. Microscopic gills fill the spaces between the spines. This starfish lives in the Indo-Pacific. 
(1232*) Marthasterias; starfish regenerating arms. This spiny starfish has lost three of its arms and is regenerating them. Starfish have the ability to regenerate a complete starfish if only an arm and one-fifth of the central disc are present. Regeneration takes about one year.

Q: Some people try to kill starfish by cutting them up. Does this work?

A: No.

(1233*) Bipinnaria larva of starfish. Starfish have external fertilization and development that results in a free-living larva that lives in the plankton. The larva is called a bipinnaria, which means two-winged. It is covered with bands of cilia that bring food to the larva's mouth and propel it through the water.

Side 2 Movie: ECHINODERM DEVELOPMENT (39043-40411*)

SUMMARY: Egg and sperm release in the starfish; living examples of fertilization, cleavage, blastula, gastrula and larval stages.

NARRATION: Here, hundreds of eggs from a female starfish are released, and drift slowly in the sea.

Nearby, the male starfish releases a milky cloud of millions of sperm. Some sperm come in contact with the eggs.

Only one sperm is needed to fertilize an egg. Once fertilization takes place, the one-celled starfish egg begins to divide, first into two cells, then four, and so on. The nucleus of each cell carries all the information needed to develop a complete starfish, similar to its parents.

(1743*) Starfish development, various stages

Class 2. OPHIUROIDEA $\left(1235^{*}\right)$ : Brittle Stars

(1236*) Ophiothrix; Brittle and serpent stars differ from starfish in several major ways. The central disc and slender arms are nearly separate structures in these animals. Their arms contain muscles and vertebrae that give them great lateral flexibility.

NOTICE: Brittle stars have spiny arms. Serpent stars have smooth, snakelike arms. A favorite trick of biology teachers is to show students one arm of a serpent star and see if they can tell that it is not the tail of a snake.

Q: What does ophiuroid mean?

A: Ophiur $=$ Serpent-tailed; oid $=$ like 


\section{C.03 Animal Kingdom Cooperative Group Stack}

This HyperCard stack was also created using Video Card, the videodisc authoring software. It was included in all 8 computers used by the subjects in the cooperative instructional groups. Once the subjects navigated though the introductory 'Five Kingdom' stack and selected a phylum, they were automatically linked to the 'Animal Kingdom Cooperative Groups' stack in which descriptions for the characteristics of the phylum are found, just like in the stack for the traditional whole-class instruction group. There is however a major difference between this stack and the one provided to the traditional instruction group: this one lacks the eventlinks numbers interspersed within the text. The eventlinks numbers are, however, found in the section which immediately follows called 'AV Events', which also contain the data for each visual the subjects are allowed to select from in order to create their own multimedia presentation. Notice that the eventlinks description (data) found here is identical to that provided to all the subjects in 'Field Biologist Handbook'.

The differences between this stack and the presentation stack previously described in appendix C.02 is just the lack of eventlinks numbers interspersed within the taxonomic text; this, however, radically changes the way the user interacts with the software when navigting though the lesson. Rather than just selecting events chosen by someone else, the subjects have to read and understand the taxonomic text, then preview the visuals (and data) and choose the location within the taxonomic text where the eventlinks best fits the textual descriptions. This would involve the same type of critical 
thinking and decision making the designer had to go through in developing the presentation stack. One of the end products of working in a cooperative group would then be to take a stack that has the appearance of this one and making it look like the stack for presentation (see appendix C.02)--a multimedia presentation on the diversity of animal life.

PHYLUM 10: ECHINODERMATA \{G., echino, spiny; derma, skin \} Marine animals with calcareous (hard), spiny coverings. Radially symmetrical adults, often with five spokes, develop by metamorphosis from bilateral larvae. Locomotion by TUBE FEET, whose movements are regulated by their unique WATER-VASCULAR SYSTEMS, a network of hydraulic canals whose function also includes feeding \& gas exchange. Sexual reproduction is external, from two separate sexes; one species of sea stars can regenerate entire body from a single spoke (arm).

Six classes:

(1) ASTEROIDEA: sea stars

(2) OPHIUROIDEA: brittle stars

(3) ECHINOIDEA: sea urchins \& sand dollars

(4) CRINOIDEA: sea lilies

(5) HOLOTHUROIDEA: sea cucumbers

(6) CONCENTRICYCLOIDEA: sea daisies

AV EVENTS

\section{PHYLUM ECHINODERMATA}

\section{Class 1. ASTEROIDEA (1229*): Sea Stars}

$\left(1230^{*}\right)$ Linckia lavigata; cobalt sea star. This brilliant blue starfish is found in the coral reefs of the Indo-Pacific. It grows up to sixteen inches in diameter. NOTICE: This starfish does not have suckers on the ends of its tube feet. Instead, the tube feet are pointed so they 
can force their way into the soft sand where this starfish lives. Each tube foot has a double ampulla to provide more force.

Q: What is the small, light blue spot in the center?

A: The madreporite (sieve plate)

Side 3 Movie: STARFISH (41933-43341*)

SUMMARY: Starfish locomotion and feeding; scallop's eyes and locomotor response to a starfish.

NARRATION: The tube feet of a starfish are arranged in rows under each of its arms. The tip of each foot can be contracted, using a system of muscles and water pressure to form a tiny suction cup. Hundreds of these provide the creature with a very firm grip on the sea bed.

The pale transparent bag appearing beneath the starfish is its stomach, which is turned inside out to digest food outside its body. Protruding from each half of the scallop's shell is a line of small, very sensitive tentacles. Between these, is a row of tiny, glistening spheres. Each one is an eye, equipped with lens, retina and nerve fiber. If the scallop senses danger, it can swim rapidly away, using a series of contractions to eject water from between the halves of its shell.

The slightest touch of the starfish on a scallop's tentacle is enough to send it scuttling away.

(2617*) Diagram: Starfish

(168*) Starfish; oral view showing stomach. NOTICE: The starfish has a very thin-walled stomach that it can slide between the valves of a clam that has been wired shut. This starfish's stomach is in the center of the picture and is partly extruded.

(2170*) Starfish dissection showing ampullae (aboral end of tube feet).

NOTICE: The light-colored spheres in the center of the picture are the ampullae that control the tube feet seen in the bottom of the picture. The top of the ray and the surrounding internal organs have been removed.

$\left(2183^{*}\right)$ Preserved starfish showing ring canal.

(2184*) Preserved starfish showing radial canal and ampullae. 


\section{Appendix D \\ Measurement Tools}

After fifteen hours of instruction in a CBIV biology unit on the diversity of animal life, the subjects achievement was measured by an 80 item researcher-designed comprehensive achievement exam, and their attitudes was also measured utilizing a 14 item inventory. They are both included here in their entirety.

\section{D.01 Researcher-Designed Achievement Test}

This exam was given in four different versions which had the same identical questions in the same order, but with the alternatives scrambled. Subjects were given all the time they needed in order to finish, which came out to be an average of about 20 minutes. The responses were recorded in a Scantron form number 20052, which allows for subject and test version identification by I.D. numbers, and is graded automatically by the computer testing program LXR-TEST by means of a Scantron optical reader interfaced with the computer containing the program. This program also performs simple statistical analyzes on test scores, and is capable of calculating the reliability of a test using the Cronbach-alpha formula.

The test is presented here in a word processing format exported from LXR•TEST. It is slightly different in appearance to the format of LXR・TEST, but the questions are identical in content. Question level is indicated prior to each, and the correct answer is either given or marked with an asterisk. 


\section{ANIMAL DIVERSITY FINAL ACHIEVEMENT TEST}

APPLICATION LEVEL

1. Which one of the following is the most fundamental difference between the five kingdoms?
A. asexual vs. sexual reproduction
B. autotrophs vs. heterotrophs
C. prokaryotes vs. eukaryotes*
D. taxonomy vs. phylogeny
E. unicellular vs. multicellular

\section{APPLICATION LEVEL}

2. Organisms having a mesoderm can best be described as being
A. asymmetrical.
B. diploblastic.
C. mesoblastic.
D. multicellular.
E. triploblastic.*

\section{KNOWLEDGE LEVEL}

3. The evolutionary history of a group of related species is referred to as
A. binomial nomenclature.
B. natural history.
C. natural selection.
D. phylogeny.*
E. taxonomy. 


\section{APPLICATION LEVEL}

4. If two similar, but not identical, organisms mate and produce fertile offspring, then they must be
A. different sexes of the same species.*
B. different species but closely related.
C. members of the same family.
D. similar species but members of the same genus.
E. None of the above.

\section{COMPREHENSION LEVEL}

5. Which one of the following is NOT a difference between prokaryotes and eukaryotes?
A. membrane-bound organelles vs. no membrane-bound organelles
B. nucleus vs. no nucleus
C. one vs. paired (homologous) chromo-somes
D. photosynthesis vs. respiration*
E. smaller vs. larger cells

\section{KNOWLEDGE LEVEL}

6. Which of the following is included in the two part Latin name assigned to each organism?
A. family-genera
B. family-species
C. genus-species*
D. kingdom-phylum
E. species-variety 
DIRECTIONS: Use the following diagram to answer questions 7-9. (The same letters may be used repeatedly; some may not be used at all.)

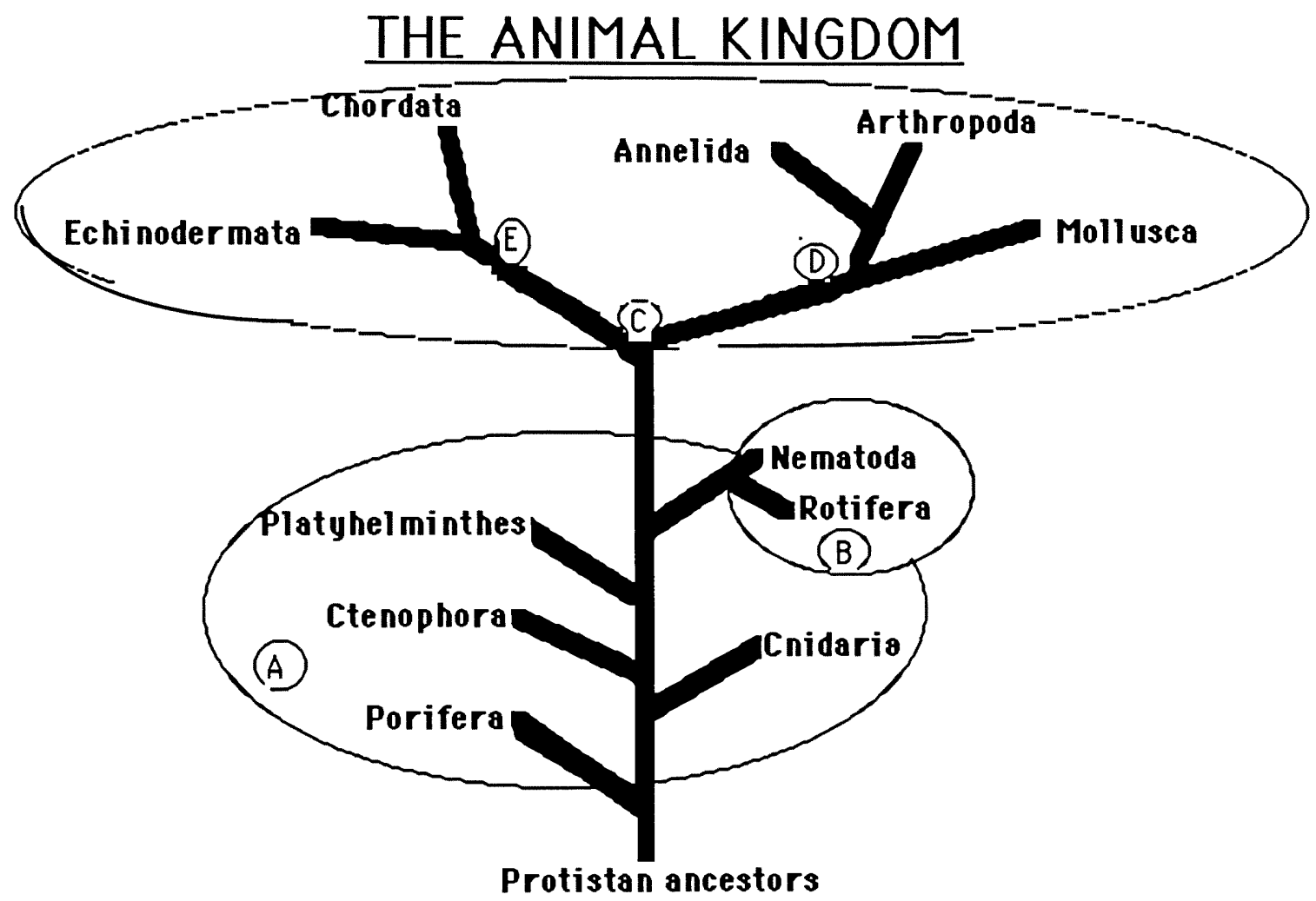

APPLICATION LEVEL

7. In which group of animals does the anus develop from the blastopore?

Answer: $\mathrm{E}$

\section{APPLICATION LEVEL}

8. Which group of animals develop a pseudocoelom? Answer: $B$ 


\section{APPLICATION LEVEL}

9. Which group of animals have a body cavity completely lined by mesodermally derived tissue?

Answer: C

COMPREHENSION LEVEL

10. Which organisms are most closely related to humans?
A. annelids
B. insects
C. octopus
D. spiders
E. starfish*

\section{KNOWLEDGE LEVEL}

11. What are porocytes?
A. The large opening through which water leaves sponges.
B. The small opening through which water enters sponges.*
C. The parasite which commonly kills sponges.
D. The breathing organ in sponges.
E. The middle body layer of sponges. 


\section{KNOWLEDGE LEVEL}

12. How does water flow through the body of sponges?
A. It enters and leaves through the osculum.
B. It enters and leaves through the pores.
C. It enters through the osculum and leaves through the pores.
D. It enters through the pores and leaves through choanocytes.
E. It enters through the pores and leaves through the osculum.*

\section{KNOWLEDGE LEVEL}

13. Which of the following is NOT true concerning the larvae produced by sponges?
A. They lack locomotive ability.*
B. They are flagellated.
C. They undergo metamorphosis.
D. They develop in the mesoglea.
E. They are a product of sexual reproduction.

\section{KNOWLEDGE LEVEL}

14. What are gemmules?
A. A special way for sponges to reproduce asexually.*
B. A subgroup of sponges.
C. Food for the sponges.
D. Male gametes in sponges only.
E. Small gems found in sponges. 


\section{COMPREHENSION LEVEL}

15. Hermaphrodites
A. produce only sperm.
B. produce only eggs.
C. produce only zygotes.
D. produce both sperm and eggs.*
E produce both collar \& epidermal cells.

\section{KNOWLEDGE LEVEL}

16. Which of the following is NOT a characteristics of sponges?
A. They are filter feeders.
B. They have bodies with 2 cell layers.
C. They use flagellated collar.
D. They allow water to enter through one opening.*
E. They have amoeboid cells that digest food and make skeletal fibers.

\section{APPLICATION LEVEL}

17. Why would you expect a sponge to appear similar to an organism from other phyla such as tunicates and coral?
A. They live in similar habitats.
B. They are closely related.
C. They defend themselves from similar predators.
D. They have similar sessile lifestyles.*
E. They need to compete with each other for survival. 


\section{KNOWLEDGE LEVEL}

18. What is the name for the free-swimming form of cnidarians?
A. bud
B. coelenterate
C. medusa*
D. nematocyst
E. polyp

\section{COMPREHENSION LEVEL}

19. How is the Portuguese man-of-war different from other common members of the same phylum?
A. It floats on the ocean surface due to air inside its medusa form.*
B. It lacks stinging cells called nematocysts.
C. It is a colonial form of specialized polyps only.
D. It lacks a nervous system to recognize prey.
E. It has a sac body system, with only a mouth and no anus.

\section{COMPREHENSION LEVEL}

20. Which is the typical body plan of the cnidarian? (In order of arrangement)
A. ectoderm, mesoderm, endoderm
B. ectoderm, mesoglea, gastroderm*
C. mesoderm, ectoderm, endoderm
D. ectoderm, mesoglea, ectoderm
E. ectoderm, gastroderm, mesoglea 


\section{KNOWLEDGE LEVEL}

21. Hydras may reproduce asexually by producing
A. buds.*
B. hermaphroditic eggs.
C. seeds.
D. sperms only.
E. spores.

\section{KNOWLEDGE LEVEL}

22. How would you best describe the relationship between corals and the algae within their bodies?
A. parasitic
B. predator-prey
C. symbiotic*
D. sexual
E. unnatural

\section{APPLICATION LEVEL}

23. Which one of the following Does Not belong to the same class as the others?
A. hydrozoans*
B. most corals
C. sea anemones
D. sea fans
E. All of the above belong to the same class. 


\section{COMPREHENSION LEVEL}

24. Which of the following is a way ctenophorans differ from a cnidarians?
A. They have radially symmetrical bodies.
B. They have two cell-layered bodies.
C. They have retractable tentacles.
D. They have more complex digestive cavities.*
E. They have translucent, gelatinous bodies.

\section{KNOWLEDGE LEVEL}

25. The term Platyhelminthes is derived from two Greek words meaning
A. complex and organism.
B. flat and crawler.
C. flat and worm.*
D. planarian worm.
E. simple and worm.

\section{COMPREHENSION LEVEL}

26. Planarians are hermaphrodites. This means that
A. each individual worm has both male and female reproductive organs.*
B. each individual worm can reproduce asexually as well as sexually.
C. individual worms have no gamete-producing structures.
D. male and female individuals exists.
E. they have a wide variety of reproductive strategies. 


\section{KNOWLEDGE LEVEL}

27. All flukes (trematoda)
A. are free living.
B. are roundworms.
C. are parasites.*
D. are segmented worms.
E. reproduce by fragmentation.

\section{COMPREHENSION LEVEL}

28. Tapeworms are highly specialized to a parasitic way of life because they
A. are lethal to their host.
B. are intestinal parasites.
C. have several hosts in their life cycle.
D. have special ways of doing things.
E. lack the organs required for 'free-living'.*

\section{COMPREHENSION LEVEL}

29. Which one of the following is NOT a characteristic of the parasitic classes of platyhelminthes?
A. They have bilateral symmetry.
B. They are tripoblastic.
C. They have enlarged nerve cords in head region.
D. They have incomplete digestive systems with one opening.
E. They have well developed organ systems.* 


\section{APPLICATION LEVEL}

30. Which organism belongs to phylum platyhelminthes?
A. earthworm
B. fluke*
C. leech
D. roundworm
E. tubeworm

KNOWLEDGE LEVEL

31. Which phylum posses mouths with a crown of cilia ('wheel') that draws-in water and microorganisms?
A. Ctenophora
B. Mollusca
C. Nematoda
D. Platyhelminthes
E. Rotifera*

\section{APPLICATION LEVEL}

32. Which of the following is common to Phyla Rotifera and Nematoda?
A. They reproduce parthenogenically.
B. They are pseudocoelomates.*
C They have worm-like bodies.
D. They have heads that are armed with suckers and hooks.
E. They are primarily parasitic. 


\section{KNOWLEDGE LEVEL}

33. Roundworms are found in phylum
A. Annelida.
B. Nematoda.*
C. Arachnida.
D. Anthropoda.
E. Ctenophora.

\section{COMPREHENSION LEVEL}

34. How do nematodes differ from platyhelminthes?
A. They are a mostly parasitic species.
B. They are capable of reproducing sexually.
C. They have longitudinal muscles in pseudocoelom.*
D. They have worm-like bodies.
E. They are tripoblastic.

\section{APPLICATION LEVEL}

35. What is the best way to prevent the disease trichinosis?
A. Cook pork thoroughly.*
B. Rinse fresh vegetables thoroughly.
C. Wash your hands before eating.
D. Wear shoes outdoors.
E. None of the above is effective. 


\section{KNOWLEDGE LEVEL}

36. The visceral mass of mollusks
A. contains the internal organs.*
B. has tentacles.
C. is used for locomotion.
D. is a rasping organ used to scrape up food.
E. produces the exoskeleton.

\section{COMPREHENSION LEVEL}

37. Shells of clams are composed of
A. calcium carbonate.*
B. carbohydrates.
C. quartz.
D. silicon oxide.
E. spongin.

\section{KNOWLEDGE LEVEL}

38. Which organisms have eyes in a mantle and are capable of locomotion by flapping their shells?
A. clams
B. mussels
C. octopuses
D. oysters
E. scallops* 


\section{KNOWLEDGE LEVEL}

39. Which of the following are insects?
A. centipedes
B. mites \& ticks
C. scorpions
D. spiders
E. silverfishes*

\section{COMPREHENSION LEVEL}

40. Millipedes feed mostly on
A. decayed plants.*
B. crustaceans.
C. other insects.
D. wood products.
E. plankton.

KNOWLEDGE LEVEL

41. The transformation of an immature form of an insect to the adult insect is called
A. development.
B. gastrulation.
C. growth.
D. metamorphosis.*
E. molting. 


\section{APPLICATION LEVEL}

42. How do annelids differ from the other worms?
A. They are hermaphroditic.
B. They have a true coelom.*
C. They are parasitic.
D. They have three tissue layers.
E. They are round.

\section{KNOWLEDGE LEVEL}

43. Respiration in the earthworm occurs primarily through their
A. gills.
B. lungs.
C moist skin.*
D. tracheal tubes.
E. None of the above.

KNOWLEDGE LEVEL

44. Liquid wastes in the earthworm are removed by structures called
A. kidneys.
B. nephridia.*
C. penises.
D. setae.
E. ureters. 


\section{APPLICATION LEVEL}

45. A new species of aquatic animal is discovered with the following characteristics: heavy exoskeleton; gills for gas exchange; many appendages and two pairs of antennae. A knowledgeable zoologist would also predict that in order to grow in size, it would have to
A. grow new body segments.
B. produce new germ layers.
C. regenerate new body parts.
D. undergo metamorphosis.
E. undergo molting.*

\section{COMPREHENSION LEVEL}

46. All of the following animal groups have evolved terrestrial life forms EXCEPT
A. Arachnida.
B. Crustacea.
C. Echinodermata.*
D. Mollusca.
E. Vertebrata.

\section{APPLICATION LEVEL}

47. All of the following are protostomes EXCEPT
A. arachnids.
B. echinoderms.*
C insects.
D. mollusks.
E. segmented worms. 


\section{KNOWLEDGE LEVEL}

48. Which is NOT a function of the water-vascular system in echinoderms?
A. It is used to regulate the tube feet.
B. It is used in feeding.
C. It is used for gas exchange.
D. It is used during reproduction.*
E. It is used in locomotion.

\section{KNOWLEDGE LEVEL}

49. Which one of the following is an echinoderm?
A. sea cucumber*
B. sea anemone
C. sea fan
D. sea horse
E. sea slug

\section{KNOWLEDGE LEVEL}

50. The name Echinodermata means
A. five parts.
B. spiny skin.*
C. jointed foot.
D. hard skin.
E. radial spokes. 


\section{KNOWLEDGE LEVEL}

51. A starfish feeds by
A. filter (suspension) feeding.
B. letting its stomach hang out of its body to digest food.*
C. pulling its prey into its stomach with tentacles.
D. tearing its prey into small pieces it can swallow.
E. use of a radula in the central part of its body.

DIRECTIONS: Use the following diagram to answer questions $52-61$. (The same letters may be used repeatedly; some may not be used at all.)

\section{PHYLUM CHORDATA:}

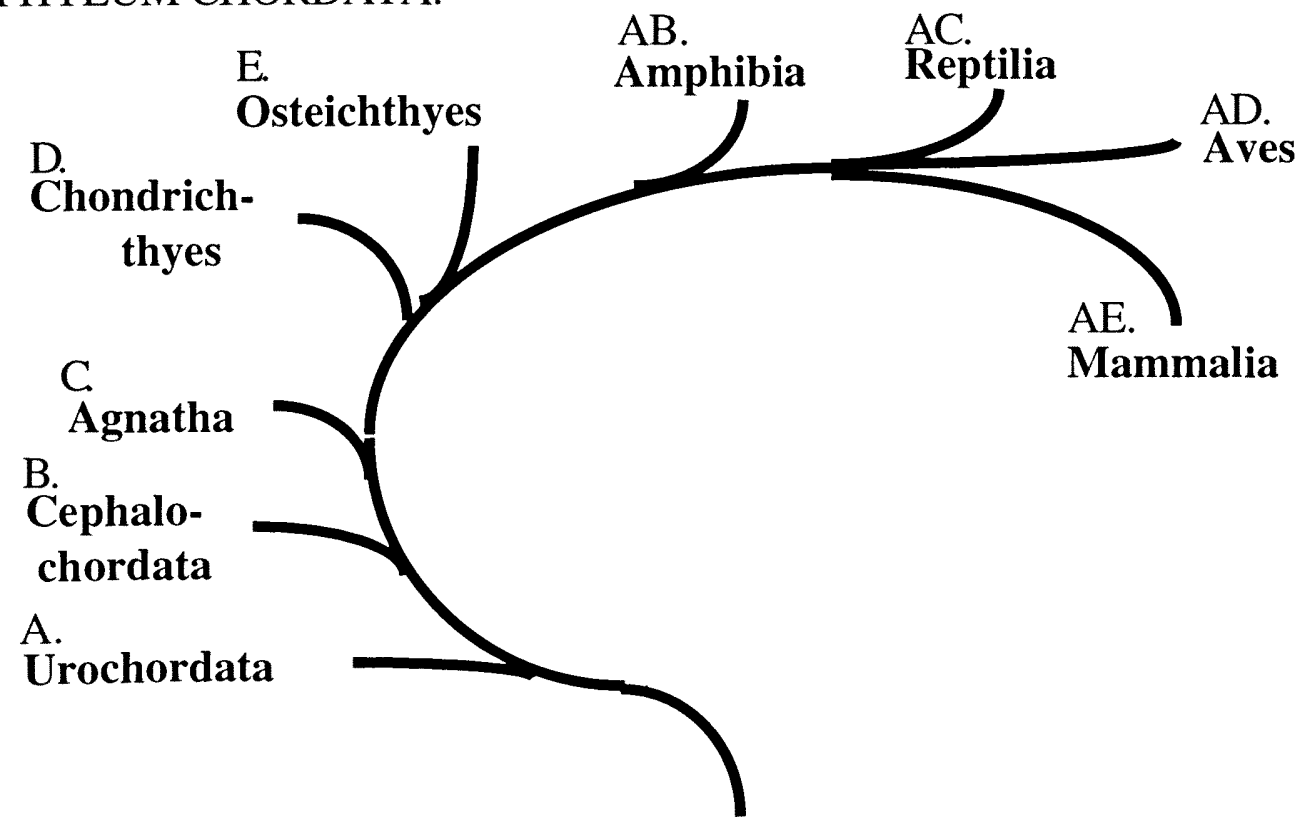




\section{KNOWLEDGE LEVEL}

52. Which letter(s) represents large sessile marine animals who produce tadpole-like larvae with chordate characteristics that are lost when they undergo metamorphosis into adult forms?

Answer: A

\section{KNOWLEDGE LEVEL}

53. Which letter(s) represents bony fishes?

Answer: $\mathrm{E}$

\section{KNOWLEDGE LEVEL}

54. Which letter(s) represents animals that are also known as lancelets?

Answer: B

\section{KNOWLEDGE LEVEL}

55. Which letter(s) represents animals that are endotherms and mostly terrestrial?

Answer: $\mathrm{AE}$

\section{KNOWLEDGE LEVEL}

56. Which letter(s) represents animals that are ancestors to birds and mammals?

Answer: AC 


\section{APPLICATION LEVEL}

57. Which letter(s) represents animals that must return to water to lay their eggs?

Answer: $\mathrm{AB}$

\section{KNOWLEDGE LEVEL}

58. Which letter(s) represents animals that are also known as tunicates?

Answer: A

\section{KNOWLEDGE LEVEL}

59. Which letter(s) represents cartilaginous fish with placoid scales?

Answer: D

\section{KNOWLEDGE LEVEL}

60. Which letter(s) represents salamanders and newts?

Answer: $\quad \mathrm{AB}$

\section{KNOWLEDGE LEVEL}

61. Which letter(s) represents lampreys, hagfish, and eels? Answer: $\mathrm{C}$ 


\section{COMPREHENSION LEVEL}

62. Jaws first occurred in which one of the following classes?
A. Agnatha
B. Cephalochordata
C. Chondrichthyes*
D. Osteichthyes
E. Urochordata

\section{APPLICATION LEVEL}

63. A newly discovered organism has the following characteristics: a vertebral column, breathe by lungs, lays eggs, and is ectothermic. To which one of the following organisms is it most closely related?
A. bat
B. chicken
C. frog
D. penguin
E. snake*

\section{APPLICATION LEVEL}

64. A newly discovered organism has the following characteristics: a vertebral column, lays eggs, soft glandular skin and is ectothermic. To which one of the following organisms is it most closely related?
A. earthworm
B. penguin
C. platypus
D. salamander*
E. snake 


\section{COMPREHENSION LEVEL}

65. Which one of the following is a chordate, BUT NOT a vertebrate?
A. frog
B. chondrichthye
C. coral
D. snake
E. tunicate*

KNOWLEDGE LEVEL

66. Which statement describes a viviparous animal?
A. Their young are born alive after developing inside an egg laid outside the body of the mother.
B. Their young are born alive after developing inside the mother's uterus.*
C. Their young are born hermaphroditic.
D. Their young are egg-laying when they mature.
E. Their young develop inside eggs within the mother's body and are released when mature. 


\section{KNOWLEDGE LEVEL}

67. Which of the following characteristics describes the class to which penguins belong?
A. aquatic; breathe by gills and lungs
B. egg-laying; feathers; endotherms*
C. insect-eating marine mammals
D. marine; carnivorous; sharp canine teeth; adapted for swimming
E. use mammary gland milk to nourish their young; have hair covering body

\section{KNOWLEDGE LEVEL}

68. Which one of the following DOES NOT have opposable thumb, forward facing eyes, and well developed cerebral cortex?
A. apes and monkeys
B. carnivora*
C. humans
D. lemurs
E. primates 


\section{KNOWLEDGE LEVEL}

69. Which one of the following is/are NOT shared by dolphins and whales?
A. fish-shaped bodies
B. marine life
C. some body hair
D. scales and gills*
E. viviparous

\section{KNOWLEDGE LEVEL}

70. A dogfish shark has a capsule known as 'mermaid's purse'. It's purpose is
A. to allow eggs to develop embryologically.*
B. to allow carry excess food.
C. to allow attack members of the opposite sex.
D. to allow attack its prey.
E. None of the above.

\section{COMPREHENSION LEVEL}

71. The territorial courtship behavior of a stickleback
A. can be stimulated by fake models.
B. involves coloration.
C. involves a dance.
D. involves body shape.
E. All of the above. * 


\section{COMPREHENSION LEVEL}

72. A seahorse belongs to which one of the following?
A. Cephalochordata
B. Chondrichthyes*
C. Echinodermata
D. Osteichthyes
E. Urochordata

\section{COMPREHENSION LEVEL}

73. The flatfish, leaffish, puffer fish, and clownfish are all characterized by
A. aggressive behavior.
B. camouflage.
C. maternal behavior.
D. passive defenses.*
E. swimming skills.

\section{COMPREHENSION LEVEL}

74. A crocodiles' maternal behavior involves
A. aggressive, even eating their young.
B. extreme care, even after hatching.*
C. laying eggs and abandoning them, just like lizards.
D. nursing with milk after they are born.
E. None of the above. 


\section{KNOWLEDGE LEVEL}

75. Which is the largest animal ever to live on earth?
A. 'big-foot'
B. blue whale*
C. dinosaur
D. elephant
E. giant squid

KNOWLEDGE LEVEL

76. Penguins are birds whose mode of locomotion includes all of the following EXCEPT
A. flying.*
B. running upright.
C. sliding on their bellies.
D. swimming.
E. walking.

\section{COMPREHENSION LEVEL}

77. Birds such as penguins, grouse, and flamingo are characterized by
A. camouflage.
B. flying skills.
C. similar courtship behavior.
D. social behavior.*
E. swimming skills. 
78. Which one of the following DOES NOT belong in the same group as the others?
A. grizzly bear*
B. kangaroo
C. marsupial
D. koala bear
E. possum (opossum)

\section{COMPREHENSION LEVEL}

79. How would you describe the defense of a pangolin?
A. aggressive
B. agonistic
C. camouflage
D. escape
E. structural*

\section{COMPREHENSION LEVEL}

80. Which one of the following DOES NOT exhibit aggressive behavior?
A. baboon
B. elephant seal
C. hippopotamus
D. lion
E. sloth* 


\section{D.02 Attitudes Survey}

At the end of the pilot study all subjects were given the Attitude Toward Science in School Assessment (ATSSA), an instrument developed by Germann (1988) as a measure of a single dimension of general attitudes toward science, specifically, how students feel toward science as a subject in school. A researchermodified version of this instrument in which the statement 'using computer-based laserdiscs' or 'by means of computer-based laserdiscs' were inserted into each item in order to measure the strength of the individual's attitudes toward science laserdisc instruction, was administered during both the pilot and research studies. Both of these instruments are included in this appendix.

The concurrent validity of the researcher-modified version of the attitudes inventory was determined by comparing the subjects responses from the two instruments obtained during the pilot study. A concurrent correlation coefficient of 0.9897 was calculated from this comparison; since this comparison establishes the validity of the more specific researcher-modified version, it alone was utilized to measure attitudes in the research study.

Since each question in the inventory has 5 responses in a Likert scale format, each response was given weighted in positive values from 1 to 5 depending on direction of positive response. This means that the most negative response possible would be 1 point for each of 14 questions for a total value of 14 . The most positive response possible would be 5 points for each of 14 questions for a total value of 70 . 
Attitude toward Science in School Assessment

Please use this scale to answer the following questions:

$$
\begin{aligned}
& \text { SA - Strongly Agree } \\
& \text { A - Agree } \\
& \text { N - Neither agree nor disagree } \\
& \text { D - Disagree } \\
& \text { SD - Strongly Disagree }
\end{aligned}
$$

\begin{tabular}{|c|c|c|c|c|c|c|}
\hline 1. & SA & A & $\mathrm{N}$ & $\mathrm{D}$ & $\mathrm{SD}$ & Science is fun. \\
\hline 2. & SA & A & $\mathrm{N}$ & $\mathrm{D}$ & SD & $\begin{array}{l}\text { I do not like science and it bothers } \\
\text { me to have to study it. }\end{array}$ \\
\hline 3. & SA & A & $\mathrm{N}$ & $\mathrm{D}$ & SD & $\begin{array}{l}\text { During science class, I usually am } \\
\text { interested. }\end{array}$ \\
\hline 4. & SA & A & $\mathrm{N}$ & $\mathrm{D}$ & SD & $\begin{array}{l}\text { I would like to learn more about } \\
\text { science. }\end{array}$ \\
\hline 5. & SA & A & $\mathrm{N}$ & $\mathrm{D}$ & $\mathrm{SD}$ & $\begin{array}{l}\text { If I knew I would never go to } \\
\text { science class again, I would feel } \\
\text { sad. }\end{array}$ \\
\hline 6. & SA & A & $\mathrm{N}$ & $\mathrm{D}$ & $\mathrm{SD}$ & $\begin{array}{l}\text { Science is interesting to me and I } \\
\text { enjoy it. }\end{array}$ \\
\hline 7. & SA & A & $\mathrm{N}$ & $\mathrm{D}$ & $\mathrm{SD}$ & $\begin{array}{l}\text { Science makes me feel } \\
\text { uncomfortable, restless, irritable, } \\
\text { and impatient. }\end{array}$ \\
\hline 8. & SA & A & $\mathrm{N}$ & $\mathrm{D}$ & $\mathrm{SD}$ & Science is fascinating and fun. \\
\hline 9. & SA & A & $\mathrm{N}$ & $\mathrm{D}$ & SD & $\begin{array}{l}\text { The feeling that I have towards } \\
\text { science is a good feeling. }\end{array}$ \\
\hline 10. & SA & A & $\mathrm{N}$ & $\mathrm{D}$ & $\mathrm{SD}$ & $\begin{array}{l}\text { When I hear the word science, } \\
\text { I have a feeling of dislike. }\end{array}$ \\
\hline 11. & SA & A & $\mathrm{N}$ & $\mathrm{D}$ & $\mathrm{SD}$ & $\begin{array}{l}\text { Science is a topic which I enjoy } \\
\text { studying. }\end{array}$ \\
\hline 12. & SA & A & $\mathrm{N}$ & $\mathrm{D}$ & $\mathrm{SD}$ & $\begin{array}{l}\text { I feel at ease with science and I } \\
\text { like it very much. }\end{array}$ \\
\hline 13. & SA & A & $\mathrm{N}$ & $\mathrm{D}$ & $\mathrm{SD}$ & $\begin{array}{l}\text { I feel a definite positive reaction } \\
\text { to science. }\end{array}$ \\
\hline 14. & SA & A & $\mathrm{N}$ & $\mathrm{D}$ & $\mathrm{SD}$ & Science is boring. \\
\hline
\end{tabular}

(Circle one choice.) 
Attitudes toward learning Science in School by means of Laserdiscs Assessment

Please use this scale to answer the following questions: SA - Strongly Agree
A - Agree
$\mathrm{N}$ - Neither agree nor disagree
D - Disagree
SD - Strongly Disagree

(Circle one choice.)

\begin{tabular}{|c|c|c|c|c|c|c|}
\hline 1. & SA & A & $\mathrm{N}$ & D & $\mathrm{SD}$ & $\begin{array}{l}\text { Science using computer-based } \\
\text { laserdiscs is fun. }\end{array}$ \\
\hline 2. & SA & A & $\mathrm{N}$ & D & $\mathrm{SD}$ & $\begin{array}{l}\text { I do not like to learn science using } \\
\text { computer-based laserdiscs and it } \\
\text { bothers me to have to study it. }\end{array}$ \\
\hline 3. & SA & A & $\mathrm{N}$ & $\mathrm{D}$ & $\mathrm{SD}$ & $\begin{array}{l}\text { During science class while using } \\
\text { computer-based laserdiscs, I usually } \\
\text { am interested. }\end{array}$ \\
\hline 4. & SA & A & $\mathrm{N}$ & D & SD & $\begin{array}{l}\text { I would like to learn more about } \\
\text { science by means of computer-based } \\
\text { laserdiscs. }\end{array}$ \\
\hline 5. & SA & A & $\mathrm{N}$ & D & SD & $\begin{array}{l}\text { If I knew I would never go to } \\
\text { science class again and learn from } \\
\text { computer-based laserdiscs, I would } \\
\text { feel sad. }\end{array}$ \\
\hline 6. & SA & A & $\mathrm{N}$ & D & SD & $\begin{array}{l}\text { Science by means of computer-based } \\
\text { laserdiscs is interesting to me and I } \\
\text { enjoy it. }\end{array}$ \\
\hline 7. & SA & A & $\mathrm{N}$ & D & SD & $\begin{array}{l}\text { Science by means of computer-based } \\
\text { laserdiscs makes me feel } \\
\text { uncomfortable, restless, irritable, } \\
\text { and impatient. }\end{array}$ \\
\hline 8. & SA & A & $\mathrm{N}$ & D & SD & $\begin{array}{l}\text { Science by means of computer-based } \\
\text { laserdiscs is fascinating and fun. }\end{array}$ \\
\hline 9. & SA & A & $\mathrm{N}$ & D & SD & $\begin{array}{l}\text { The feeling that I have towards } \\
\text { science by means of computer-based } \\
\text { laserdiscs is a good feeling. }\end{array}$ \\
\hline 10. & SA & A & $\mathrm{N}$ & D & SD & $\begin{array}{l}\text { When I hear the word science by } \\
\text { means of computer-based laserdiscs, } \\
\text { I have a feeling of dislike. }\end{array}$ \\
\hline 11. & SA & A & $\mathrm{N}$ & D & SD & $\begin{array}{l}\text { Science is a topic which I enjoy } \\
\text { studying by means of computer-based } \\
\text { laserdiscs. }\end{array}$ \\
\hline 12. & SA & A & $\mathrm{N}$ & D & SD & $\begin{array}{l}\text { I feel at ease with science by means } \\
\text { of computer-based laserdiscs and I } \\
\text { like it very much. }\end{array}$ \\
\hline 13. & SA & A & $\mathrm{N}$ & D & SD & $\begin{array}{l}\text { I feel a definite positive reaction } \\
\text { to science by means of computer- } \\
\text { based laserdiscs. }\end{array}$ \\
\hline 14. & $\mathrm{SA}$ & A & $\mathrm{N}$ & D & SD & $\begin{array}{l}\text { Science by means of computer-based } \\
\text { laserdiscs is boring. }\end{array}$ \\
\hline
\end{tabular}




\section{Statistical Information}

The data obtained was listed into thirteen categories. Category 2 (GP.ID) through 8 (GPA) are all independent variables. Categories 9 (ACHIV.L1) through 13 (ATTI) are dependent variables. They are all described and listed in this appendix.

\begin{tabular}{|c|c|c|c|c|}
\hline SUB.ID & GP.ID & CLASS.LEVEL & GENDER & ETHNIC \\
\hline $\begin{array}{l}\text { subject ID, } \\
\text { values } 1-64\end{array}$ & $\mid \begin{aligned} & 1= \text { cooperative } \\
& 2= \text { traditional } \\
& \text { (whole-class } \\
& \text { lecture) }\end{aligned}$ & $\begin{array}{l}1=\text { honors } \\
2=\text { regular }\end{array}$ & $\begin{array}{l}1=\text { female } \\
2=\text { male }\end{array}$ & $\begin{array}{l}1=\text { black } \\
2=\text { hispanic } \\
3=\text { white } \\
4=\text { other }\end{array}$ \\
\hline
\end{tabular}

\begin{tabular}{|l|l|l|l|l|}
\hline MATH & LANGUAGE & G.P.A. & ACHIV.L1 & ACHIV.L2 \\
\hline Ave. Math & Ave. & un- & Achievement, & Achievement, \\
Stanford & Language & weighted & Knowledge & Comprehension \\
Score = 1-9 & $\begin{array}{l}\text { Stanford } \\
\text { Score =1-9 }\end{array}$ & $0.0-4.0$ & Level =0-40 & Level =0 - 22 \\
\hline
\end{tabular}

\begin{tabular}{|l|l|l|}
\hline ACHIV.L3 & ACHIV.TL & ATTI \\
\hline Achievement, & Total (Overall) & Attitudes \\
Application & Achievement. All & toward CBIV \\
Level =0-18 & $\begin{array}{l}\text { three levels } \\
\text { combined =0 - 80 }\end{array}$ & \begin{tabular}{l}
$14-70$ \\
\hline
\end{tabular} \\
\hline
\end{tabular}

\section{$\underline{\text { Data }}$}

SUB.ID GP.ID CLAS.L GEN ETH MATH LANG GPA ACHI.L1 ACHI.L2 ACHI.L3 ACHI..TL ATTI

$\begin{array}{lllllllllclll}1 & 1 & 1 & 1 & 2 & 7.5 & 7.0 & 3.70 & 21 & 10 & 12 & 43 & 54 \\ 2 & 1 & 1 & 1 & 2 & 7.5 & 7.0 & 3.28 & 23 & 14 & 13 & 50 & 52 \\ 3 & 1 & 1 & 2 & 1 & 5.0 & 4.5 & 2.83 & 17 & 9 & 8 & 34 & 50 \\ 4 & 1 & 1 & 2 & 2 & 8.0 & 4.5 & 3.83 & 22 & 13 & 9 & 44 & 60\end{array}$


$\begin{array}{lllllllllllll}5 & 1 & 1 & 2 & 4 & 8.5 & 8.0 & 3.56 & 32 & 16 & 13 & 61 & 48\end{array}$ $\begin{array}{lllllllllllll}6 & 1 & 1 & 1 & 2 & 6.0 & 4.0 & 3.28 & 11 & 9 & 6 & 26 & 54\end{array}$ $\begin{array}{lllllll}7 & 1 & 1 & 1 & 3 & 7.0 & 5.0\end{array}$ $\begin{array}{lllllll}8 & 1 & 1 & 2 & 2 & 4.5 & 3.0\end{array}$ $\begin{array}{lllllll}9 & 1 & 1 & 2 & 3 & 7.5 & 6.0\end{array}$ $\begin{array}{lllllll}10 & 1 & 1 & 1 & 2 & 4.0 & 6.0\end{array}$

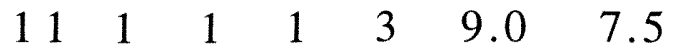
$\begin{array}{lllllll}12 & 1 & 2 & 2 & 2 & 4.5 & 3.0\end{array}$ $\begin{array}{lllllll}13 & 1 & 2 & 2 & 2 & 3.5 & 3.5\end{array}$ $\begin{array}{lllllll}14 & 1 & 2 & 1 & 2 & 6.0 & 4.5\end{array}$ $\begin{array}{lllllll}15 & 1 & 2 & 2 & 3 & 1.5 & 3.5\end{array}$ $\begin{array}{lllllll}16 & 1 & 2 & 2 & 2 & 3.0 & 4.0\end{array}$ $\begin{array}{lllllll}17 & 1 & 2 & 2 & 1 & 3.0 & 2.0\end{array}$ $\begin{array}{lllllll}18 & 1 & 2 & 2 & 2 & 4.5 & 2.0\end{array}$ $\begin{array}{lllllll}19 & 1 & 1 & 2 & 2 & 6.5 & 6.5\end{array}$ $\begin{array}{lllllll}20 & 1 & 2 & 1 & 1 & 3.0 & 1.5\end{array}$ $\begin{array}{lllllll}21 & 1 & 2 & 2 & 2 & 3.0 & 3.0\end{array}$ $\begin{array}{lllllll}22 & 1 & 2 & 1 & 2 & 7.0 & 5.0\end{array}$ $\begin{array}{lllllll}23 & 1 & 2 & 2 & 2 & 2.0 & 4.5\end{array}$ $\begin{array}{lllllll}24 & 1 & 2 & 2 & 2 & 3.0 & 1.5\end{array}$ $\begin{array}{lllllll}25 & 1 & 2 & 1 & 2 & 5.0 & 4.0\end{array}$ $\begin{array}{lllllll}26 & 1 & 2 & 2 & 1 & 4.0 & 3.0\end{array}$ $\begin{array}{lllllll}27 & 1 & 1 & 2 & 3 & 6.0 & 5.5\end{array}$ $\begin{array}{lllllll}28 & 1 & 1 & 2 & 2 & 5.5 & 3.5\end{array}$ $\begin{array}{lllllll}29 & 1 & 1 & 1 & 2 & 5.0 & 4.5\end{array}$ $\begin{array}{lllllll}30 & 1 & 2 & 2 & 1 & 3.0 & 2.0\end{array}$ $\begin{array}{lllllll}31 & 1 & 2 & 2 & 2 & 3.0 & 3.0\end{array}$ $\begin{array}{llllllll}32 & 1 & 1 & 2 & 3 & 6.0 & 5.5\end{array}$ $\begin{array}{lllllll}33 & 2 & 1 & 1 & 2 & 5.5 & 3.5\end{array}$ $\begin{array}{lllllll}34 & 2 & 1 & 1 & 2 & 6.0 & 6.0\end{array}$ $\begin{array}{lllllll}35 & 2 & 1 & 2 & 2 & 6.5 & 5.5\end{array}$ $\begin{array}{lllllll}36 & 2 & 1 & 1 & 4 & 8.0 & 6.5\end{array}$ $\begin{array}{lllllll}37 & 2 & 1 & 1 & 2 & 6.5 & 6.5\end{array}$ $\begin{array}{lllllll}38 & 2 & 1 & 1 & 3 & 8.5 & 7.0\end{array}$ $\begin{array}{lllllll}39 & 2 & 1 & 2 & 2 & 2.5 & 3.5\end{array}$ $\begin{array}{lllllll}40 & 2 & 1 & 2 & 2 & 7.0 & 5.0\end{array}$ $\begin{array}{lllllll}41 & 2 & 1 & 1 & 4 & 4.0 & 4.5\end{array}$ $\begin{array}{lllllll}42 & 2 & 1 & 2 & 2 & 5.5 & 4.5\end{array}$ $\begin{array}{lllllll}43 & 2 & 1 & 2 & 2 & 6.5 & 7.0\end{array}$ $\begin{array}{lllllll}44 & 2 & 1 & 2 & 2 & 5.5 & 7.0\end{array}$ $\begin{array}{lllllll}45 & 2 & 2 & 2 & 2 & 6.5 & 5.5\end{array}$ $\begin{array}{lllllll}46 & 2 & 2 & 2 & 3 & 4.5 & 4.5\end{array}$

$\begin{array}{llllll}3.61 & 21 & 12 & 9 & 42 & 49\end{array}$ $\begin{array}{llllll}3.17 & 10 & 5 & 3 & 18 & 47\end{array}$ $\begin{array}{llllll}2.85 & 19 & 10 & 8 & 37 & 28\end{array}$ $\begin{array}{llllll}3.00 & 18 & 7 & 3 & 28 & 53\end{array}$ $\begin{array}{llllll}3.25 & 28 & 18 & 13 & 59 & 46\end{array}$ $\begin{array}{llllll}1.75 & 16 & 11 & 9 & 36 & 63\end{array}$ $\begin{array}{llllll}1.67 & 11 & 3 & 6 & 20 & 58\end{array}$ $\begin{array}{llllll}1.96 & 16 & 10 & 7 & 33 & 36\end{array}$ $\begin{array}{llllll}2.00 & 13 & 6 & 5 & 24 & 46\end{array}$ $\begin{array}{llllll}2.40 & 10 & 4 & 5 & 19 & 46\end{array}$ $\begin{array}{llllll}2.13 & 8 & 6 & 3 & 17 & 54\end{array}$ $\begin{array}{llllll}2.38 & 6 & 2 & 0 & 8 & 48\end{array}$ $\begin{array}{llllll}2.37 & 21 & 15 & 10 & 46 & 65\end{array}$ $\begin{array}{llllll}2.25 & 10 & 5 & 5 & 20 & 41\end{array}$ $\begin{array}{llllll}1.74 & 11 & 4 & 2 & 17 & 52\end{array}$ $\begin{array}{llllll}2.28 & 9 & 8 & 4 & 21 & 38\end{array}$ $\begin{array}{llllll}1.44 & 6 & 7 & 2 & 15 & 48\end{array}$ $\begin{array}{llllll}2.21 & 13 & 4 & 4 & 21 & 56\end{array}$ $\begin{array}{llllll}1.80 & 18 & 13 & 4 & 35 & 48\end{array}$ $\begin{array}{llllll}1.75 & 8 & 6 & 2 & 16 & 49\end{array}$ $\begin{array}{llllll}3.50 & 12 & 10 & 9 & 31 & 53\end{array}$ $\begin{array}{lllllll}2.5 & 12 & 10 & 8 & 30 & 67\end{array}$ $\begin{array}{llllll}2.83 & 8 & 9 & 6 & 23 & 61\end{array}$ $\begin{array}{llllll}2.13 & 9 & 6 & 2 & 17 & 52\end{array}$ $\begin{array}{llllll}1.74 & 12 & 4 & 2 & 18 & 52\end{array}$ $\begin{array}{llllll}3.50 & 15 & 12 & 10 & 37 & 56\end{array}$ $\begin{array}{llllll}4.0 & 10 & 6 & 5 & 21 & 47\end{array}$ $\begin{array}{llllll}3.38 & 21 & 12 & 10 & 44 & 36\end{array}$ $\begin{array}{llllll}3.00 & 20 & 11 & 6 & 37 & 52\end{array}$ $\begin{array}{llllll}3.33 & 25 & 14 & 12 & 51 & 30\end{array}$ $\begin{array}{llllll}3.70 & 26 & 10 & 11 & 47 & 47\end{array}$ $\begin{array}{lllllll}3.81 & 18 & 11 & 10 & 39 & 29\end{array}$ $\begin{array}{llllll}2.84 & 7 & 1 & 3 & 11 & 57\end{array}$ $\begin{array}{llllll}2.38 & 12 & 12 & 3 & 27 & 56\end{array}$ $\begin{array}{llllll}3.17 & 9 & 5 & 5 & 19 & 64\end{array}$ $\begin{array}{llllll}2.33 & 6 & 5 & 4 & 15 & 62\end{array}$ $\begin{array}{llllll}3.77 & 5 & 12 & 7 & 24 & 57\end{array}$ $\begin{array}{llllll}3.67 & 20 & 11 & 6 & 37 & 54\end{array}$ $\begin{array}{llllll}3.50 & 13 & 10 & 8 & 31 & 62\end{array}$ $\begin{array}{llllll}2.04 & 6 & 3 & 1 & 10 & 30\end{array}$ 


$\begin{array}{llllllllcccll}47 & 2 & 2 & 2 & 2 & 1.5 & 2.5 & 1.76 & 12 & 4 & 6 & 22 & 28 \\ 48 & 2 & 2 & 2 & 2 & 2.5 & 5.0 & 2.25 & 10 & 6 & 3 & 19 & 32 \\ 49 & 2 & 2 & 2 & 2 & 3.0 & 3.5 & 2.32 & 14 & 11 & 6 & 31 & 4 \\ 50 & 2 & 2 & 1 & 2 & 3.5 & 3.0 & 1.86 & 10 & 6 & 4 & 20 & 41 \\ 51 & 2 & 2 & 2 & 2 & 5.0 & 4.0 & 1.89 & 8 & 7 & 6 & 21 & 43 \\ 52 & 2 & 2 & 1 & 2 & 2.5 & 1.0 & 1.33 & 6 & 6 & 2 & 14 & 50 \\ 53 & 2 & 2 & 2 & 2 & 3.0 & 4.0 & 1.43 & 8 & 8 & 5 & 21 & 57 \\ 54 & 2 & 2 & 1 & 2 & 6.0 & 3.0 & 1.00 & 9 & 2 & 6 & 17 & 50 \\ 55 & 2 & 2 & 1 & 3 & 4.5 & 6.0 & 1.73 & 10 & 12 & 7 & 29 & 60 \\ 56 & 2 & 2 & 1 & 2 & 2.0 & 2.5 & 1.52 & 9 & 1 & 7 & 17 & 47 \\ 57 & 2 & 2 & 2 & 2 & 2.0 & 1.5 & 1.42 & 8 & 3 & 4 & 15 & 53 \\ 58 & 2 & 2 & 1 & 2 & 3.0 & 2.5 & 1.75 & 10 & 5 & 1 & 16 & 48 \\ 59 & 2 & 2 & 2 & 2 & 2.5 & 2.0 & 1.89 & 5 & 3 & 0 & 8 & 46 \\ 60 & 2 & 1 & 1 & 3 & 8.0 & 8.5 & 3.75 & 29 & 19 & 12 & 60 & 51 \\ 61 & 2 & 1 & 2 & 2 & 5.0 & 4.0 & 2.63 & 7 & 3 & 5 & 15 & 40 \\ 62 & 2 & 1 & 2 & 2 & 6.5 & 5.5 & 3.30 & 11 & 11 & 3 & 25 & 53 \\ 63 & 2 & 1 & 2 & 2 & 7.0 & 5.0 & 3.40 & 20 & 12 & 5 & 37 & 50 \\ 64 & 2 & 2 & 2 & 1 & 4.0 & 3.0 & 1.75 & 8 & 6 & 2 & 16 & 51\end{array}$

\section{Some Statistical Formulas}

POINT BISERIAL In educational statistics, a measure of the reliability of a particular question. The formula used is

$$
\mathrm{r}_{\mathrm{pb}}=\frac{\left(\overline{\mathrm{Y}}_{1}-\overline{\mathrm{Y}}\right)}{\mathrm{s}} \sqrt{\frac{\mathrm{n}_{1} \mathrm{n}}{\left(\mathrm{n}-\mathrm{n}_{1}\right)(\mathrm{n}-1)}}
$$

where $\mathrm{n}$ and $\mathrm{n} 1$ are the total number of examinees and the number who pass the item; $\mathrm{Y}$ and $\mathrm{Y} 1$ are the mean score for all examinees and the mean score for those who pass the item; and $\mathrm{s}$ is the standard deviation (Bredehoft, J., Dewart, S., and Tindall, R., 1991). 
DISCRIMINATION INDEX In educational statistics, a number that measures the "discriminating power" of a question. Specifically, the discrimination index measures the correlation between the way that a set of students perform on a particular question and the way that the students performed on the entire test. The discrimination index can range from +1 (question answered correctly by examinees who scored high on the entire test, missed by low-scoring examinees), to -1 (question answered correctly by examinees who scored low on the entire test, missed by high-scoring examinees)

The formula used is $(\mathrm{H}-\mathrm{L}) / \mathrm{N}$, where,

$\mathrm{H}$ : number of students with the top $25 \%$ of the test scores who answere the question correctly.

L: number of students with the bottom $25 \%$ of the test scores who answered the question correctly.

$\mathrm{N}$ : $25 \%$ of the total number of students who took the test.

(Bredehoft, J., Dewart, S., and Tindall, R., 1991).

TEST RELIABILITY In educational statistics, a measure of the reliability of a test. LXR.TEST calculates test reliability using the Cronbach-Alpha formula (also known as the coefficient alpha formula). The formula used is 


$$
\alpha=\frac{\mathrm{b}}{\mathrm{b}-1}\left(1-\frac{\sum \mathrm{Si}^{2}}{\mathrm{St}^{2}}\right)
$$

where

$b=$ total number of items on the test

$\mathrm{i}=\mathrm{a}$ particular student

$\mathrm{j}=\mathrm{a}$ particular item on the test

$\mathrm{Si}^{2}=\frac{1}{\mathrm{a}-1} \sum(\mathrm{Xij}-\overline{\mathrm{Xi}})^{2}$

$\mathrm{St}_{\mathrm{t}}^{2}=\frac{1}{\mathrm{a}-1} \sum\left(\mathrm{T}_{\mathrm{i}}-\overline{\mathrm{T}}\right)^{2}$

$\mathrm{Ti}=$ sum of all items scores in row $\mathrm{i}$

$\mathrm{T}=$ mean sum

(Bredehoft, J., Dewart, S., and Tindall, R., 1991). 


\section{VITA}

January 16, $1951 \quad$ Born, Guantanamo, Cuba

1969

High School Graduation

Coral Gables Senior High School

Coral Gables, Florida

1974

B.S., Chemistry

University of Florida

Gainesville, Florida

1976

B.S., Biology and Education

Florida International University

Miami, Florida

$1976-1977$

Science Teacher

Robert E. Lee Junior High School

Miami, Florida

1981

M.S., Science Education

Florida International University

Miami, Florida

$1982-1983$

Adjunct Professor, Chemistry

Florida International University

Miami, Florida

1977 - Present

Biology and Chemistry Teacher

South Miami Senior High School

Miami, Florida

1983 - Present

Adjunct Professor, Biology and Chemistry Miami-Dade Community College

Miami, Florida

1991- Present

Chairperson, Science Department

South Miami Senior High School

Miami, Florida 